University of San Diego

Digital USD

2006-05-01

\title{
Officers' Use of Leadership Skills Learned in the Navy's Intermediate Officer Leadership Training Course: A Replication Study
}

Terrence Eugene Hammond EdD

University of San Diego

Follow this and additional works at: https://digital.sandiego.edu/dissertations

Part of the Leadership Studies Commons

\section{Digital USD Citation}

Hammond, Terrence Eugene EdD, "Officers' Use of Leadership Skills Learned in the Navy's Intermediate Officer Leadership Training Course: A Replication Study" (2006). Dissertations. 758.

https://digital.sandiego.edu/dissertations/758

This Dissertation: Open Access is brought to you for free and open access by the Theses and Dissertations at Digital USD. It has been accepted for inclusion in Dissertations by an authorized administrator of Digital USD. For more information, please contact digital@sandiego.edu. 


\title{
OFFICERS' USE OF LEADERSHIP SKILLS LEARNED IN THE NAVY'S INTERMEDIATE OFFICER LEADERSHIP TRAINING COURSE - A REPLICATION STUDY
}

\author{
by
}

TERRENCE EUGENE HAMMOND

\author{
A dissertation submitted in partial fulfillment \\ of the requirement for the degree of \\ Doctor of Education \\ University of San Diego
}

May 2006

\author{
Dissertation Committee \\ Robert Donmoyer, Ph.D. \\ Fred J. Galloway Ed.D. \\ Marlene C. Browne, Ph.D. \\ William F. Conroy III, Ed.D.
}


(C) Copyright by Terrence Eugene Hammond 2006 All Rights Reserved 


\begin{abstract}
All Naval enlisted personnel and officers are required to attend Leadership Continuum courses at designated career intervals. One of the required courses for officers is the Intermediate Officer Leadership Training Course (IOLTC).

This study replicated William F. Conroy III's 2001 dissertation study of graduates of the IOLTC offered in San Diego with graduates of a similar course offered by the Center for Naval Leadership (CNL) at Naval Amphibious Base (NAB), Little Creek, VA. Like the Conroy study, this study attempted to identify barriers and incentives that IOLTC graduates encounter on-the-job that either encourage or discourage their use of leadership skills taught in the IOLTC.

Both studies, in fact, were organized around the following questions: (a) Do graduates believe that they were able to use their skills on the job? (b) If so, approximately how much time had elapsed after completion of IOLTC before the graduates exercised the leadership skills acquired during the course? (c) What are the IOLTC graduates' perceptions of their bosses' attitudes toward their using the leadership skills learned during the leadership-training course? (d) What factors (barriers or incentives) seem to be associated with skill use across the four IOLTC sub-units (leadership, communication, delegation, and command climate)? (e) Do the answers to the previous questions vary depending upon demographics (gender, race, line/staff officers, etc.)? This study asked one additional question: To what extent are the findings from this study consistent with the Conroy study?
\end{abstract}


As in the Conroy study, a survey design was employed. The major procedural difference was that this study surveyed graduates through the Internet rather than through regular mail.

Results of this replication study were similar to Conroy's results. For instance, women continued to perceive that they had less opportunity to implement the leadership skills they were taught. There were two interesting differences, however: (a) respondents in this study reported that it took less time to be able to use the skills they were taught; (b) in this study, unlike the Conroy study, resistance from subordinates was cited more frequently as a barrier to implementing the acquired leadership skills that were taught. 


\section{DEDICATION}

To my wife Robin for her love and support. To my mother Verlynne for her inspiration and constant prayer. To my father Clarence for his motivation and pride. To my sisters Danita, and Schanetta for their kind words and loving spirit. To my brothers Michal, and John for their counsel, and encouragement to keep going. Finally, to Captain Terry Merritt for her trust and confidence in my ability to succeed. 


\section{ACKNOWLEDGEMENTS}

I would like to acknowledge and sincerely thank my dissertation chairman and advisor, Dr. Robert Donmoyer, and my dissertation committee members, Dr. Fred Galloway, Dr. Marlene Browne and Dr. William Conroy, for their expert direction and professional guidance. I would also like to thank Dr. Darren McGlynn for his friendship, peer mentoring, and consultation from the beginning of this journey until the completion of this dissertation. In addition, I acknowledge Dr. James Hammond and Dr. Carol Hammond for their doctoral and spiritual mentoring. I also need to express my very sincere appreciation to two distinguished Navy Professionals, CDR Rose Conn, and LCDR Gayle Wilson from the Center for Naval Leadership for their hours of staff work, which helped me gain access to the survey respondents. Moreover, I am also indebted to Ms. Beth Yemma for her fantastic administrative support and professional advice and counsel. I salute and thank each of you! 


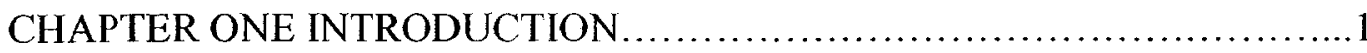

Background ..........................................................

Problem Statement...................................................... 7

Purpose of the Study .............................................. 8

Research Questions ..............................................8

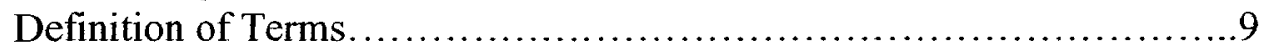

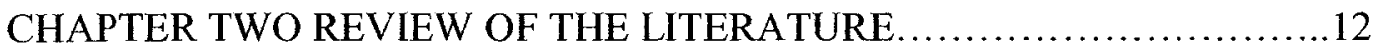

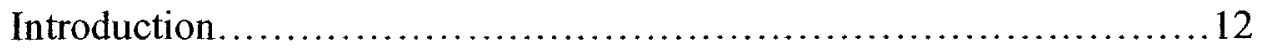

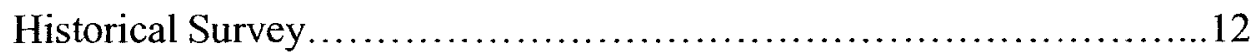

Effectiveness Studies................................... 18

Navy Leadership Competency Model.......................20

CHAPTER THREE RESEARCH DESIGN ................................23

Research Design Overview.......................................23

The Survey Instrument................................24

Sample Selection.........................................29

Permission to Survey ..................................... 30

Survey Implementation...................................... 30

Survey Response Expectations.............................. 31

Actual Survey Response Rate...........................32

Analysis................................................... 32

Assumptions of the Study ........................................ 33

Limitations of the Study .......................................... 34

Role of the Researcher............................................ 35

CHAPTER FOUR RESULTS ............................................. 36

Introduction ..................................................... 36

Part I Overall Characteristics of Survey Respondents and Their

Perceptions about Skill Utilization, Barriers and Incentives ..............37

Characteristics of Survey Respondents..........................37

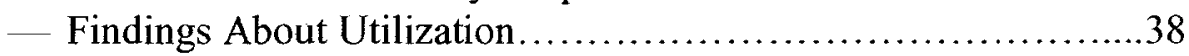

Findings About Perceived Barriers..........................40

Findings About Incentives....................................41

Superiors' Attitudes as Barrier or Incentive...............42

Summary Overall Characteristics of Survey Respondents and

Their Perceptions about Skill Utilization, Barriers and Incentives..........43

Part II Demographic and Contextual Variables and Inferential

Statistics.........................................................43

Variables and Summary of Results..........................44 
Race/Ethnicity.

Average Elapsed Weeks prior to Graduates'

Use of Acquired Leadership Skills on the Job

Gender.

By Race/ Ethnic Group Summary of Results.......45

Average Elapsed Weeks prior to Graduates'

Use of Acquired Leadership Skills on the Job

by Gender Summary of Results...................46

Duty Status............................................46

Line / Staff............................................47

Inferential Statistics.......................................48

Respondent's Position Comparison........................49

Supervisor's Position Comparison.........................51

Type of Duty Comparison..............................52

Type of Officer Comparison.............................53

Gender Comparison...................................53

Summary of Demographic and Contextual Variables and Inferential Statistics...................................55

Part III Study Comparisons...........................................55

Summary of Study Comparisons. ...................................59

CHAPTER FIVE DISCUSSION .........................................60

Review of the Study Purpose and Methods..............................60

Purpose......................................................60

Methodology...............................................60

Summary of Findings.............................................61

Summary of Part I............................................61

Summary of Part II.........................................62

Summary of Part III........................................62

Skills Utilization...........................................62

Average Elapsed Time Prior to Skill Utilization.................63

Graduate's Perceptions of their Bosses' Attitudes..................63

Barriers or Incentives.........................................63

Comparison of findings between the two studies..................64

Interpretation of Findings........................................... 64

Training the Next Generation...............................65

Recommendations for the Center for Naval Leadership..........66

Recommendations for Future Research......................67

Summary ......................................................68

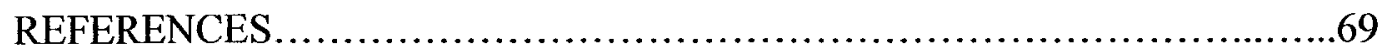

APPENDIX A COVER E-MAIL ......................................74

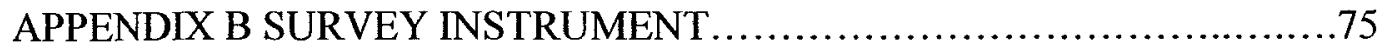


APPENDIX C CONROY SURVEY INSTRUMENT .99

APPENDIX D FOLLOW-UP E-MAIL .................................. 112

APPENDIX E SURVEY SPONSOR LETTER ..........................113

APPENDIX F SURVEY APPROVAL LETTER ........................114

APPENDIX G RAW SUMMARY OF RESULTS $\ldots \ldots \ldots \ldots \ldots \ldots \ldots \ldots \ldots \ldots$

APPENDIX H LEADERSHIP MODLES UTILIZATION TIME ...............135

APPENDIX I SITUATIONAL COMMUNICATION UTILIZATION

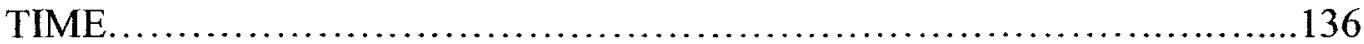

APPENDIX J DELIGATION UTILIZATION TIME .......................137

APPENDIX K COMMAND CLIMATE TIME ..........................138

APPENDIX L LEADERSHIP MODLES BARRIERS ......................139

APPENDIX M SITUATIONAL COMMUNICATION BARRIERS ...........140

APPENDIX N DELIGATION BARRIERS .................................. 141

APPENDIX O COMMAND CLIMATE BARRIERS ........................ 142

APPENDIX P LEADERSHIP MODLES INCENTIVES ......................143

APPENDIX Q SITUATIONAL COMMUNICATION INCENTIVES......... 144

APPENDIX R DELEGATION INCENTIVES .......................... 145

APPENDIX S COMMAND CLIMATE INCENTIVES ......................146

APPENDIX T RACE / ETHNIC HISPANIC OR LATINO ................. 147

APPENDIX U RACIAL BACKGROUND .............................. 148

APPENDIX V SURVEY OPTIONAL COMMENTS.......................149 


\section{LIST OF TABLES}

Table 1 Summary of Graduates' Assessments.

Table 2 Mean Number of Weeks Elapsed Prior to Utilization of Acquired

Leadership Skills Across the Four IOLTC Sub-Units.

Table 3 Barriers that Obstructed the IOLTC Graduates

Table 4 Incentives to Use Skills.

Table 5 IOLTC Graduates' Bosses’ Attitudes

Table 6 Means for Average Elapsed Weeks Prior to Graduates' Use of Acquired Leadership Skills on the Job by Race / Ethnic Group.

Table 7 Means for Average Elapsed Weeks Prior to Graduates' Use of Acquired Leadership Skills on the Job by Gender.

Table 8 Distribution of IOLTC Graduates by Duty Status

Table 9 Distribution of IOLTC Graduates by Line Officer Community...

Table 10 Distribution of IOLTC Graduates by Staff Officer Community.

Table 11 Graduates' Job Position. .48

Table 12 Graduates' Supervisor's Position. .48

Table 13 ANOVA Results for Respondents' Position. .50

Table 14 ANOVA Results for Respondent's Supervisors' Position .51

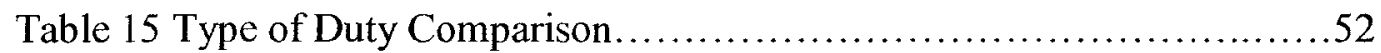

Table 16 Line Officer - Staff Officer Comparison........................53

Table 17 Male Female Officer Comparison...............................54

Table 18 Population Comparison by Gender Percent..........................55

Table 19 Population Comparison by Type Duty Percent......................56 


\section{CHAPTER 1 INTRODUCTION}

The Leadership Continuum is the core of the current U.S. Navy Professional Military Education (PME) Continuum training program (Navy, 2005). After completing initial leadership training, both officers and enlisted personnel begin a clearly defined positional leadership progression path. All enlisted personnel and officers, in other words, are required to attend Leadership Continuum courses at designated career intervals. One of the required courses for officers is the Intermediate Officer Leadership Training Course (IOLTC) (Conroy, 2001).

In 2001, William F. Conroy, III conducted a dissertation study that focused on whether graduates of the United States Navy's Naval Leader Training Unit ${ }^{1}$ IOLTC were able to use the leadership knowledge and skills they learned in the course on the job. In the final chapter of that study, Conroy suggested that his study needed to be replicated with graduates who had participated in Naval Leader Training Unit leadership training at sites other than the Southern California learning site that was the focus of his study. The Little Creek, Virginia, site is the Navy's other major IOLTC training location. It should come as no surprise, therefore, that Conroy specifically mentioned that graduates of the Little Creek, IOLTC needed to be surveyed about their on-the-job use-or lack of use-of the skills they were taught to use in their work environments.

\footnotetext{
${ }^{1}$ In March of 2003 the Naval Leader Training Units became the "Center for Naval Leadership Learning Sites."
} 


\section{Background}

Navy training is based on the idea that, in order to maintain strategic advantage in the future and to meet the challenges of increasing national security, naval officers must have the very best training and education the country can provide. In the 1940s, naval officer training focused on ensuring an officer could efficiently handle any job on board a naval ship (Thompson, 1943). Lieutenant Commander W. K. Thompson, USNR (1943) wrote:

The regular 'line' officer was trained with the idea that he should be able to handle efficiently any job on board ship. For example, an officer assigned to duty as navigator of a ship, after completing such duty, might suddenly be ordered to duty as an engineering officer of another ship. (p. 1)

As technology advanced, however, and the Navy adapted its strategic vision to accommodate the technological advances, it also had to change the focus of officer training. In fact, in the early1940s technical advances in weaponry, propulsion, and navigation caused the Navy to abandon traditional general-purpose training and adopt specialized training for modern sea warfare (Thompson, 1943).

In addition, the Navy recognized that officers were increasingly coming from different places. Whereas in the past, most officers had been groomed in places such as the Naval Academy, and the Naval Reserve Officer Training Corps (NROTC) programs at select universities, in the 1940s, because the country was at war, there was a shift in the officer ranks to reserve officers with limited leadership training. 
Eventually, this shift resulted in periodic leadership training being integrated into a naval officer's career after the formal education had been completed.

Today, more than 60 years after the Navy began specialized leadership training, Navy training continues to include several areas of specialized training and more general leadership training. All naval officers from the commissioning rank of Ensign (division/branch officer) to a senior rank of Captain (commanding officer) receive some initial leadership training in order to acquire basic naval leadership skills. However, as officers are promoted and earn increased responsibility, additional training is made available. In addition, leadership training is now provided to enlisted personnel. The training schedule for enlisted personnel mimics the training for officers.

The training schedule alluded to in the previous paragraph has been and continues to be based on the belief that senior naval leadership has assumed (and continues to assume) that the best way to provide leadership training is throughout the career of the Sailor ${ }^{2}$ (Palmisano, 2001). The Navy, in fact, talks of the "Leadership Continuum" as a career-long series of leadership development, from recruitment to retirement.

For almost 14 years, the Navy has used the Leadership Continuum program (Chief of Naval Education and Training [CNET], 2002). Today, the Navy is making changes that are intended to bring alignment between the duties that Sailors perform and the training that they receive. In the recent past, the Leadership Continuum was

\footnotetext{
${ }^{2}$ Navy professional writing convention dictates the capitalization of "Sailor" and the occasional use of titles as nouns.
} 
comprised of eight leadership-training courses: four for officers and four for enlisted men and women. The courses were designed to have all Sailors, officer and enlisted, attend a series of leadership instruction courses that were offered progressively as promotion milestones were met. The courses were designed to be taken in sequence with a change of duty assignment. The four courses available to officers were Basic (division/branch officer-officers with 0-2 years of service and perhaps on a first assignment), Intermediate (department head/aviation second sea tour-officers with 79 years of service on a third or fourth assignment), Advanced (executive officerofficers/aviation department head with 11-14 years of service most likely on fifth or sixth assignment) and Command (commanding officer/aviation executive officerofficers with 15-20+ years of service) (Conroy, 2001).

The courses have been retuned, as Navy leadership roles are no longer necessarily tied to pay grades. The Center for Naval Leadership (CNL) has initiated the Leadership Development Program (LDP) to align leadership training to the jobs Sailors perform, regardless of rank. In essence, the program allows all Sailors officially assigned to an organizational leadership position to participate in the development of professional leadership (Military, 2005).

In the past, all courses were approximately 2 weeks long and supported four major leadership themes: values, responsibility, authority, and accountability of leadership. The Navy developed the continuum of courses in an effort to provide Sailors with intense, hard-hitting fleet relevant (in support of the Navy's current strategic vision) leadership skills. 
Today, for the enlisted Sailors there are three 9-day courses offered through CNL to staff at Training Support Center (TSC) Learning Sites Great Lakes, including the First Line Leadership Development Program, Primary Leadership Development Program, and Advanced Leadership Development Program. These programs are based upon leadership positions of authority, rather than pay grade. The Navy has implemented enlisted leadership development programs that link the right training to the right Sailor at the right time, regardless of their rank (Military, 2005). Although the courses have been shortened the leadership themes are the same. In addition, the training continuum for the Officers is still the same although soon it may follow the path of the enlisted continuum.

Within the Navy's current strategic vision, "Forward from the Sea," the Navy is putting additional emphasis on leadership development. The "Sea Power 21" concept describes a future Navy that will provide the nation with a triad of capabilities that are unique to the naval service. These capabilities are designed to meet the challenges brought about by the political, strategic, and technological changes that have occurred since the fall of communism and the onset of the Global War on Terror ("President's forum- U.S. Navy Sea Power 21," 2003). The personal and professional development element of Sea Power 21 is "Sea Warrior." The Sea Warrior program reemphasizes the Leadership Development Continuum and implements the Navy's longstanding commitment to the growth and development of Sailors.

The ultimate goal of Sea Warrior is investing in Sailors, by developing naval professionals, who are highly skilled, powerfully motivated and optimally employed 
for mission success (Chief of Naval Information [CHINFO], 2004). In particular, the Navy is working directly with fleet Sailors who are requested to provide feedback to researchers and curriculum developers to identify, enhance, and strengthen leadership skills and behaviors, which will ultimately contribute to mission accomplishment. In response to this, current strategic vision, past surveys and studies, the Navy has continued to expend much effort and resources in an attempt to provide the optimal training possible. Thirteen percent of Navy personnel (Over 50,000 of the Navy's 373,800 Sailors) will attend at least one of the Chief of Naval Education and Training's Leadership Training Courses this year (CNET, 2004).

Although we are currently at war and the Navy has adopted a new strategic vision, it is again focused on improving the training afforded to its Sailors. However, reduced financial resources are forcing the Navy to optimize leadership training to get the best value for the dollars spent. A major area of concern with respect to optimizing training programs is within the area of effectiveness and applicability of Navy leadership development training.

One question that was asked by previous researchers is whether IOLTC graduates receive an opportunity to apply the leadership skills on the job. The question was explored in a study conducted in 1990 by the Navy Personnel Research and Development Center, San Diego, CA (Wilcove, 1992). In fact, Wilcove's study revealed that $60 \%$ of the officer respondents and $53 \%$ of the enlisted respondents indicated that they had been able to apply some of their most recently acquired leadership training skills on the job. 
In 1999, Terrie N. Lohmeyer, a naval officer attending San Diego State University, conducted a study involving graduates of the IOLTC. One of the multiple purposes of Lohmeyer's study was to ascertain if the knowledge the graduates acquired during the leadership course was utilized in their current leadership roles back on the job. Lohmeyer's study revealed that IOLTC “Students do, at least to some extent, use the information taught in the course once they return to the work site" (Lohmeyer, 1999, p. 24). Lohmeyer also recommended, however, that additional research be conducted to explore (a) if graduates did or did not modify their leadership behavior after IOLTC participation and (b) if the graduates organizational culture encouraged or hindered behavioral changes on the job.

\section{Problem Statement}

Research in the past has suggested that officers who receive leadership development training are learning useful on-the-job skills and that most IOLTC graduates have an opportunity to use at least some of the skills on the job. However, the authors of previous studies also suggest that additional information is needed to make a determination on the actual application of skills and the usefulness of skills learned in Navy leadership courses. Naval leaders, in particular, are interested in IOLTC graduates and the barriers and incentives that either encourage or discourage the use of acquired IOLTC leadership skills within their work environments (CHINFO, 2004). There is little information about whether the particular leadership skills taught in IOLTC are actually applied by the IOLTC graduates.

Because of this lack of information, Conroy (2001) did a dissertation study focused on the use of IOLTC skills on the job. His study, however, focused on 
graduates from only one of the IOLTC sites, the one in Coronado, California and it was conducted during peacetime. As Conroy himself noted, there is a need to study graduates from the other IOLTC site in Little Creek, Virginia. A study conducted at this current time had the added advantage of focusing on opportunities to use leadership skills in a wartime context.

\section{Purpose of the Study}

This study responded to the need articulated in the Conroy study and closely replicated the procedures and analysis used in that study with graduates of the Navy's IOLTC offered by the Center for Naval Leadership (CNL) learning site at Naval Amphibious Base (NAB) Little Creek, Virginia. This replication study gathered and analyzed survey responses from graduates of the Little Creek, IOLTC to determine whether they have had an opportunity to use the skills taught in IOLTC on the job. This study used nearly the same instrument and procedures that the Conroy (2001) study employed, and, like the Conroy study, attempted to determine what barriers and incentives IOLTC graduates encountered that either encouraged or discouraged their use of acquired IOLTC leadership skills within their work environments.

\section{Research Questions}

The research questions were a duplication of the ones posed in the Conroy study with the exception of one additional question. The research questions are as follows:

1. Do graduates believe that they were able to use their skills on the job? 
2. If so, approximately how much time had elapsed after completion of IOLTC before the graduates exercised the leadership skills acquired during the course?

3. What are the IOLTC graduates' perceptions of their bosses' attitudes toward their using the leadership skills learned during the leadership-training course? More specifically, do graduates perceive that their bosses prevent, discourage, encourage, or require the use of graduates' newly acquired leadership skills back on the job, or do graduates perceive that their bosses take a neutral stance?

4. What factors (barriers or incentives) seem to be associated with skill use across the four IOLTC subunits (leadership, communication, delegation, and command climate)?

5. Do the above answers vary depending upon demographics (gender, race, line/staff officers, etc.) and contextual variables (4 IOLTC subunits, shore/sea duty, active duty/reserve component, etc.)?

6. To what extent are the findings from this study consistent with the Conroy study?

\section{Definition of Terms}

1. Leadership Continuum - a career-long continuum of Navy leader development, from recruitment to retirement (CNET, 2001).

2. Professional Military Education (PME) - progressive levels of military education that prepares military officers for leadership. It includes various basic level courses for the new and junior officers, command and staff colleges for the mid-level officers, and war colleges for the senior officers (DSCA, 2004). 
3. Intermediate Officer Leadership Training Course (IOLTC) - a course designed to provide leadership training in the areas of values, leadership, communication, subordinate development, managing systems and processes, command development, and mission execution (Lohmeyer, 1999).

4. Ensign - a commissioned officer in the navy or coast guard ranking above a chief warrant officer and below a lieutenant junior grade (Merriam-Webster's Online, 2006).

5. Lieutenant (Junior Grade) - a commissioned officer in the navy or coast guard ranking above an ensign and below a lieutenant (Merriam-Webster's On- line, 2006).

6. Lieutenant - a commissioned officer in the navy or coast guard ranking above a lieutenant junior grade and below a lieutenant commander (MerriamWebster's On- line, 2006).

7. Lieutenant Commander - a commissioned officer in the navy or coast guard ranking above a lieutenant and below a commander (Merriam-Webster's On- line, 2006).

8. Commander - a commissioned officer in the navy or coast guard ranking above a lieutenant commander and below a captain (Merriam-Webster's On- line, 2006)

9. Captain - a commissioned officer in the navy or coast guard ranking above a commander and below a rear admiral (Merriam-Webster's On- line, 2006).

10. Branch Officer - The senior officer within a segment of a division responsible to the division officer. 
11. Division Officer - The senior officer within a functional segment of a department responsible to the department head.

12. Department Head - "The senior officer within a major functional segment (department) of a naval command, such as Administration, Operations, Weapons Communications or Supply" (Glenn, 1987, p. 7).

13. Executive Officer - The officer second in command of a naval organization (Merriam-Webster's On- line, 2006).

14. Commanding Officer - "The senior person of a command who is officially charged with the authority, responsibility and accountability for the management of the command" (Glenn, 1987, p. 7). 


\section{CHAPTER 2 REVIEW OF THE LITERATURE}

\section{Introduction}

There is a fair amount of literature on the history of leadership training programs in the Navy. In addition, there is an increasing amount of literature on the effectiveness of the programs offered. Yet there are sparse amounts of literature regarding the utility of the leadership taught. The literature on this topic was briefly discussed in the problem statement. In this chapter, the literature is reviewed in detail. The review begins with an expanded survey of the literature on the history of leadership training in the Navy. The focus then shifts to studies about the effectiveness of one's training.

\section{Historical Survey}

During the years of peace prior to 1940 , and also for a number of years following World War II, naval officer training consisted of sending young men through four years of college-like education at the United States Naval Academy (Thompson, 1943). For the most part, after graduation, junior officers learned specific leadership skills on the job. Each Ensign, most likely a recent graduate from the Naval Academy, was placed in a probationary status and successively assigned to short periods of duty in each department of the ship. The goal of the training was to expose the young officer to many different aspects of skills required on the ship (Thompson, 1943). This process was a very hands-on approach to training.

In the years after World War II, and also during the 1950 s, naval leaders thought they had to examine the traditional leadership taught throughout the Navy (Vandover \& Villarosa, 1981). On May 17, 1958, the Secretary of the Navy issued 
Navy General Order 21, instructing all commanding officers to integrate leadership training into the technical training of their Sailors (Vandover \& Villarosa, 1981). During this time, leadership-training programs reflected each commanding officer's own ideas, educational background, and knowledge of leadership, as well as individual officer's abilities to execute a leadership program (Vandover \& Villarosa, 1981).

General Order 21 never brought about its intended effect and in 1960 formal leadership training was still not a priority for the Navy (Vandover \& Villarosa, 1981). Even as late as 1966, naval leadership training was merely part of a broader training program called General Military Training (GMT) (Parker, 1980). In fact, most officers received whatever leadership training they experienced in college NROTC programs or in officer indoctrination courses they took after they earned a bachelor's degree.

The Navy attempted to streamline human resource management in the $1970 \mathrm{~s}$. Leadership training received attention as part of this streamlining effort. The N-Man book (Navy Optimum Means of Integrating Men and Mission), a leadership training tool for Navy leaders using a seven-step command development model, was constructed and incorporated into the Navy's "Command Development" course (Lewis, 1990). The book was based on Blake and Mouton's view of leadership, which conceptualized leadership in terms of two concerns: (a) concern for people and (b) concern for production (Robbins, 1994). The N-Man book's underlying assumption was that self-awareness and motivation to change should be sufficient to improve naval personnel's leadership skills (Foley, 1983). 
The year 1972 saw an end to the leadership training component of the command development course. This component was replaced by an initiative called Leadership Management and Training (LMT). According to Foley (1983), "LMT was based largely on Transactional Analysis theory which had gained currency in civilian sectors" (p. 29). According to Burns, in his 1978 book, Leadership, transactional leaders "base their influence on an exchange relationship between leaders and followers" (Thomas, 1998, p. 61).

Foley (1983) notes that LMT was exceedingly popular; however, this popularity was also its own undoing. To accommodate high demand, commanding officers established and reproduced LMT courses within their own commands as a consequence of frustration with limited quotas at the authorized training sites. As a result, the commanding officers achieved almost $100 \%$ attendance because of greater flexibility in scheduling their personnel for leadership training courses (Foley, 1983). The quality of some of the locally developed and delivered courses was, however, questionable.

In the late 1970s the Navy developed leadership courses based on the skills, knowledge, and abilities demonstrated on the job by officers judged to be highly effective (Duncan-White 1997; Foley 1983). The Navy, in other words, adopted a training program built around research-derived competencies. The research was conducted by the Harvard affiliated McBer and Company, a Boston, Massachusetts, consulting firm founded in 1970 by Dr. David C. McClelland and David Berlew (Cissell \& Polley, 1987; Foley, 1983). Using the methodology that McClelland had refined during previous studies within the civilian industrial community (Foley, 
1983), the company conducted research to uncover necessary Navy leadership and management competencies (Duncan-White, 1997). In essence, the methodology involved gathering and analyzing self-reported incidents of success and failure in leadership situations by individuals who supposedly were exceptional leaders and those who were not successful leaders. Ultimately, 16 competencies were identified and courses were created to "teach" these competencies to officers and enlisted personnel. By the end of 1983, Leadership, Management, Education and Training (LMET) was fully functioning and had replaced the approximately 167 courses and course sequences that had been used to teach some aspect of basic leadership and management to Navy personnel (Arnold 1980; Duncan-White 1997).

LMET changed somewhat over the next ten years. These revisions included name changes. LMET first became the Navy Leader Development Program (NAVLEAD) and then the Naval Leadership Continuum. NAVLEAD represented more than a name change. In the NAVLEAD initiative, leadership-training courses were based on Navy core values (i.e., honor, courage, and commitment) and basic leadership principles. According to Duncan-White, "These courses were designed to be no frills, provide what was needed on the job, with learning enhanced by job related simulations $(1997$, p. 7$)$.

There was also an attempt in the 1990s to integrate the concept of Total Quality Management (TQM) (relabeled Total Quality Leadership (TQL) by Admiral Kelso) into NAVLEAD (Duncan-White, 1997). This TQL focus was short-lived, however. A much more comprehensive and enduring initiative was the establishment of the Navy Leadership Continuum. The Leadership Training Courses within the 
Leadership Continuum were first conceived in 1992 by the Chief of Naval Operations (CNO), Admiral Kelso, as a means to formalize leadership training in the Navy (CNL 2005). This leadership program, approved by Admiral Kelso in 1994, continues to guide and direct leadership training today.

The Navy Leadership Continuum, mentioned earlier, is a series of eight courses designed for mid- to senior-level enlisted personnel and officers at key intervals in their careers. The officer leadership continuum courses are tailored for assigned duty positions at the basic (branch officer and division officer), intermediate (aviation second sea tour and department head), advanced (aviation department head and executive officer), and command (aviation executive officer and commanding officer) levels (Duncan-White, 1997). The purpose of the leadership continuum is to provide consistency and continuity of training in leadership and management topics across all Navy communities.

According to Kowalski (2005), the Navy has also concurrently designed a Navy Leadership Development Program (NLDP) where leadership training is aligned to the jobs of Sailors regardless of rank. Any Sailor who is in an organizational leadership position can participate in this program. There are three 9-day courses offered at the Training Support Center (TSC) Learning Sites Great Lakes, including all of the following: First Line Leadership Development Program, Primary Leadership Development Program and Advanced Leadership Development Program. According to Kowalski (2005), in 2004, 849 Sailors, Petty Officer Third Class (E-4) to Chief Petty Officer (E-7), participated in the program at Great Lakes. These 
programs, specifically designed for enlisted personnel show the Navy's commitment to offering leadership skills at all levels, regardless of rank:

The First Line Leadership Program, which is a general introduction and prerequisite for the Primary Leadership Program, trains Sailors for their first leadership position in the chain of command dealing with the fundamentals of growth, development and daily direction of subordinates. The Primary Leadership Development Program adds to the basic fundamentals and trains Sailors for leadership roles responsible for planning and executing divisional functions, including the professional and personal growth of those personnel assigned within that division. (Kowalski, 2005, pp. 9-10)

Advanced courses also offer Sailors the opportunity to bring their past experiences into teaching the Sailors to become the future leaders of the Navy. As Kowalski reported, the Navy has committed to training officers and enlisted in their new leadership programs.

At present, the Navy is focusing on how to use the resources available to get the biggest return on training dollar investments and provide training in the most efficient and effective way possible (Craine, 2001). The Navy Leadership Continuum is still a part of the Navy's current training initiative. Under the umbrella of the "Revolution in Navy Training," the Center for Naval Leadership sites located in Coronado, California and Little Creek, Virginia are now the Navy's major sites to develop and train officers requiring intermediate officer training. 


\section{Effectiveness Studies}

As mentioned earlier, several studies have been conducted to research and assess the effectiveness of Navy leadership training programs. The Navy's current leadership training initiative, studied by Lohmeyer (1999) and, subsequently by Conroy (2001) have produced somewhat positive findings regarding the impact of training skills utilization on the job. However, the findings for some of the earlier leadership training studies were not as encouraging.

Arnold's (1980) study on board the aircraft carrier USS KITTY HAWK (CV 63), for example, looked at the effect Leadership and Management Education and Training (LMET) had on subordinates' attitudes about their supervisor's leadership ability after the subordinates graduated from the course. Arnold concluded that there was no significant change in the attitude of the non-supervisory crewmembers of the USS KITTY HAWK (CV 63) toward supervisory leadership during the period 1975 to 1979 (Arnold, 1980). In the year following the publication of Arnold's report, a similar study by David L. Vandover and John P. Villarosa (1981) revealed there were no systematic behavior changes with respect to any improvements over nongraduates in terms of attitudes towards supervisory leadership (Vandover \& Villarosa, 1981, p. $88)$.

In 1983, utilizing the methodology established by the LMET designers McBer and Company (Lewis, 1990), Lieutenant Patricia G. Foley extended the earlier research efforts that focused on the benefits and limitations of LMET. Foley learned that the command climate determined a student's ability to use the LMET competencies (Lewis, 1990). 
In 1990, Wilcove conducted a Navy personnel survey and an analysis of educational and training issues to provide policy makers with personnel feedback on a variety of key issues including leadership training. Although Wilcove's work produced a number of findings, his most germane one was that students were split on their opinions on whether the leadership training in the Navy had helped them to perform their jobs better, with $41 \%$ agreeing; $45 \%$ disagreeing; the remainder reporting mixed feelings (Wilcove, 1990).

A prior study by Cissell and Polley (1987) produced somewhat more definitive results. Their study focused on whether or not graduates of leadership training programs use--and are encouraged to use--the skills they learned in training back on the job. Cissell and Polley claim that no argument for a significant measure of degree of command support for LMET could be made based on the evidence they collected.

Using the information gleaned from the previously mentioned studies, Lohmeyer, in her 1999 study, examined whether students had an opportunity--and were, in fact, encouraged--to apply what is learned in current leadership training courses on the job.

The study by Conroy responded to many of the previous studies and in particular Lohmeyer's recommendations. Conroy summarized his conclusions as follows:

The results of the study indicate that graduates, on average, utilized acquired leadership skills on the job within six to eight weeks after completing IOLC. The incentives identified by IOLC graduates, while 
attempting to apply acquired leadership skills on the job seem, for the most part, to have outweighed the barriers they encountered. The vast majority of IOLC graduates (over $89 \%$ ) perceived that their immediate superiors either encouraged the use of acquired leadership skills on the job or took a neutral stance. However, responses from IOLC graduates also revealed some evidence of resistance to leadership skills use on the job. (Conroy, 2001 p. 101)

As has already been noted, Conroy also suggested that what he did with graduates of the Coronado, California leadership training site be replicated with graduates from the Little Creek, Virginia site. This study responded to that recommendation and the next section reviews the methodology that was used in the study.

\section{Navy Leadership Competency Model (NLCM)}

This literature review would not be up to date without a discussion of the Navy's most current leadership training design, the Leadership Competency Model (NLCM), which is being incorporated into the curriculum of the Center for Naval Leadership. According to the leadership model, Navy leadership is based on five core competencies - a competency being a defined behavior that describes excellent performance in a particular assigned task. The Navy believes a competency is what superior performers do more often that produces the best possible job results. The following are the five competencies listed in the NLCM (2006):

1. Accomplishing Mission--Stresses Accountability and Continuous

Improvement. It includes the ability to make timely and effective decisions and 
produce results through strategic planning and the implementation and evaluation of programs and policies.

2. Leading People--The ability to design and implement strategies that maximize personnel potential and foster high ethical standards in meeting the Navy's vision, mission, goals, and core values (honor, courage, and commitment).

3. Leading Change--Encompasses the ability to develop and implement an organizational vision that integrates key naval national and program goals, priorities, values, and other factors. Inherent to it is the ability to balance change and continuity - to create a work environment that encourages creative thinking and innovation.

4.Working with People--Involves the ability to explain, advocate, and express facts and ideas in a convincing manner and negotiate with individuals and groups internally and externally.

5. Resource Stewardship--Involves the ability to acquire and administer human, financial, material, and information resources in a manner that instills public trust and accomplishes the Navy's mission; and to use new technology to enhance decision-making (NLCM, 2006, p. 2).

This model offers some specific benefits: (a) explains and makes clear workforce standards and expectation; (b) makes sure individuals are aligned with Navy strategy; (c) improves performance while maintaining accountability; (d) gives directions for individual and professional development; (e) promotes equitable decisions; (f) increases the effectiveness of Navy training and professional leadership development by linking those to success criteria; $(\mathrm{g})$ promotes behavioral standards of 
excellence for leaders in the Navy (NLCM, 2006). The level of skills and knowledge increases as the level of position increases; the model helps ensure that Navy leaders are effective in whatever position they hold. In addition, this model is the basis for the next generation of training courses offered in the Navy Leadership Training Continuum that has recently changed names to the Navy Leadership Development Continuum. 


\section{CHAPTER 3 RESEARCH DESIGN}

\section{Research Design Overview}

The methodology of this research was quantitative in nature. The study employed a survey design. The research instrument for this study was a selfadministered Internet e-mail linked web-based electronic questionnaire. Conroy's rationale for using a mail type of survey instrument was that it provided access to the IOLTC graduates who were stationed throughout the United States of America and deployed overseas using the most economical means possible (Conroy, 2001). This researcher's rationale for using an Internet e-mail linked survey was, in part, the same as Conroy's rationale for using a mail type instrument: An e-mail linked web-based survey would allow for the surveying of IOLTC graduates around the world. In addition, as Dillman (2000) suggests, using the e-mail linked Internet design nearly eliminates the cost of paper, postage, mailing, and data entry. Using an online survey service such as "SurveyMonkey.com" requires only a nominal fee. Thus, the Internet survey strategy accomplished the same goal that motivated Conroy to use mail surveys, yet the e-mail strategy was less costly to implement than the mail-out survey strategy that Conroy used.

Of course, the e-mail linked web-based electronic survey also required the researcher to take a somewhat different look at the social exchange elements of responding to a survey (Dillman, 2000 p.353). For instance, security and confidentiality factors associated with electronic technologies raise issues of trust: these can be mitigated in a cover letter or privacy statement, however. In this 
instrument, the cover letter (Appendix A) explained that confidentiality is guaranteed. Paragraph four in appendix A states that:

Although the SurveyMonkey.com web-based program will be used to host the survey, and track those individuals responding to the survey participant names, addresses and duty stations will not be revealed to anyone. Confidentiality, in other words, is guaranteed. Even the researcher will not match your information with the survey. The researcher will only use the names and numbers to determine who should receive a reminder e-mail.

\section{The Survey Instrument}

The survey instrument (Appendix B) was almost an exact duplicate of the one used in the Conroy study (Appendix C). The only changes involved (a) adding an explanation of the purpose at the outset of the survey in response to a request made by the Navy Personnel Research, Studies and Technology, Navy Survey Approval Manager, (b) updating the racial and ethnic group categories in the demographic section of the questionnaire so they are consistent with the current Department of Defense and the Department of the Navy formats, and (c) transforming the mailed questionnaire to a web-based format.

Conroy's instrument was adapted from a sample questionnaire found in the second edition of Ronald Kirkpatrick's (1998) book, Evaluating Training Programs (p. 197). As Conroy mentioned, several of Kirkpatrick's survey questions had to be revised or omitted in order to answer the research questions for his (and, of course, this) study. A few additional revisions were made to the questionnaire after Conroy 
received feedback from peers and from the professor of a survey design course the researcher completed as part of the doctoral-level curriculum (Conroy, 2001).

The survey instrument that was used in both Conroy's original study and the web-based study required 26 responses relating to the IOLTC training received. However, Conroy's instrument used an alphanumeric grouping for the first four questions. In this study, an additional question was added. The first question asked for a survey number provided in the subject line of the invitation e-mail. Conroy placed the numbers on the questionnaire prior to mailing. That was not an option for the web-based survey because of the electronic nature of the system. The survey number participants were asked to enter in their survey, was used to track participants who may required a reminder or follow up e-mail. In addition, the survey contained three groups of general questions and two individual questions. The design of the first group of questions (survey questions $3,5,8$, and 11), was two fold: (a) to ascertain the amount of time that had elapsed between the completion of the graduates' leadership training and the graduates returning to their jobs, and (b) to determine whether or not the graduates were able to apply their leadership skills when they had returned to their jobs.

The purpose of the second group of questions $(2,6,9$, and 12$)$ was to recognize the barriers that obstructed the IOLTC graduates' use of leadership skills taught on the job. The third group $(4,7,10$, and 13) attempted to discover what incentives were provided to encourage IOLTC graduates to use the leadership skills taught in training at work. 
There were two individual questions. One (question number 14) sought to ascertain the percentages of respondents whose managers' attitudes either prevented, discouraged, encouraged, or required the use of leadership skills used on the job (or had a neutral effect). The other question (number 15) was a dichotomous question (Ary, Jacobs \& Razavieh, 1996) with only two available responses: yes or no. This question was designed to obtain the percentages of respondents who have access to available leadership-related resources (e.g., leadership textbooks and other relevant reference materials) on the job.

The last section of the research instrument contained 11 demographic questions. The first of these questions (number 16) asked the respondent to identify the position that he/she held in his/her command. Next, question number 17 asked the respondent about the position the respondent's immediate supervisor held in his/her command. Question number 18 asked the respondent to identify the type of duty (sea, shore, or other) the respondent had performed during the majority of the time since graduating from IOLTC.

The responses to questions 16 through 18 were used to search for possible patterns, relating to the types of duty and positions held in order to assist Navy Leadership Continuum curriculum developers with determining where to concentrate their improvement efforts. In addition, the researcher will report to the staff of the Center for Naval Leadership Curriculum Development Department regarding which levels of the Navy hierarchy are either encouraging or obstructing the graduates from utilizing acquired leadership skills on the job. 
Question number 19 collected data to ascertain if the respondent is either a Line Officer (a naval officer who is eligible for a command at sea or an operational command ashore) or a Staff Officer (a naval officer who is not eligible for an operational command either at sea or ashore). Question 20 was for the respondents who are line officers; its purpose was to identify line officers' specific career specialties. The line officers are further broken down into two categories: restricted line (more specialized field, i.e., Aerospace Maintenance, Oceanography, Intelligence) that are not ineligible for command at sea; and unrestricted line (naval officers who are eligible for operational command of a naval squadron or of a ship-ofthe-line).

Question number 21 collected data recognizing the area of the naval service (i.e., supply, medical, dental, civil engineering, etc.) to which the staff officers who participated in the study were assigned. The answers to the above questions were used by the researcher to compare responses among the various occupational communities that made up the survey sample.

Question number 22 asked whether the respondents are currently on active duty (regular Navy), reserve duty (Navy Reserve, serves only one weekend a month and for 2 consecutive weeks on an annual basis), or Full Time Support (FTS) (personnel who do not serve aboard U.S. Naval Ships) or fit into some other category, such as a U.S. Navy doctor who has returned to active duty for an assignment to Afghanistan or Iraq after a brief hiatus for a predetermined period of time to serve in an advisory capacity. Question number 22 was also used to compare answers among 
the various categories of respondents to see if there was a difference between the active duty Navy, the Navy Reserve, or the FTS.

Question number 23 collected information about the respondents' gender. The gender information was used to determine if there is a difference in the perceived utilization of acquired leadership skills between the male and female respondents. Conroy added question number 24 to the research instrument after completion of the pilot study to find out how long the respondents were assigned to their present command in order to analyze whether responses to survey questions 2-23 appeared to be influenced by their actual time spent on the job after completion of IOLTC training.

Questions 25 and 26 were also modified by Conroy after completion of the pilot study because the pilot study participants felt more comfortable answering Department of Defense (DoD) structured race/ethnic-related questions rather than using the approach wording for these items from the original questionnaire. These questions attempted to ascertain the race and ethnic backgrounds of the respondents in order to explore whether any difference in utilization of acquired IOLTC skills existed among people of different races/ethnic backgrounds. Since the Conroy study was completed, DoD classification has been altered. Consequently, Questions 25 and 26 were areas in which the Conroy instrument was modified for the current study. The second one was the fact that the study was web based and had the numbering to the questions changed. The third was the introduction needed to address the privacy act. The last question (number 27) was an open-ended question, allowing the 
respondents an opportunity to include additional comments. As noted, appendix B contains the current survey; appendix C contains the Conroy survey.

\section{Sample Selection}

The sample of former IOLTC students surveyed consisted of 327 naval officers who completed Learning Site Little Creek, IOLTC training from 2 July 2003 to 30 June 2004. Since Conroy used the same survey in his 2001 research, there was no reason for additional piloting of the survey instrument. The sample cover letter type e-mail, the survey, the Conroy instrument, and follow-up e-mail are included as appendices A, B, C, and D, respectively.

The Center for Naval Leadership (CNL) provided the names and rank information of each student who graduated from IOLTC between the period of 2 July 2003 and 30 June 2004. The researcher used Navy Knowledge On-line ${ }^{3}$ (NKO) to get the e-mail addressed for the initial mailing. For the returned e-mails and the followup, the researcher used a more comprehensive source: the Navy and Marine Corps white pages. The list of graduates CNL provided contained the names of 439 graduates. In previous years, the CNL offered 18 Two-week IOLTCs with a class size of about 30-35 students (Center for Naval Leadership, 2005). The average number of students that graduated from the Little Creek, Virginia site IOLTC each year was approximately 525. Today leadership training course attendance is low. Military operations such as Operation Enduring Freedom in Afghanistan and Operation Iraqi Freedom in Iraq may have impacted the number of students attending leadership courses beginning March 2003.

\footnotetext{
${ }^{3}$ Navy Knowledge Online is a system to provide Navy wide connectivity via a single, integrated online learning network with access throughout the world.
} 
Permission to Survey

In order to survey Navy Personnel, special permission was required according to a Chief of Naval Operations Instruction OPNAV 5300.8B. The instruction directed all persons desiring to survey Navy service members to obtain a sponsor and request permission form the Navy Survey Approval Manager (PERS-14). The researcher obtained a sponsor letter from the Center for Naval Leadership Commanding Officer Captain McDonald (Appendix E) and received a survey approval letter (Appendix F) from the Navy Survey Approval Manager.

\section{Survey Implementation}

In order to achieve a better than average response rate, the researcher used a modified version of the Dillman (2000) method that also was used in the Conroy study. In this study, the researcher deviated and did not mail the pre-notice letter 2 weeks prior to mailing the survey. The researcher did not believe that the additional e-mail created by the pre-notice would increase the response rate nor did the researcher think that the pre-notice letter served as a necessary tool to inform volunteers of the conditions, which they should be aware of before deciding on whether or not to participate. The cover letter e-mail was clear and explained what was required before launching the survey web site. In addition, the beginning of the web survey contained information, as mandated by the DoD, Public Law 93-579, called the Privacy Act of 1974, which required that participants be informed of the purpose of this survey and the uses to be made of the information collected. 
In retrospect, the decision not to send a pre-notice may not have been a good idea. This decision may account for a lower response rate in this study than in the Conroy study.

Two weeks following the first e-mail (Appendix A), the researcher collected all of the returned undeliverable e-mails, researched and located different addresses, and again e-mailed the message to the new addresses. The new e-mail again contained the link to the survey (Appendix B). Each e-mail cover letter for the first and subsequent mailings requested that the respondents use the linked survey web site and take the survey at their earliest convenience. As each of the surveys was completed, the researcher began to review the survey responses and export them into a statistical analysis program. After 4 weeks, the researcher began to assess the number of survey respondents to make a list of graduates who had not responded to the request. The researcher reviewed the list and created the follow up e-mail. At the end of the fifth week, the researcher e-mailed a follow-up e-mail (Appendix D) to all of the graduates who had not responded, including those who previously had undeliverable addresses. The researcher continued collecting data until the seventh week and then closed the survey. The researcher finished analysis during the eighth week from the time of the initial survey mailing.

Survey Response Expectations

The researcher anticipated achieving a $60 \%$ to $80 \%$ response rate. According to Dillman (2000), those who used his total design method averaged response rates from $58 \%$ to $92 \%$ with an average return rate of $74 \%$. Conroy (2001) writes: "According to Babbie (1990), a 50\% response rate is considered adequate; a $60 \%$ 
response rate is considered good, and a $70 \%$ rate is ideal" (p. 42). Conroy anticipated achieving 50 to $70 \%$ response rate. The actual response rate for the Conroy study was $52.3 \%$, which met Babbie's definition of adequate.

Actual Survey Response Rate

Fifty-one web questionnaires were completed within the first 3 days of emailing and an additional 20 were completed within the first 4 weeks. A second mailing of 276 e-mails requesting web survey participation was sent within 4 weeks of the date of the first set. Over the next week, 52 additional web surveys were completed for a total of 123 responses. The overall return rate was $37.6 \%$.

\section{Analysis}

The researcher used descriptive statistics to answer research questions 2 through 13 in order to display variation of responses between the several subgroups. By using descriptive statistics, the researcher was able to organize, analyze, and summarize the responses obtained (Ary, Jacobs \& Razavieh, 1996). Descriptive statistics has been the preferred method for analyzing data from the previous two Naval Leadership Continuum studies (Duncan-White, 1997: Lohmeyer, 1999).

The researcher used inferential statistics to analyze the responses to research questions 14 and 15. More specifically, to answer research questions number 14 and 15, the researcher used an Analysis of Variance (ANOVA) to see if the responses between the respondent subgroups were statistically significant.

Descriptive statistics was also used to display variation across contextual and demographic variables. The researcher used descriptive statistics to highlight different responses between different subgroups. For example, responses to questions 
2 through 13 were provided to determine the percentage of the sample or frequency of respondents that did or did not utilize the leadership skills learned during the four IOLTC subunits: leadership models, situational communications, delegation, and command climate. Questions 2 through 13 were also used to compare the average time that elapsed after the IOLTC graduates completed leadership training to the time when they were able to apply their skills on the job.

In addition to descriptive statistics, the researcher was able to employ inferential statistics in an attempt to find out if survey responses varied across demographic and contextual variables in statistically significant ways (see research question number five). For example, inferential statistics were used to examine and either reject, or fail to reject the Null Hypothesis $\left(\mathrm{H}_{\mathrm{o}}\right)$ that there is no statistically significant difference between the use of acquired leadership skills on the job between IOLTC graduates who are represented by the various demographics (e.g., gender, race, sea/shore duty, or component).

\section{Assumptions of the Study}

Based on the review of the literature, the researcher assumed that there might be barriers on the job that preclude the graduates from using their acquired leadership skills. The researcher also assumed that there were few incentives, if any, which encourage IOLTC graduates to use their leadership skills on the job. However, if in fact there were incentives that existed, the researcher hypothesized that such incentives would be found among shore-based commands rather than sea-going units because the tempo of operations is usually more demanding and fast-paced with seaduty commands. The researcher also hypothesized that this study would reveal that 
the majority of the IOLTC graduates have bosses that have either an "encouraging" or "neutral" attitude toward allowing them to use their newly acquired leadership skills on the job. In addition, the researcher hypothesized that a) the research would have shown evidence of a reward system throughout the fleet that encouraged graduates to use their leadership skills on the job and b) the results would closely follow the results of the Conroy study.

\section{Limitations of the Study}

There were two significant limitations to this study. Although gathering data from a site other than the Coronado, California site was a recommendation of the Conroy study, one of the limitations of this study was that researcher only sampled IOLTC graduates from the Navy's East Coast leadership training site located at NAB, Little Creek, Virginia. Even though at the time the survey was sent out a small portion of IOLTC graduates had subsequently transferred to a West Coast or overseas activity after completing formal leadership training, the percentage is small when compared to the majority of graduates who remained on the East Coast.

Another limitation was that the study primarily focused on the IOLTC graduates' perceptions of their immediate superiors and not on the potential negative biases that some IOLTC graduates might have regarding the formal leadership training and their unwillingness to utilize the acquired leadership skills on the job. However, in an attempt to counter this limitation Conroy included a "resistance to change (self)" as one of the available choices listed on the research instrument for barriers encountered when trying to utilize the acquired skills learned on the job. Also, since the study results are based on the perceptions IOLTC graduates have of 
their superiors' attitudes toward use of their leadership skills, these perceptions may have reflected the lack of chemistry between the IOLTC graduate and his / her boss rather than what the questionnaire attempted to measure: opportunity and encouragement to practice skills learned in leadership training on the job.

Role of the Researcher

At the time of this study, the researcher was an active duty Navy Commander, Aerospace Engineering Duty Officer (Maintenance), and assigned to the Naval Personnel Development Command's Center for Naval Aviation Technical Training on shore duty as a Liaison Staff Member to the Naval Aviation Systems Command, Aviation Training Systems Program Manager Air (PMA205). The researcher was very familiar with Navy Leadership Training, the Navy Leadership Training Continuum, and attended Basic Officer Training Course, Intermediate Officer Leadership Training Course, and Advanced Officer Leadership Training Course. He clearly understands that his experiences helped shape the survey's qualitative aspects and assumptions that support this research but believed that the quantitative methodology provided the right level of objectivity to the research and analysis process. 


\section{CHAPTER 4 RESULTS}

Introduction

The data collection and analysis procedures described in the previous chapter were used to answer the following questions, the first five of which were also employed in the Conroy (2001) study:

1. Do graduates believe that they were able to use their skills on the job?

2. How much time had elapsed after completion of IOLTC before the graduates exercised the leadership skills acquired during the course?

3. What are the IOLTC graduates' perceptions of their bosses' attitudes toward their using the leadership skills learned during the leadership-training course? More specifically, do graduates perceive their bosses prevent, discourage, encourage, or require the use of graduates' newly acquired leadership skills back on the job or do graduates perceive their boss takes a neutral stance?

4. What factors (barriers or incentives) are associated with skill use across the four IOLTC subunits (leadership, communication, delegation, and command climate)?

5. Are there differences in the perceptions of Leadership, Communication, Delegation, and Command Climate when scores are compared by gender, supervisor's position, respondent's position, line/staff officer, and duty type? 6. To what extent are the findings from this study consistent with the Conroy study? 
Consistent with the format used in the Conroy (2001) study, the results of this replication study are reported in different parts, the first two of which correspond to different sections of the survey. The first part describes the characteristics of the data in terms of frequencies, means, and standard deviations and describes the responses of survey participants to survey questions 2 though 13 . The second part presents the results of inferential analyses that were conducted using the responses to questions 14 through 26 . The final part of this section compares findings from this study with findings from the Conroy study, which this study replicated.

\section{Part I}

Overall Characteristics of the Survey Respondents and Their Perceptions About Skill Utilization, Barriers, and Incentives

\section{Characteristics of Survey Respondents}

The sample consisted of 439 U.S. Navy Officers graduating from IOLTC at NAB Little Creek, Virginia, from 2 July 2003 to 30 June 2004. Eighty-eight (20\%) of the e-mails sent were returned as undeliverable. Twenty-three $(5 \%)$ of the e-mail addresses were unavailable, and one participant e-mailed and declined to participate. The sample size was reduced accordingly to 327 graduates. One hundred twenty-three IOLTC graduates completed the web survey for a response rate of $37.6 \%$. According to Babbie (1990), a 50\% response rate is considered adequate. However, according to Hager, Wilson, Pollak, \& Rooney (2003), the standards for acceptable return rates are shaped not as much by how many responses a researcher can get, but by how many he/she should get. In short, a number of factors influence the rate of return for a given research project, and since this survey occurred during wartime, there were a number 
of logistical challenges. For example, records indicate that of the 416 requests sent, 88 were undeliverable; nine respondents were on temporary assignments and were unable to take the survey before expiration of the Institutional Review Board (IRB) authorization. When these factors are considered, a response rate of around $40 \%$ would be appropriate as such. The $37.6 \%$ response rate achieved appears adequate.

Out of the 123 respondents, $37(30.1 \%)$ were female and $86(69.9 \%)$ were male. There were a total of 105 females $(32.2 \%)$ and 222 males $(67.8 \%)$ in the survey population. Thus, the gender distribution of the survey respondents was reasonably representative of the population's gender distribution. The frequency of responses by gender also was very similar to that of the Conroy study. Out of the 264 respondents in the Conroy study, $76(28.8 \%)$ were female and $188(71.2 \%)$ were male, compared with a total of 163 females (32.3\%) and 342 males (67.7\%) in the Conroy survey population.

\section{Findings About Utilization}

Table 1 summarizes the graduates' assessment of whether or not they utilized acquired leadership skills across the four IOLTC subunits. The table demonstrates that most graduates who responded to the request to participate in the study believed that they had at least some opportunity to use the skill taught in each of the IOLTC subunits. Indeed, the difference across subunits was negligible. 
Table 1

Summary of Graduates' Assessments

\begin{tabular}{lccc}
\hline IOLTC Subunit & Utilized & Not Utilized & Cumulative \\
\hline Leadership Model(s) & $110(89.4 \%)$ & $13(10.6 \%)$ & 123 \\
Situational Communications & $110(89.4 \%)$ & $13(10.6 \%)$ & 123 \\
Delegation & $112(91.1 \%)$ & $11(8.9 \%)$ & 123 \\
Command Climate & $114(92.7 \%)$ & $9(7.3 \%)$ & 123 \\
\hline
\end{tabular}

The survey also asked about the amount of time before graduates could put each of the four skill sets to use (See Appendices H, I, J, and K for a summary of the data). Table 2 presents the means and standard deviations for lapsed time to implementation. The data summarized in Table 2 suggest most students used the Delegation, and Command Climate skills during their first month on the job. However, it appears as if the Leadership Models and Situational Communication skills required a bit longer than one month to be utilized. These categories also received the lowest overall usage scores, but, again, the differences seem relatively small.

Taken together, the data support the claim that most leadership skills taught in the IOLTC are used within the first 4-6 weeks after graduates complete their training and return to the work environment. Within each of the subunits, however, the number of people reporting that they were unable to use the skills taught did not exceed $10.6 \%$. 
Table 2

Mean Number of Weeks Elapsed Prior to Utilization of Acquired Leadership Skills Across the Four IOLTC Subunits

\begin{tabular}{lccc}
\hline IOLTC Subunit & Mean in Weeks & Standard Deviation & \# of Respondents \\
\hline Leadership Model(s) & 4.37 & 1.48 & 123 \\
Situational & 4.15 & 1.63 & 123 \\
Communications & & & 123 \\
Delegation & 4.02 & 1.73 & 123 \\
Command Climate & 4.03 & 1.69 & \\
\hline
\end{tabular}

\section{Findings about Barriers}

The purpose of a second group of questions (Questions 2, 6, 9, and 12) was to identify the barriers to on-the-job use of leadership skills taught in the IOLTC course. Table 3 reports the number and percentage of graduates reporting barriers to implementing the leadership skills associated with the course's four subunits.

As Table 3 clearly indicates, most of the graduates reported having encountered some barriers when attempting to use the skills taught in the leadership models and situational communications components of the course. The barrier that was most often cited was "resistance to change by subordinates." With respect to both the delegation and command climate skills, however, the majority of the survey respondents reported that no barriers were encountered. Moreover, among those reporting barriers in these areas, "resistance to change by subordinates" was, once 
again, identified as a significant barrier (See Appendices L, M, N, and O for a summary of these data).

Table 3

Barriers that Obstructed the IOLTC Graduates

\begin{tabular}{lccc}
\hline IOLTC Subunit & Barriers & No barriers & Cumulative \\
\hline Leadership Model(s) & $95(61.0 \%)$ & $48(39.0 \%)$ & 123 \\
Situational Communications & $65(53.3 \%)$ & $57(46.7 \%)$ & $122 *$ \\
Delegation & $61(49.6 \%)$ & $62(50.4 \%)$ & 123 \\
Command Climate & $54(43.9 \%)$ & $69(56.1 \%)$ & 123 \\
\hline
\end{tabular}

Note. ${ }^{*} \mathrm{~A}$ respondent skipped this question

Findings About Incentives

Table 4 provides information about the perceived incentives for using skills taught in the IOLTC course on the job (Questions 4,7,10, and 13). The findings here are considerably more positive than negative for all of the four skill sets taught, though from $21 \%$ to $24 \%$ in each of the four subcategories did not perceive any incentives for using skills taught in IOLTC on the job.

Responses to other questions indicate the sorts of incentives that graduates identified and are included in appendices $P, Q, R$, and $S$. These responses indicate that a substantial number of respondents cited open lines of communication with both superiors and subordinates as incentives for implementing the leadership skills that were taught in the IOLTC. 
Table 4

Incentives to Use Skills

\begin{tabular}{lccc}
\hline IOLTC Subunit & Incentives & No Incentives & Cumulative \\
\hline Leadership Model(s) & $95(78.9 \%)$ & $27(21.1 \%)$ & $122^{*}$ \\
Situational Communications & $95(78.5 \%)$ & $26(21.5 \%)$ & $121^{* *}$ \\
Delegation & $94(76.0 \%)$ & $29(24.0 \%)$ & $121^{* *}$ \\
Command Climate & $96(78.7 \%)$ & $26(21.3 \%)$ & $122^{*}$ \\
\hline
\end{tabular}

Note. ${ }^{*}($ A respondent skipped this question $) *($ Two respondents skipped this question)

Superiors' Attitudes as Barrier or Incentive

Clearly, the attitude of a graduate's immediate superior toward using IOLTC

skills on the job can be either a significant barrier or a significant incentive.

Therefore, one of the research questions was focused on this issue, and one of the survey questions asked about supervisors' attitudes. Once again, the responses were quite positive. Table 5, in fact, indicates the majority of responses ( 71 of 123 or $57.7 \%$ ) reported that their boss either encouraged or required that they use IOLTC leadership skills in their work. 
Table 5

IOLTC Graduates' Bosses' Attitudes

\begin{tabular}{llll}
\hline Bosses' Attitude & Encouraging \& & Neutral, Preventing, \& & Cumulative
\end{tabular} Requiring Discouraging

\begin{tabular}{llll}
\hline Perceptions of Bosses' & $71(57.7 \%)$ & $52(42.3 \%)$ & 123
\end{tabular}

Attitudes towards

utilization of skills

learned during IOLTC

Summary of Overall Characteristics of the Survey Respondents and Their Perceptions

About Skill Utilization, Barriers, and Incentives

The data in Part I documented the respondents perceptions of the learned skills used on the job. Although the respondents' choices to question two of the survey regarding barriers encountered using the leadership models were only offered a single discrete choice as compared to questions 6,9 , and 12 , which offered multiple choices, the data in the frequency distribution, is nearly the same.

\section{Part II}

Demographic and Contextual Variables and Inferential Statistics

In the next part of the chapter, descriptive data about demographic and contextual variables are presented. The focus of this section shifts to the fifth research question - Do the answers to the questions about utilization, barriers, and incentives 
vary depending on demographic and contextual variables?-and do the results of tests of a number of null hypotheses relate to this fifth research question.

\section{Variables and Summary of Results}

Survey questions 16-26 were designed to solicit responses about demographic (line/staff officers, gender, and race) and contextual variables (the four IOLTC subunits, type duty, and component) as a precursor to answering, through inferential analysis, the fifth research question regarding the impact of demographic and contextual variables on skills use. The following is a summary of the IOLTC graduates' responses to survey questions 16-26.

Race/Ethnicity. In the current survey, $1(.8 \%)$ of the survey respondents was American Indian or Alaska Native; 5 (4.1\%) were Asian (e.g. Asian Indian, Chinese, Filipino, Japanese, Korean, Vietnamese, etc.); 10 (8.1\%) were Black or African American; $0(0.0 \%)$ Native Hawaiian or other Pacific Islander (e.g., Samoan Guamanian, Chamorro, etc.); 97 (78.9\%) White; 4 (3.3\%) Spanish (Hispanic or Latino origin); and 6 (4.9\%) other (See Appendices $T$ and $U$ for a summary of the race/ethnicity responses). 
Table 6

Means for Average Elapsed Weeks Prior to Graduates' Use of Acquired Leadership Skills on the Job by Race / Ethnic Group

\begin{tabular}{|c|c|c|c|c|c|}
\hline $\begin{array}{l}\text { Race / } \\
\text { Ethnic } \\
\text { Group }\end{array}$ & Weeks Elapsed & $\begin{array}{l}\text { Leadership } \\
\text { Models }\end{array}$ & $\begin{array}{c}\text { Situational } \\
\text { Communication }\end{array}$ & Delegation & $\begin{array}{c}\text { Command } \\
\text { Climate }\end{array}$ \\
\hline \multirow[t]{3}{*}{ Indian } & Mean & 5.00 & 5.00 & 4.00 & 5.00 \\
\hline & $\mathrm{N}$ & 1 & 1 & 1 & 1 \\
\hline & Std. Deviation & .00 & .00 & .00 & .00 \\
\hline \multirow[t]{3}{*}{ Asian } & Mean & 3.80 & 3.40 & 3.80 & 3.60 \\
\hline & $\mathrm{N}$ & 5 & 5 & 5 & 5 \\
\hline & Std. Deviation & 2.17 & 1.95 & 2.17 & 2.07 \\
\hline \multirow[t]{3}{*}{ Black } & Mean & 4.70 & 4.80 & 3.70 & 4.30 \\
\hline & $\mathrm{N}$ & 10 & 10 & 10 & 10 \\
\hline & Std. Deviation & 1.25 & .92 & 2.26 & 1.42 \\
\hline \multirow[t]{3}{*}{ White } & Mean & 4.43 & 4.18 & 4.10 & 4.06 \\
\hline & $\mathrm{N}$ & 97 & 97 & 97 & 97 \\
\hline & Std. Deviation & 1.46 & 1.65 & 1.67 & 1.69 \\
\hline \multirow[t]{3}{*}{ Other } & Mean & 3.33 & 3.33 & 3.50 & 3.33 \\
\hline & $\mathrm{N}$ & 6 & 6 & 6 & 6 \\
\hline & Std. Deviation & 1.63 & 2.07 & 2.17 & 2.34 \\
\hline \multirow[t]{3}{*}{ Latino } & Mean & 4.00 & 4.00 & 4.00 & 4.00 \\
\hline & $\mathrm{N}$ & 4 & 4 & 4 & 4 \\
\hline & Std. Deviation & 1.16 & 1.42 & 1.41 & 1.41 \\
\hline \multirow[t]{3}{*}{ Total } & Mean & 4.37 & 4.15 & 4.02 & 4.03 \\
\hline & $\mathrm{N}$ & 123 & 123 & 123 & 123 \\
\hline & Std. Deviation & 1.48 & 1.63 & 1.73 & 1.69 \\
\hline
\end{tabular}

Average Elapsed Weeks Prior to Graduates' Use of Acquired Leadership

Skills on the Job by Race / Ethnic Group Summary of Results. The average elapsed weeks prior to utilization of all Subunit skills was the lowest among the group called "Other." The one Native Indian reported taking the longest amount of time (in average elapsed weeks) to apply the skills learned in IOLTC on the job. In general, the Asian population had a tendency to put the skills to use faster than the majority of the other ethnic groups. 
Gender. The results for elapsed weeks by gender are presented in Table 7.

Table 7

Means for Average Elapsed Weeks Prior to Graduates' Use of Acquired Leadership Skills on the Job by Gender

\begin{tabular}{llcccc}
\hline Gender & Weeks Elapsed & $\begin{array}{c}\text { Leadership } \\
\text { Titles }\end{array}$ & $\begin{array}{c}\text { Situational } \\
\text { Communication }\end{array}$ & $\begin{array}{c}\text { Delegation } \\
\text { Command } \\
\text { Climate }\end{array}$ \\
\hline Male & Mean & 4.30 & 4.03 & 3.83 & 3.88 \\
& $N$ & 86 & 86 & 86 & 86 \\
& Std. Deviation & 1.51 & 1.63 & 1.72 & 1.71 \\
Female & Mean & 4.51 & 4.43 & 4.49 & 4.38 \\
& N & 37 & 37 & 37 & 37 \\
& Std. Deviation & 1.41 & 1.59 & 1.69 & 1.62 \\
Total & Mean & 4.37 & 4.15 & 4.02 & 4.03 \\
& N & 123 & 123 & 123 & 123 \\
& Std. Deviation & 1.48 & 1.63 & 1.73 & 1.69 \\
\hline
\end{tabular}

Average Elapsed Weeks Prior to Graduates' Use of Acquired Leadership

Skills on the Job by Gender Summary of Results. The average elapsed weeks prior to utilization of leadership skills were higher among the female respondents across all four of the IOLTC subunits. The most notable difference in average elapsed weeks between male and female respondents was the use of delegation; the gender-based difference was .66 weeks.

Duty Status. As Table 8 indicates, $97 \%$ of all respondents were active duty and no relevant analysis of duty status can be performed. The results in Table 8 also indicate that there were no Full Time Support officers who responded to the survey. 
Table 8

Distribution of IOLTC Graduates by Duty Status

\begin{tabular}{lc}
\hline Type Duty & $\begin{array}{c}\text { Number and Percent of } \\
\text { Graduates }\end{array}$ \\
\hline Active & $120(97.6 \%)$ \\
Selected Reservist & $1(0.8 \%)$ \\
Full Time Support & $0(0.0 \%)$ \\
Other & $2(1.6 \%)$ \\
Total & $123(100.0 \%)$ \\
\hline
\end{tabular}

Line / Staff. Twenty-nine respondents $(23.6 \%)$ were regular line officers.

However the aggregate of Tables 9 and 10 indicated that perhaps five respondents provided inputs for both line and staff because there are $99(80 \%)$ respondents for the staff question.

Table 9

Distribution of IOLTC Graduates by Line Officer Community

\begin{tabular}{lc} 
Community & Number and Percent of Graduates \\
\hline Unrestricted Line & $17(13.8 \%)$ \\
URL LDO & $1(0.8 \%)$ \\
RL Oceanography & $1(0.8 \%)$ \\
RL Public Affairs & $2(1.6 \%)$ \\
Other & $8(6.5 \%)$ \\
Total & $29(23.6 \%)$ \\
\hline
\end{tabular}

Table 10

Distribution of IOLTC Graduates by Staff Officer Community

\begin{tabular}{lc}
\hline Community & $\begin{array}{c}\text { Number and Percent of } \\
\text { Graduates }\end{array}$ \\
\hline Supply & $7(5.7 \%)$ \\
Medical & $25(20.3 \%)$ \\
Medical Service & $33(26.8 \%)$ \\
Nurse Corps & $32(26.0 \%)$ \\
Chaplain Corps & $2(1.6 \%)$ \\
Total & $99(80.5 \%)$ \\
\hline
\end{tabular}


Respondents were also inspected by job position as presented in Table 11 and by the graduates' supervisor's position as shown in Table 12 .

Table 11

Graduates' Job Position

\begin{tabular}{lc}
\hline & $\begin{array}{c}\text { Number and Percent of } \\
\text { Graduates }\end{array}$ \\
\hline Director & $7(5.7 \%)$ \\
Department Head & $41(33.3 \%)$ \\
Asst Department Head & $10(8.1 \%)$ \\
Division Officer & $19(15.4 \%)$ \\
Other & $46(37.4 \%)$ \\
Total & $123(100.0 \%)$ \\
\hline
\end{tabular}

Table 12

Graduates' Supervisor's Position

\begin{tabular}{lc}
\hline & $\begin{array}{c}\text { Number and Percent of } \\
\text { Graduates }\end{array}$ \\
\hline Executive Officer & $28(22.8 \%)$ \\
Department Head & $40(32.5 \%)$ \\
Asst Department Head & $2(1.6 \%)$ \\
Division Officer & $5(4.1 \%)$ \\
Other & $48(39.0 \%)$ \\
Total & $123(100.0 \%)$ \\
\hline & \\
& Inferential Statistics
\end{tabular}

In order to ascertain if there were statically significant differences between demographic variables and findings about skill use among respondents a one-way ANOVA (Norusis, 2000) was performed. As previously stated in Chapter 3, analysis of the differences between the mean for various groups and the variance or "random error" of each group provides information needed to determine if the difference 
between the two is statistically significant. Like Conroy (2001), this researcher used the ANOVA to test and either accept or reject the null hypothesis $\left(\mathrm{H}_{0}\right)$.

The ANOVAs were tested at the $95 \%$ confidence level. As discussed in the previous chapter, in order to test for false positives associated with Type I errors (the error occurring when a researcher rejects a null hypothesis that is in fact true (Ary, Jacobs \& Razavieh, 1996), post hoc tests are usually conducted when there are significant differences in order to identify how the dissimilar groups differed (Norusis, 1999).

A univariate ANOVA was conducted separately for the independent variables of gender, respondents' position, respondents' supervisor's position, type of duty, and line or staff officer. A Scheffe post hoc comparison was planned in the inferential analysis for each selected independent variables if the ANOVA was established to be significant at $p=.05$ or less. Generally speaking, post hoc comparisons are not necessary for those variables with only two levels, such as gender and line or staff. The dependent variables were the elapsed time (in weeks) to implement training, barriers to implementation, and incentives to implement training for Leadership Models, Situational Communication, Delegation, and Command Climate. Due to survey preparation error, however, the results for barriers to leadership models could not be calculated using an inferential technique.

\section{Respondent's Position Comparison}

As can be seen in Table 13, there were no statistically significant differences in the ANOVA results when they were compared by respondents' position (Director, Department Head, Asst. Department Head, Division Officer, or Other). The 
respondents' position did not result in any significant differences in the time to implement, barriers to implementation, or incentives to implementation; thus, the researcher believed it was not necessary to conduct or report the post hoc analysis since the results were not significant.

Table 13

ANOVA Results for Respondents' Position

\begin{tabular}{llll}
\hline Dependent Variable & F-stat & $d f$ & $p$ \\
\hline Leadership - Time to Implement & .95 & 4,118 & .44 \\
Leadership - Incentives to Implement & 1.19 & 1,117 & .32 \\
Communication - Time to Implement & .11 & 4,118 & .96 \\
Communication - Barriers to Implement & 2.05 & 4,117 & .09 \\
Communication - Incentive to Implement & 1.11 & 4,116 & .36 \\
Delegation - Time to Implement & 1.24 & 4,118 & .30 \\
Delegation- Barriers to Implement & .99 & 4,118 & .41 \\
Delegation- Incentive to Implement & .68 & 4,118 & .61 \\
Climate - Time to Implement & .53 & 4,118 & .72 \\
Climate - Barriers to Implement & .14 & 4,118 & .97 \\
Climate - Incentive to Implement & .96 & 4,117 & .43 \\
\hline Note* p $\leq .05$ & & & \\
\hline
\end{tabular}


Supervisor's Position Comparison

The second inferential analysis involved comparing survey participants on their responses to the time, barriers, and incentives by the supervisor's position of the participants. Table 14 illustrates the results of this analysis and indicates there are no statistically significant differences for the analysis by supervisor's position. Post hoc tests were not conducted, as there were no significant differences found.

Table 14

ANOVA Results for Respondent's Supervisor's Position

\begin{tabular}{llll}
\hline Dependent Variable & $F$-stat & $d f$ & $p$ \\
\hline Leadership - Time to Implement & .95 & 4,118 & .44 \\
Leadership - Incentives to Implement & 1.19 & 4,117 & .32 \\
Communication - Time to Implement & .11 & 4,118 & .98 \\
Communication - Barriers to Implement & 2.05 & 4,117 & .09 \\
Communication - Incentive to Implement & 1.11 & 4,116 & .36 \\
Delegation - Time to Implement & 1.24 & 4,118 & .30 \\
Delegation- Barriers to Implement & .99 & 4,118 & .41 \\
Delegation- Incentive to Implement & .68 & 4,116 & .61 \\
Climate - Time to Implement & .53 & 4,118 & .72 \\
Climate - Barriers to Implement & .14 & 4,118 & .97 \\
Climate - Incentive to Implement & .96 & 4,117 & .43 \\
\hline
\end{tabular}


Type of Duty Comparison

The third inferential comparison using a univariate ANOVA was by

respondents' type of duty, shore duty, sea duty, or other. Type of duty was compared on the time, barriers, and incentives for Leadership, Situational Communication,

Delegation, and Command Climate. As can be seen in Table 15, there were no statistically significant differences in perceptions based on the respondents' type of duty. Since there were no significant differences, no post hoc tests were performed.

Table 15

Type of Duty Comparison

\begin{tabular}{llll}
\hline Dependent Variable & F-stat & $d f$ & $p$ \\
\hline Leadership - Time to Implement & .18 & 2,120 & .83 \\
Leadership - Incentives to Implement & 1.77 & 2,119 & .18 \\
Communication - Time to Implement & .30 & 2,120 & .74 \\
Communication - Barriers to Implement & .56 & 2,119 & .57 \\
Communication - Incentive to Implement & 1.48 & 2,118 & .23 \\
Delegation - Time to Implement & .06 & 2,120 & .94 \\
Delegation- Barriers to Implement & 1.36 & 2,120 & .26 \\
Delegation- Incentive to Implement & .87 & 2,118 & .42 \\
Climate - Time to Implement & .35 & 2,120 & .70 \\
Climate - Barriers to Implement & 1.79 & 2,120 & .17 \\
Climate - Incentive to Implement & .06 & 2,119 & .94 \\
\hline
\end{tabular}




\section{Type of Officer Comparison}

Analysis of variance was also used to test for differences in the perceptions of respondents by officer type, line officer or staff officer, on their responses to time, barriers, and incentives. As with the previous analyses, there were no statistically significant differences for this grouping of the survey respondents.

Table 16

Line Officer - Staff Officer Comparison

\begin{tabular}{|c|c|c|c|}
\hline Dependent Variable & $F$-stat & $d f$ & $p$ \\
\hline Leadership - Time to Implement & .12 & 1,121 & .73 \\
\hline Leadership - Incentives to Implement & .80 & 1,120 & .37 \\
\hline Communication - Time to Implement & .43 & 1,121 & .51 \\
\hline Communication - Barriers to Implement & 2.03 & 1,120 & .16 \\
\hline Communication - Incentive to Implement & .38 & 1,119 & .54 \\
\hline Delegation - Time to Implement & $.04^{*}$ & 1,119 & .84 \\
\hline Delegation- Barriers to Implement & .25 & 1,121 & .62 \\
\hline Delegation- Incentive to Implement & 2.03 & 1,121 & .16 \\
\hline Climate - Time to Implement & $.00^{*}$ & 1,121 & .98 \\
\hline Climate - Barriers to Implement & .54 & 1,121 & .47 \\
\hline Climate - Incentive to Implement & 1.76 & 1,120 & .17 \\
\hline
\end{tabular}

Note $^{*} \mathrm{p} \leq .05$

Gender Comparison

The last inferential comparison made was by gender, male and female, on the time, barriers, and incentives scores. There was one statistically significant difference between the males and females for the amount of time needed to implement or use 
Delegation skills $(F(1,121)=3.83, p=.052)$. Males used an average of 3.83 weeks to implement $(S D=1.72)$ while females implemented Delegation skills in an average of 4.49 weeks $(S D=1.85)$. Since there were only two levels of the independent variable, no post hoc tests were necessary. Table 17 presents the results of this analysis by gender.

Table 17

Male/ Female Officer Comparison

\begin{tabular}{llll}
\hline Dependent Variable & F-stat & $d f$ & $p$ \\
\hline Leadership - Time to Implement & .53 & 1,121 & .47 \\
Leadership - Incentives to Implement & .01 & 1,120 & .95 \\
Communication - Time to Implement & 1.56 & 1,121 & .22 \\
Communication - Barriers to Implement & .04 & 1,120 & .85 \\
Communication - Incentive to Implement & .92 & 1,119 & .34 \\
Delegation - Time to Implement & 3.85 & 1,121 & $.05^{*}$ \\
Delegation- Barriers to Implement & 2.17 & 1,121 & .14 \\
Delegation- Incentive to Implement & .32 & 1,119 & .57 \\
Climate - Time to Implement & 2.23 & 1,121 & .14 \\
Climate - Barriers to Implement & .45 & 1121 & .51 \\
Climate - Incentive to Implement & .01 & 1,120 & .94 \\
\hline
\end{tabular}
Note $^{*} \mathrm{p} \leq .05$ 
Summary of Demographic and Contextual Variables and Inferential Statistics

Based on these findings, there was only one significant difference for time to implement Delegation skills by gender, with males having a shorter amount of time than did females.

\section{Part III}

\section{Study Comparisons}

In this third and final part of the findings discussion, a comparison is made with the results of this study and the Conroy study. The discussion begins with a comparison of the two studies' populations and then highlights differences and similarities in results.

Overall, the two studies were quite similar samples, although the Conroy population was 505 and the current study had a population of 439 . Each had a similar make up of respondents in terms of gender and type duty. Tables 18 and 19 demonstrate this high degree of comparability.

Table 18

Population Comparison by Gender Percent

\begin{tabular}{lccc}
\hline Gender & This Study & Conroy Study & Difference \\
\hline Male & $69.9 \%(86)$ & $72.1 \%(188)$ & $2.2 \%$ \\
Female & $30.1 \%(37)$ & $32.3 \%(163)$ & $2.2 \%$ \\
\hline
\end{tabular}


Table 19

Population Comparison by Type Duty Percent

\begin{tabular}{lccc}
\hline Type Duty & This Study & Conroy Study & Difference \\
\hline Male & $65.9 \%(81)$ & $69.7 \%(184)$ & $3.2 \%$ \\
Female & $27.6 \%(34)$ & $20.5 \%(54)$ & $7.1 \%$ \\
Other & $6.5 \%(8)$ & $9.8 \%(26)$ & $3.3 \%$ \\
\hline
\end{tabular}

Differences exist between the two studies in response to questions about the amount of time required before a graduate could use IOLTC skills on the job. The Conroy survey asked respondents to write in the answer in terms of the number of days; however, to facilitate data collection, this Internet web-based survey provided discrete response categories. The categories were a) less then seven days, b) within one week, c) within 2 weeks, d) within 1 month, e) more than 1 month, f) have not yet used. Despite the use of different response options, there does not appear to be any actual inconsistency in the results of the two studies. The data collected in the Conroy study used the increment of days, which may seem more accurate. However, when asking respondents to think about when they used skills learned during a period more than two years ago, weeks were thought to be more appropriate. In addition, the respondents had a choice to fill in the amount of time in days, weeks, or months. Most respondents chose weeks.

The barriers identified in the two studies also are, for the most part, the same; however, it is clear that in this study, subordinates were perceived as more of a barrier than in the Conroy study. The difference here, however, is a matter of degree as the 
barrier that was most often cited in the Conroy study also was "resistance to change by subordinates."

In addition, respondents in both studies cited open lines of communication with both superiors and subordinates as incentives for implementing the leadership skills that were taught in the IOLTC. Also in both studies, the majority of the survey respondents reported that no barriers were encountered in implementing delegation and command climate skills.

One similar result related to gender differences. In both studies there were apparent differences. In this study, the difference between male and female responses to questions about time that had elapsed before Delegation skills could be implemented was .66 weeks. The Conroy study reported a similar finding. In the area of Command Climate, however, Conroy reported a much larger difference of 3.5 weeks. In this study, the difference between females and males was .5 weeks.

In the second part, ANOVA tests were conducted to look for significant differences. A univariate ANOVA was conducted separately for the independent variables of gender, respondents' position, respondents' supervisor's position, type of duty, and line or staff officer. There was only one significant difference for time to implement delegation skills by gender with males having a shorter amount of time than did females. The remainders of the ANOVAs conducted for this analysis were not found to be statistically significant.

In general, the respondent's position did not result in any significant differences in the time to implement, barriers to implementation, or incentives to implementation; thus, the researcher believed it was not necessary to conduct or 
report the post hoc analysis since the results were not significant. Although Conroy conducted several post hoc, tests the results from his ANOVA testing were very similar to the results of this study.

Finally, a comparison of the open-ended questions provided only some general comments that do not fit in any particular category. Thirty-five out of 123 respondents completed the "Optional Comments" question provided at the end of the survey. (See Appendix V for the actual comments.)The following is a summary of the comments that related to the purpose of the study and research questions:

1. Six of the IOLTC graduates indicated that they could not remember the course content too well.

2. Three of the graduates suggested that the course is common sense and it does not need to be taught.

3. Three of the graduates had a blended AOLTC and IOLTC course that was reported to be of little value to them in terms of learning about leadership.

4. Four responses from the IOLTC graduates addressed superior and or subordinate support. The general consensus is that the command climate may be a factor in applying the leadership skills learned in IOLTC and whether they can be applied on the job. The barriers and incentives may be a function of the command climate as well.

5. Two IOLTC graduates suggested that the course was a waste of time and money. 
6. Four graduates indicated that they enjoyed the course, that it was beneficial and may have improved their leadership skills and professional reputation.

\section{Summary of Study Comparisons}

The findings from this study largely mirrored the findings of the Conroy study. In addition, the open-ended comments were very much the same with some respondents making nearly identical comments to the comments the IOLC graduates made in the Conroy study. 


\section{CHAPTER 5 DISCUSSION}

Chapter 5 provides a summary of the research presented in this dissertation. The summary briefly reviews the study's purpose, the methodology, and findings. The chapter concludes with recommendations for (a) future research, and a synopsis of the Navy's training path for the next generation and (b) future research.

Review of the Study's Purpose and Methods

\section{Purpose}

The purpose of the study was to replicate William Conroy's study with a different population and at a different time. The goal of both studies was to obtain feedback from graduates of the U.S. Navy's IOLTC on (a) opportunities to use skills learned during IOLTC on the job, and (b) how their immediate superiors responded when the graduates used the leadership skills learned during the IOLTC.

\section{Methodology}

The methodology of this research was primarily quantitative and utilized an Internet e-mail linked one-page web-based survey instrument. E-mails with links were sent to 327 U.S. Navy Officers (with valid e-mail addresses) who graduated from IOLTC at NAB Little Creek, VA from 2 July 2003 to 30 June 2004. A total of 123 respondents participated for a return rate of $37.6 \%$. If messages that were undeliverable counted as returned surveys (This study was conducted, after all, during wartime.), the response rate would be $50.8 \%$. This study, like the Conroy study before it, focused on only four of the IOLTC's 32 subunits: Leadership Model(s), Situational Communications, Delegation, and Command Climate. The survey participants were divided into the following subgroups representing the positions that they held at their 
job: the positions held by their immediate superiors, the type of duty they served (Shore, Sea or Other), whether they were Restricted or Unrestricted Line Officers, Staff Officers, Duty status (Active, Reserve or FTS), gender, and race/ethnic background. Descriptive statistics were used to highlight the distribution of responses among the various previously mentioned subgroups. Inferential statistics were used in this study to see if any of the responses contained statistically significant (the possibility of being true) relationships with any particular demographic or contextual job-related variable. The Least Significant Difference (LSD) and Scheffe Post hoc tests were not conducted as the ANOVA $t$ tests performed on the data indicated they were not warranted.

\section{Summary of Findings}

This summary will, first, provide a brief overview of the three sections of the findings discussion presented in Chapter 4 . Then specific substantive findings will be discussed in a bit more detail.

\section{Summary of Part I}

All of the data in Part I documented the respondents perceptions of the learned skills used on the job. Although the respondents' choices to question two of the survey regarding barriers encountered using the leadership models were only offered a single discrete choice as compared to questions 6,9 , and 12 , which offered multiple choices, the data in the frequency distribution, is nearly the same. In general the findings support that the graduates' use of the leadership skill learned during IOLTC training across all four subunits during IOLTC training are used on the job within one month of returning or reporting to a duty station. 


\section{Summary of Part II}

This section of the analysis of the IOLTC survey results used inferential statistical analysis to uncover any differences in the results among various subgroups of the sample. The findings reported in this section indicate that there was only one apparent difference: a shorter amount of time was required to use acquired skills on the job was reported by males than females. of the time, barriers, and incentives to implement skills learned in training. Based on these findings, there was only one significant difference for time to implement Delegation skills by gender, with males having a shorter amount of time than did females. The remainder of the ANOVAs conducted for this analysis was not found to be statistically significant.

\section{Summary of Part III}

The final part of the findings discussion compared the results of this study with the results of the Conroy study. The findings from this study largely mirrored the findings of the Conroy study. The exception was the time to implement the skills. The utilization was less and subordinates appeared to be more of a barrier with respect to skills utilization. In addition, the open-ended comments were very much the same with some respondents making nearly identical comments to the comments the IOLC graduates made in the Conroy study.

\section{Skills Utilization}

The first of the six research questions in the study asked if IOLTC graduates believed that they were able to use their skills on the job. The answer was yes for the majority of the survey respondents. The IOLTC graduates who participated in the study reported a high degree of utilization among three of the four IOLTC subunits: 
Leadership Model (s), and Situational Communications - 89.4\%, and Delegation 91.1\%. The final subunit, Command Climate $-92.7 \%$ was reported as the most used (see Table 1).

\section{Average Elapsed Time Prior to Skill Utilization}

The second research question asked about how much time had elapsed after completion of IOLTC before the graduates exercised the leadership skills acquired during the course. The average length was 4 weeks before respondents began utilization of acquired leadership skills across the four IOLTC subunits. As reported by the survey respondents the Leadership models subunit was the least used and when it was used took the greatest amount of time, 4.37 weeks, to employ on the job.

\section{Graduates' Perceptions of Their Bosses' Attitudes}

The majority of the respondents, $57.7 \%$, reported the perception of their boss was either encouraging or requiring with respect to utilization of the skills. Specifically, $52.8 \%$ reported having bosses who encouraged respondents to apply their IOLTC learning on the job.

\section{Barriers or Incentives}

Most of the students encountered barriers, particularly using the Leadership Models. Specifically, the barrier experienced most was "resistance to change by subordinates." Sixty-one percent of the respondents reported that they experienced barriers that kept them from using the IOLTC learned Leadership models.

\section{Differences in Perceptions of IOLTC Subunits by Contextual Variables}

A univariate ANOVA conducted separately for independent variables of gender, respondent's position, respondent's supervisor's position, type duty, and line 
or staff officer revealed no significant relationship between the IOLTC Subunits and contextual variables.

\section{Comparison of Findings between the Two Studies}

In comparison, this longitudinal study of IOLTC supports the trend that there is an improvement in utilization rates among IOLTC graduates' on the job application of skills learned. In addition, the Conroy study noted that there might be differences in utilization rates by gender and type of duty. This study cannot confirm that there is a difference by type of duty but does confirm differences by gender.

\section{Interpretation of Findings}

In both studies, report a favorable reaction to the IOLTC skills utilization. Respondents reported generally liked the courses and indicated that they learned skills that they could put to use on the job. The reported time required to use skills was less in this study. The graduates' immediate superiors appeared to play critical roles in the use of IOLTC skills learned in both study. In this study, however, subordinate's attitudes appeared as an apparent barrier to skill use. This perceived barrier did not surface in the Conroy study. In addition, the open lines of communication with subordinates were important as well. Finally, it must be mentioned that the command climate is critical to the utilization of skills on the job.

The differences between this study's findings and the findings reported in the Conroy study may be attributable to the fact that, when this study was conducted, the United States was at war. The need for action during wartime may account for the shorter timeframe for skill use reported in this study. If graduates, in fact, became more active earlier in exercising leadership skills, this might, in turn, account for the 
greater levels of subordinate resistance found in this study. Overall, however, the findings reported in this study tended to reinforce the findings reported in the Conroy study.

Unlike some earlier studies, both studies tend to provide a largely positive picture about the utility of the IOLTC in on-the-job situations. Despite these positive findings, the Navy is currently revising its Leadership Development initiatives. The next section begins with and brief discussion of the Navy's new direction. This discussion is followed by a number of recommendations inspired by this study.

\section{Training the Next Generation}

Navy leadership currently stresses; "Leadership is the cornerstone of our Navy and the key to our continued success" (CNP, 2006, p.). Naval leaders acknowledge that strong leadership ensures mission readiness for the Global War on Terrorism (GWOT) and provides our Sailors and their families with a sense of purpose and commitment. In today's environment, and the warfighting environment of the future, the Navy demands well led, motivated Sailors who are prepared to execute the Navy's missions. The vision for the future needs to be in focus and reinforced in leadership training courses. Today's naval leaders and the Sailors in their charge must understand their responsibilities and ensure subordinates' personal and professional development is a top priority.

The next generation leadership continuum is focused on providing the right tools to meet future challenges. The Center for Naval Leadership (CNL) has again designed robust and intensive learning opportunities that capitalize on scenariodriven, dynamic educational experiences. VADM Harvey (Chief of Naval Personnel 
Deputy Chief of Naval Operations (Manpower, Personnel, Education and Training)), emphasized that, "Sailors who complete the leadership programs will be better prepared to master the complexities of human interaction and the challenges ahead" (CNP, 2006, p. ). As discussed in previous chapters the legacy leadership courses have been fundamentally revised, and future courses plan to leverage documented research, current fleet issues, and the experiences of those in attendance.

However, the Navy stresses, as personnel are continually assigned leadership responsibilities based on pay grade, that varying levels of leadership proficiency are required of all Navy personnel. Navy leadership also suggests it is imperative that all Sailors receive the training and education necessary to enhance their leadership skills at the earliest opportunity following advancement and to prepare themselves most effectively for positions of increased responsibility (CNP, 2006). The leadership continuum will continue to support all training and development events from initial entry through retirement. The continuum will strive to contain numerous leadership development programs designed to provide all Sailors, officer and enlisted, active duty component and reserve component, with the knowledge, skills, and abilities required for positions they will hold throughout their careers.

\section{Recommendations for the Center for Naval Leadership}

1. Whatever course structure is used in the future, whether a new intermediate officer training course or a combined IOLTC and AOLTC, it would be helpful to develop and implement a survey instrument that could be used for ongoing formative evaluation purposes. The survey instrument, which would assess participants' perceptions about the utility of the course, might be administered 
at the completion of training programs and, again, after a specified time when a graduate is back on the job. In essence, this recommendation suggests that variations of the procedures used in this and the Conroy study be institutionalized and made a standard operating procedure in an ongoing initiative for continual course improvement.

2. Develop course metrics that can be used to provide measurable feedback upon exit and post return to command via survey in order to tailor the course curriculum to the needs of the attendees.

3. Prior to implementing Recommendation 2, follow through with the plan to use past research for course improvement. In particular, catalogue previously discussed evaluations and recommendations from and use this and prior research and use this catalog of information research and past studies during the curriculum development and course reviews.

\section{Recommendations for Future Research}

1. A similar study should be conducted for the Center for Naval Leadership re-designed Department Head Leadership Course (DHLC).

2. A qualitative study should look at the optional responses that were provided in open-ended, additional comments, survey question 27. In particular, command climate. There were several comments regarding the role that command climate plays in the on-the-job utilization of leadership skills learned during leadership training. 
3. A study should address the new direction of the Leadership Continuum to see if the Computer Based Training (CBT) version of this course has similar value to of the instructor-led training.

\section{Summary}

The results of the study indicate that graduates, on average, utilized acquired leadership skills on the job within 4 weeks after completing IOLTC. The incentives identified by IOLTC graduates, while attempting to apply acquired leadership skills on the job, seem to have generally outweighed any barriers they may have encountered. The majority of IOLTC graduates $(57.7 \%)$ perceived that their immediate superiors either required or encouraged the use of leadership skills learned during IOLTC. However, some responses from IOLTC graduates open-ended questions also revealed some evidence of resistance to their utilization of the learned leadership skills on the job due to the operational tempo of their assigned unit.

The responses varied, to a small degree, by demographics such as gender, race, line/staff officers, type duty and duty component. Differences were evident between male and female utilization of learned IOLTC skills on the job. However, the differences found in race also may be a significant factor, though the sample size here was incredibly small and, consequently, the differential impact of race can only be treated as an interesting hypothesis that needs further investigation. In general, the skills learned during the course are being used on the job and supportive superiors and open lines of communication with subordinates create the command climate that allows for the skills' use on the job. 


\section{REFERENCES}

Arnold, R. B. (1981). The effect of leadership and management education and Training for U.S. Navy supervisory personnel on the attitude of subordinates toward supervisory leadership. Unpublished doctoral dissertation, United States International University, 1981.

Ary, D., Jacobs, L. C., \& Razavieh, A. (1996). Introduction to research in education. ( $5^{\text {th }}$ ed.). Orlando, FL: Harcourt Brace.

Babbie, E. (1990). Survey research methods. Belmont, CA: Wadsworth.

Belcher, J. (1996). Transformational leaders: Meeting the challenges of a changing society. (ERIC Document Reproduction Service No. ED 394-544).

Blake, R. R. \& Mouton, J. S. (1963). A 9.9 approach for increasing organizational productivity. In W. G. Bennis (Ed.), Organizational change. New York: Wiley.

Blake, R. R. \& Mouton, J. S. (1964). The managerial grid. Houston: Gulf Publishing Co.

Blake, R. R. \& Mouton, J. S. (1966). Some effects of managerial grid seminar training on union and management attitudes toward supervision. Journal of Applied Behavioral Science, 2(4), 387-400.

Blanchard, K. (1992). The situational leadership II, The article. Escondido, CA: Center for Leadership Studies. 
Brown, B. A. (1998). Responses to the quality mandate by the noncommissioned officers at Hickam Air Force Base, Hawaii (United States Air Force, Military) (Doctoral dissertation, Walden University, 1998). Dissertation Abstracts International, 59-01A, 0543.

Brown, G., \& Irby, B. J. (1995). The preparation of today's educational leaders: Inclusively of women (Report No. EA 026 786). Paper presented at the Annual Meeting of the American Educational Research Association, San Francisco, CA: April 18-22, 1995. (ERIC Document Reproduction Service No. ED 384 104).

Burns, J. (1978). Leadership. New York : Harper \& Row, Publishers, Inc.

Center for Naval Leadership. (2005). Center for Naval Leadership Little Creek Learning site. Retrieved September 1, 2005, from https://www.npdc.navy.mil/cnl/nltulck/index.htm

Chief of Naval Education and Training. (2001a). Leadership continuum. Retrieved September 23, 2005, from http://www.cnet.navy.mil/leadcon.html Chief of Naval Education and Training. (2002). Leadership Continuum. Leadership Continuum. Retrieved September 23, 2005, from http://www.cnet.navy.mil/leadcon.html

Chief of Naval Education and Training. (2004). Intermediate Officer Leadership Training Course. Retrieved October 15, 2005, from http://www.cnet.navy.mil/cnet/nltulck/intoff.html 
Chief of Naval Information [CHINFO]. (2004). Naval Transformation Roadmap. Retrieved October 15, 2005, from http://www.chinfo.navy.mil/navpalib/transformation/trans-pg82.html Chief of Naval Personnel (CNP) Deputy Chief of Naval Operations (Manpower, Personnel Education and Training). (2006). Navy Leadership Continuum Course. Retrieved March 28, 2006, from http:/www.navyadvancement.com/navy-news/index.php?showtopic=207

Cissell, T. C. \& Polley, D. P. (1987). Leadership and management education and training (LMET): Its relationship to shipboard effectiveness and readiness. Unpublished master's thesis, Naval Postgraduate School, Monterey, CA 1987).

Conroy, W.F. (2001). Officer's use of leadership skills learned in the navy's intermediate officer leadership course. Unpublished doctoral dissertation, University of San Diego.

Defense Security Cooperation Agency (DSCA). (2005). Retrieved October 16, 2005, from http://www.dsca.mil/home/professional military education.htm Department of Defense. (2001). Department of Defense Dictionary of Military and Associated Terms, 12 April 2001 (as amended through 31 August 2005).

Dillman, D. A. (2000). Mail and Internet surveys: The tailored design method. $\left(2^{\text {nd }}\right.$. ed.). New York: Wiley \& Sons.

Duncan-White, D. A. (1997). Evaluating the effectiveness of the U.S. Navy leadership continuum curricula. Unpublished master's thesis, U.S. Army Command and General Staff College. 
Foley, P. G. (1983). From classroom to wardroom: internalizing, integrating and reinforcing leadership and management, education and training (LMET) skills in the navy. Unpublished master's thesis, Naval Postgraduate School, Monterey, CA.

Fowler, F. J. (1993). Survey research methods. (2 ${ }^{\text {nd }}$ ed.). Newbury Park, CA: Sage. Hager, M. A., Wilson, S., Pollak T. H., \& Rooney, P. M. Response Rates for Mail Surveys of Nonprofit Organizations: A review and Empirical Test Nonprofit and Voluntary Sector Quarterly, vol 32, no. 2, June 2003, 252-267.

Kirkpatrick, D. L. (1998). Evaluating training programs: The four levels $\left(2^{\text {nd }}\right.$ ed.). San Francisco:Berrett-Koehler.

Kowalski, E. (2005). Center for Navy leadership provides ongoing training. All Hands, 1064, 9-11.

Leithwood, K. A. (1992). Leadership. Educational Leadership, 49 (5), 8.

Lewis, J. J. (1990). Naval leadership: A study of views on leadership competencies and methods to reinforce leadership skills. Unpublished master's thesis, Naval Post Graduate School, Monterey, CA.

Lohmeyer, T. N. (1999). Running head: Curriculum influence of the navy intermediate officer leadership training course. Unpublished master's thesis, San Diego State University.

Merriam-Webster. (2006). Merriam-Webster Online, Retrieved March 25, 2006, from http://www.m-w.com/dictionary.htm

Naval War College Review. (2003). President's forum- US Navy Sea Power 21, Spring 2003 Retrieved October 16, 2005, from http://www.findarticles.com/p/articles/mi_m0JIW/is_2_56/ai_101614284 
Navy Leadership Competency Model (NLCM). (2006, February). Retrieved March Im 2006, from http://leadership.au.af.mil/sls-skil.htm\#navy.

Peterson, G. I. (2002). Department of the Navy warfighting budget request emphasizes personnel, current operations, and readiness. Retrieved October 15, 2005, from www.navyleague.org/sea_power/march_02_06.php Palmisano-Flathmann, G.J. (2001). Virtual reality suitability for the U.S. Navy training continuum. Unpublished doctoral dissertation, NOVA Southeastern University.

Rea, L. M. \& Parker, R. A. (1997). Designing and conducting survey research. San Francisco: Jossey-Bass.

Thomas, T. A. (1998). The impact of training and culture on leadership values and perceptions at the United States Army Engineer School. Unpublished doctoral dissertation, University of Missouri-Rolla.

Vandover, D. L. \& Villarosa, J. P. (1981). Leadership and management education and training [LMET] effectiveness: A pilot study for evaluation. Unpublished master's thesis, Naval Postgraduate School.

Walter, J. D. (2002). Navy personnel testing blended leadership course. Task Force EXCEL Week of 11-15 Feb 2002 update.

Wilcove, G. L. (1992). Navy personnel survey 1990: Analysis of educational and training issues. Navy Personnel Research and Development Center, San Diego, CA. Report No. TN-92-9.

Winter, D. G. (1979). An introduction to LMET theory and research Boston: McBer and Company. 


\section{APPENDIX A COVER E-MAIL}

15 January 2006

Dear Intermediate Officer Leadership Training Course (IOLTC) Graduate:

I am an active duty Naval officer, and a graduate student at the University of San Diego. I am conducting a survey (http: / /www - surveymonkey.com/s.asp?u=214481642732\&c=1000) in order to gain data on current utilization of skills learned during IOLTC training and to ascertain if your command's environment is conducive to allowing those skills to be utilized on the job. Navy Personnel Research, Studies and Technology has granted survey approval. (Report Control Symbol 5351-1).

Your name was selected from a list of all graduates of the IoLTC training at the Little Creek, Virginia site from 02 July 2003 to 30 June 2004 . I am required to inform you of certain conditions which potential survey participants should be aware of before deciding on whether or not to participate. The conditions are as follows :

1. You are being asked to complete a survey regarding your experiences on the job since graduating from the Center for Naval Leadership Intermediate officer Leadership Training course (IOLTC) . Survey data will be used in my doctoral dissertation and possibly in other publications based on the dissertation. The survey responses will be destroyed after five years.

2. There are no physical risks associated with participation in this research outside of the general fatigue and mental discomfort associated with completing a web based survey.

3. Participation in this research is entirely voluntary and opting not to participate is completely acceptable.

4. Although the SurveyMonkey.com web based program will be used to host the survey and track those individuals responding to the survey, participant names, addresses and duty stations will not be revealed to anyone. Confidentiality, in other words, is guaranteed. Even I will not match your information with the survey that you complete. I will only use the names and numbers to determine who should receive a reminder e-mail.

5. You will have an opportunity to review the results of the study upon your e-mail request.

If you have any questions about the study, please contact me at (832) 606-0620 or terrence.hammondenavy.mil. You may also contact my dissertation advisor Dr. Robert Donmoyer at (619) 260-7445 or donmoyerasandiego. edu. Your assistance is greatly appreciated. To complete the survey please use the following Internet 1ink: http: / / www. surveymonkey. com/s. asp?u=214481642732\&c=1000

Sincerely, Terrence E. Hammond 
APPENDIX B SURVEY INSTRUMENT

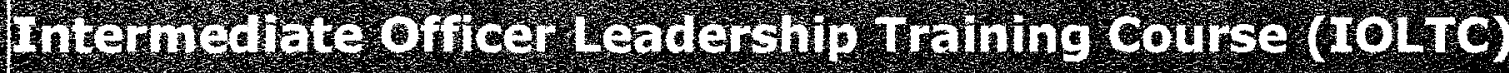

\section{TOLTCSurvey}

\section{PRIVACY ACT STATEMENT}

Public Law 93-579, called the Privacy Act of 1974, requires that you be informed of the purpose of this survey and of the uses to be made of the information collected.

AUTHORITY: CDR Terrence Hammond/Center for Naval Leadership may collect the information requested in this survey under the authority of Title 5, U.S., Code 301, and Title 10, U.S. Codes 3051 and 3052, and Executive Order 9397. License to administer this survey is granted under OPNAV Report Control Symbol 5351-1, which expires 31 Dec 2006.

PRINCIPAL PURPOSE: The information collected in this survey will be used to evaluate existing and proposed policies, procedures, and programs in the Navy. The data will be analyzed and maintained by CDR Terrence Hammond and The Center for Naval Leadership.

CONFIDENTIALITY: All responses will be held in confidence. The information you provide will be considered only when statistically combined with the responses of others, and will not be identified to any single individual.

PARTICIPATION: Providing information is completely voluntary. Failure to respond to any questions will not result in any penalties except lack of your opinions in the survey results. 
1. Please enter your survey number as provided the subject line of your invitation e-mail.

2. I have encountered the following barriers when trying to utilize the leadership models learned during IOLTC training.

My immediate superior doesn't support

- Resistance to change (self)

Resistance to change (peers)

- Resistance to change (subordinates)

3 The ideas don't seem to work

3 Didn't learn anything new

Don't recall content

I have encountered no barriers

Other (please specify) 
3. After training $\mathrm{I}$ used the leadership models in the class.

Less than 7 days

Within 1 week

Within 2 weeks

Within 1 month

More than 1 month

Have not used yet

Within __days/weeks/months 
4. I have encountered the following incentives that encouraged me to utilize the leadership models learned during IOLTC training.

My immediate superior is supportive

Command rewards via praise and recognition

My immediate superior monitors my leadership performance and provides constructive feedback

My immediate superior sets a proper example

I have been assigned a mentor

Open lines of communication with my immediate superior

Open lines of communications with subordinates

Receptiveness from subordinates

The leadership models worked when used

I have encountered no incentives

Other (please specify) 
5. After training I used the situational communication skills that I learned in the class.

3 Less than 7 days

3 Within 1 week

Within 2 weeks

Within 1 month

More than 1 month

Have not used yet

Within__days/weeks/months 
6. I have encountered the following barriers when trying to utilize the situational communications skills learned during IOLTC.

My immediate superior doesn't support

Resistance to change (self)

Resistance to change (peers)

Resistance to change (subordinates)

The ideas don't seem to work

Didn't learn anything new

Don't recall content

I have encountered no barriers

Other (please specify) 
7. I have encountered the following incentives that encouraged me to utilize the situational communications skills learned during IOLTC training.

My immediate superior is supportive

Command rewards via praise and recognition

My immediate superior monitors my leadership performance and provides constructive feedback

My immediate superior sets a proper example

I have been assigned a mentor

Open lines of communication with my immediate superior

Open lines of communications with subordinates

Receptiveness from subordinates

The leadership models worked when used

I have encountered no incentives

Other (please specify) 
8. After returning from training I used the delegation skills that I learned in the class.

Less than 7 days

Within 1 week

Within 2 weeks

Within 1 month

More than 1 month

$\$$ Have not used yet

3 Within_days/weeks/months 
9. I have encountered the following barriers when trying to utilize the delegation skills learned during IOLTC training.

My immediate superior doesn't support

Resistance to change (self)

Resistance to change (peers)

Resistance to change (subordinates)

The ideas don't seem to work

Didn't learn anything new

Don't recall content

I have encountered no barriers

Other (please specify) 
10. I have encountered the following incentives that encouraged me to utilize the delegation skills learned during IOLTC training.

Command rewards via praise and recognition

My immediate superior monitors my leadership performance and provides constructive feedback

My immediate superior sets a proper example

I have been assigned a mentor

Open lines of communication with my immediate superior

Open lines of communications with subordinates

Receptiveness from subordinates

The leadership models worked when used

I have encountered no incentives

Other (please specify) 
11. After training I used the leadership skills that $I$ learned in the class.

Less than 7 days

Within 1 week

Within 2 weeks

Within 1 month

3 More than 1 month

Have not used yet

Within_days/weeks/months 
12. I have encountered the following barriers when trying to utilize the leadership skills learned during IOLTC training.

My immediate superior doesn't support

Resistance to change (self)

Resistance to change (peers)

Resistance to change (subordinates)

The ideas don't seem to work

Didn't learn anything new

Don't recall content

I have encountered no barriers

Other (please specify) 


\section{I have encountered the following incentives that encouraged} me to utilize the leadership skills learned during IOLTC training.

My immediate superior is supportive

Command rewards via praise and recognition

My immediate superior monitors my leadership performance and provides constructive feedback

My immediate superior sets a proper example

I have been assigned a mentor

Open lines of communication with my immediate superior

Open lines of communications with subordinates

Receptiveness from subordinates

The leadership models worked when used

I have encountered no incentives

Other (please specify) 
14. Please indicate your perception of how your immediate superior would view your utilization of the acquired leadership skills used on the job.

Preventing: The boss forbids me form doing what I have been taught to do during IOLTC.

Discouraging: The boss doesn't say, "You can't do it," but he or she makes it clear that I should not change my behavior because it would make him or her unhappy. Or, the boss doesn't model the behavior taught during IOLTC, and this negative example discourages me form changing.

Neutral: My boss doesn't care what leadership style I use as long as

$\mathcal{L}$ the job gets done.

Encouraging: The boss encourages me to learn and apply my learning on the job.

Requiring: The boss knows what I learned during IOLTC and makes

sure that the leadership skills I learned transfer to the job. 
15. The skills-related resources that were used in class are available for use on the job (e.g., reference manuals and books on Leadership such as The Sit Lead II, the article and Leadership and the One-Minute Manager by K. H. Blanchard; The Transformational Leader by N. M. Tichy and M. A. Devanna; The 7 Habits of Highly Effective People by S. R. Covey, etc.).

¿Yes

2 No 
16. The position you presently hold in your command?

\author{
Director \\ Department Head \\ Asst. Department Head \\ Division Officer \\ Other (please specify)
}


17. The position your immediate superior presently holds in you command?

3 Executive Officer

Department Head

Asst. Department Head

Division Officer

Other (please specify) 
18. Indicate the type of duty you have served since graduating form IOLTC. If more than one response applies, choose the type of duty where you spent the majority of your time.

Shore duty

Sea duty

Other (please specify)

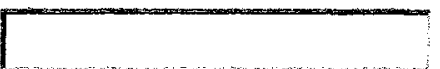

19. Are you a line or staff officer?

$\ldots$ Line

Staff 
20. If you are a Line Officer please indicate what community you are presently serving in.

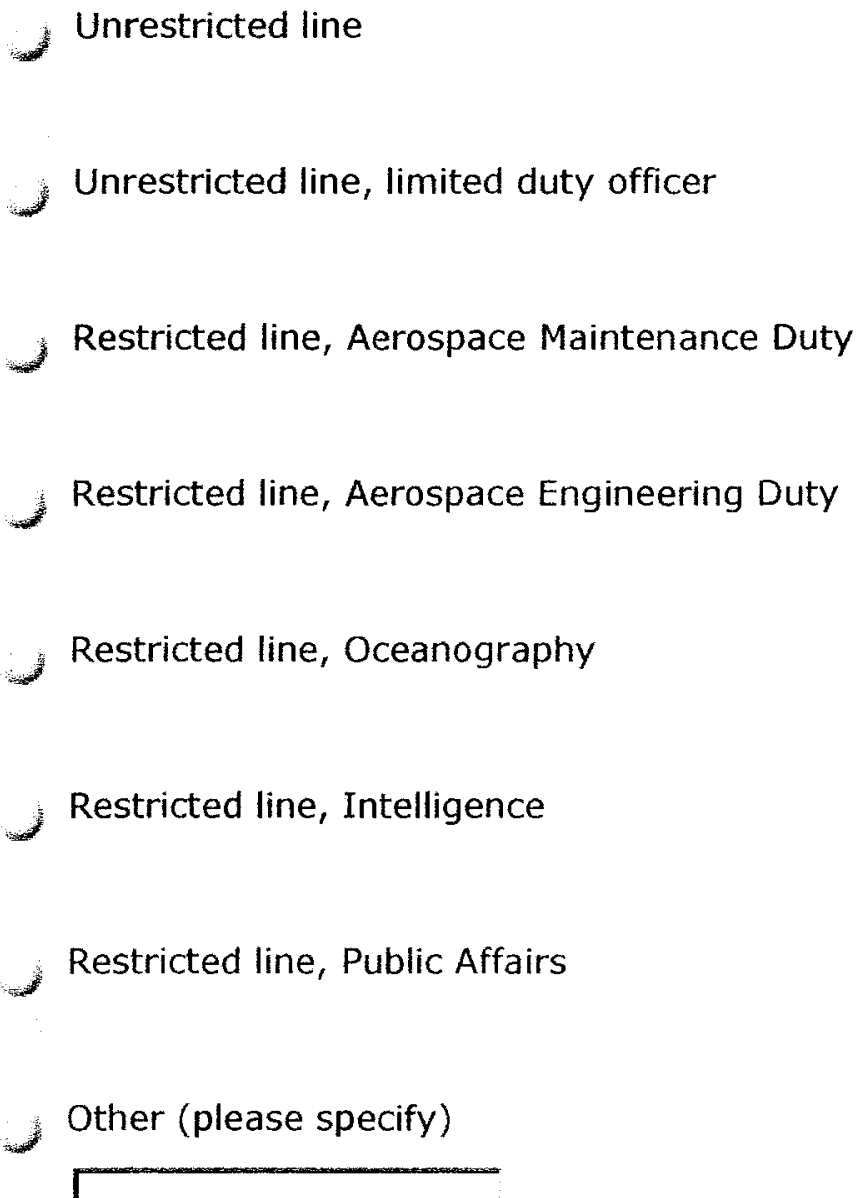


21. If you are a Staff Officer please indicate what community you are presently serving.

\author{
Supply \\ Medical \\ Dental \\ Medical Service Corps \\ Nurse Corps \\ Judge Advocate General \\ Civil Engineering Corps \\ Limited duty officer \\ Chaplain Corps \\ Other (please specify)
}


22. Indicate your status since graduating from IOLTC.

Active duty

Selected Reservist

Full time support (formerly Training and Administration of Reserves (TAR))

Other (please specify)

23. What is your gender?

Male

Female 
24. Indicate approximately how long you have been assigned to your present command?

More than three years

Fill in the number and indicate days, weeks, months or, years

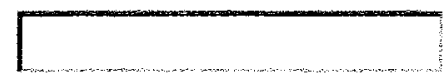

25. With reference to your race/ethnic background are you of Spanish, Hispanic or Latino origin?

Yes

No 
26. What is your racial background? (Please do not answer this question if you responded yes to the above question) If you are of mixed heritage please select the response(s) which you MOST closely identify.

American Indian or Alaska Native

Asian (e.g. Asian Indian, Chinese, Filipino, Japanese, Korean, Vietnamese, etc.)

Black or African-American

- Native Hawaiian or other Pacific Islander (e.g., Samoan, Guamanian, Chamorro, etc)

White

Other (please specify) 
27. Optional Comments

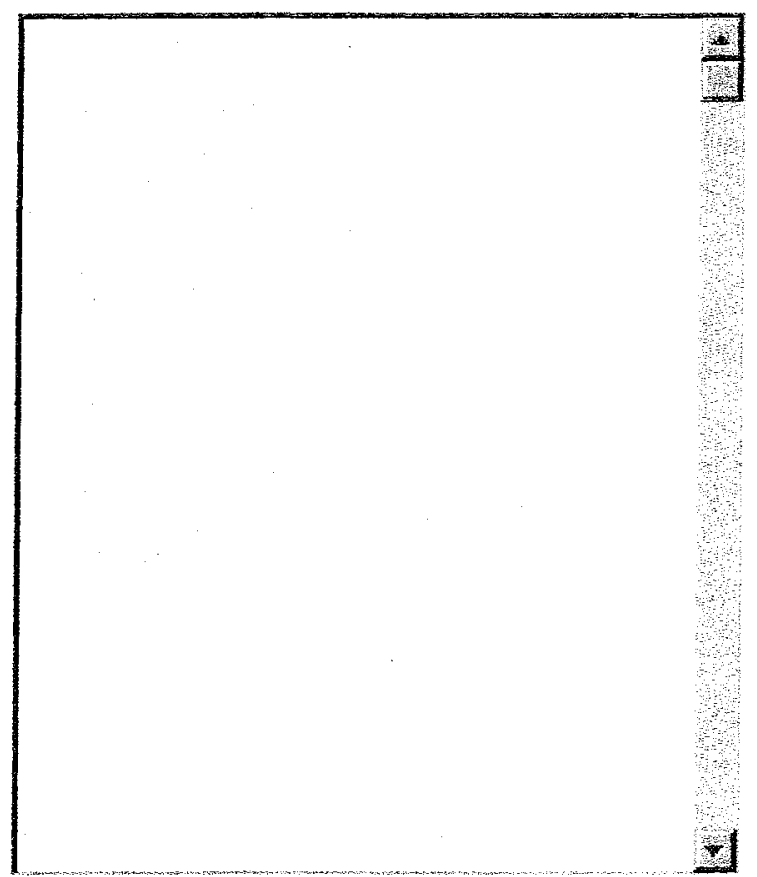

Reproduced with permission of the copyright owner. Further reproduction prohibited without permission. 


\section{APPENDIX C CONROY SURVEY INSTRUMENT}

\section{Intermediate officer Leadership Course Survey \\ Part I}

The following questions apply to Lesson 1-6, Leadership Models - transformational leadership (utilizes motivation, encouragement and leading by example while using inputs from the collective group); transactional leadership (involves "buying" compliance by providing immediate tangible rewards to those who follow orders); and, situational leadership (utilization of multiple leadership styles (that were depicted on the wall chart in the IOLC classroom) depending on the follower that they are working with and on the situation, e.g. Directing (S1) - high task, low relationship; Coaching (s2) - high task, high relationship; supporting (s3) low task, high relationship; and, Delegating (S4) - low task, low relationship).

1A. After training I used the leadership models I learned in the class. Circle your response.

(a) Within days/weeks/months (fill in the

blank with a number and circle either

days/weeks/months)

(b) Have not used yet

1B. I have encountered the following barriers when trying to utilize the leadership models learned during IOLC training. Circle all applicable letters.

(a) My immediate superior doesn't support

(b) Resistance to change (self)

(c) Resistance to change (peers)

(d) Resistance to change (subordinates)

(e) The ideas don't seem to work

(f) Didn't learn anything new

(g) Don't recall content

(h) I have encountered no barriers

(i) Other (please specify) 
1C. I have encountered the following incentives that encouraged me to utilize the leadership models learned during IOLC training. Circle all applicable letters.

(a) My immediate superior is supportive

(b) Command rewards via praise and recognition

(c) My immediate superior monitors my leadership performance and provides constructive feedback

(d) My immediate superior sets a proper example

(e) I have been assigned a mentor

(f) Open lines of communication with my immediate superior

(g) Open lines of communications with subordinates

(h) Receptiveness from subordinates

(i) The leadership models worked when used

(j) I have encountered no incentives

(k) Other (please specify) 


\section{Intermediate officer Leadership Course Survey}

\section{Part II}

The following questions apply to Lesson 2-4, situational Communications. This sub-unit focused on the best methods and styles of communication that must be adjusted to fit the situation, which includes, but is not limited to, formal or informal counseling of a subordinate and interacting with a superior. This lesson also included a class exercise which consisted of IOLC students sharing their personal experiences of communicating with juniors. IOLC students were also asked to identify the situation as either formal or informal, or stressful or normal.

2A. After training I used the situational communications skills that I learned in the class. Circle your response.

(a) Within days/weeks/months (fill in the blank with a number and circle either days/weeks/months)

(b) Have not used yet

$2 B$. I have encountered the following barriers when trying to utilize the situational communications skills learned during IOLC training. Circle all applicable

\section{letters.}
(a) My immediate superior doesn't support
(b) Resistance to change (self)
(c) Resistance to change (peers)
(d) Resistance to change (subordinates)
(e) The ideas don't seem to work
(f) Didn't learn anything new
(g) Don't recall content
(h) I have encountered no barriers
(i) Other (please specify) 
2C. I have encountered the following incentives that encouraged me to utilize the situational communications skills learned during IOLC training. Circle all applicable letters.

(a) My immediate superior is supportive

(b) Command rewards via praise and recognition

(c) My immediate superior monitors my leadership performance and provides constructive feedback

(d) My immediate superior sets a proper example

(e) I have been assigned a mentor

(f) Open lines of communication with my immediate superior

(g) Open lines of communications with subordinates

(h) Receptiveness from subordinates

(i) The leadership models worked when used

(j) I have encountered no incentives

(k) Other (please specify) 


\section{Intermediate Officer Leadership Course Survey}

\section{Part III}

The following questions apply to Lesson 3-2, Delegation. This sub-unit discussed the concept of delegation, what to delegate, when to delegate, and how it should be done. How a Department Head uses delegation for subordinate development and empowerment was also discussed.

3A. After returning from training I used the delegation skills that I learned in the class. Circle your response.
(a) Within days/weeks/months (fill in the blank with a number and circle either days/weeks/months)
(b) Have not used yet

3B. I have encountered the following barriers when trying to utilize the delegation skills learned during IOLC training. Circle all applicable letters.
(a) My immediate superior doesn't support
(b) Resistance to change (self)
(c) Resistance to change (peers)
(d) Resistance to change (subordinates)
(e) The ideas don't seem to work
(f) Didn't learn anything new
(g) Don't recall content
(h) I have encountered no barriers
(i) Other (please specify) 
3C. I have encountered the following incentives that encouraged me to utilize the delegation skills learned during IOLC training. Circle all applicable letters.

(a) My immediate superior is supportive

(b) Command rewards via praise and recognition

(c) My immediate superior monitors my leadership performance and provides constructive feedback

(d) My immediate superior sets a proper example

(e) I have been assigned a mentor

(f) Open lines of communication with my immediate superior

(g) Open lines of communications with subordinates

(h) Receptiveness from subordinates

(i) The leadership models worked when used

(j) I have encountered no incentives

(k) Other (please specify) 


\section{Intermediate Officer Leadership Course Survey}

\section{Part IV}

The following questions apply to Lesson 5-4, Command climate. This sub-unit discussed the concepts and behaviors that form a command's climate, and the ways we may affect the underlying culture beneath that supports the command's climate. The following components of a command's culture were discussed during IOLC training: organizational structure; command philosophy; people; and, command plans, policies, and operating procedures. Methods of assessing command climate include examining records and reports, observing behavior, interviewing individuals and groups, and through command assessment surveys.

4A. After training I used the skills that I learned in the class. Circle your response.
(a) Within days/weeks/months (fill in the blank with a number and circle either days/weeks/months )
(b) Have not used yet

4B. I have encountered the following barriers when trying to utilize the skills learned during IOLC training. circle all applicable letters.
(a) My immediate superior doesn't support
(b) Resistance to change (self)
(c) Resistance to change (peers)
(d) Resistance to change (subordinates)
(e) The ideas don't seem to work
(f) Didn't learn anything new
(g) Don't recall content
(h) I have encountered no barriers
(i) Other (please specify) 
4C. I have encountered the following incentives that encouraged me to utilize the leadership skills learned during IOLC training. Circle all applicable letters.

(a) My immediate superior is supportive

(b) Command rewards via praise and recognition

(c) My immediate superior monitors my leadership performance and provides constructive feedback

(d) My immediate superior sets a proper example

(e) I have been assigned a mentor

(f) Open lines of communication with my immediate superior

(g) Open lines of communications with subordinates

(h) Receptiveness from subordinates

(i) The leadership models worked when used

(j) I have encountered no incentives

(k) Other (please specify) 


\section{Intermediate Officer Leadership Course Survey}

\section{Part V}

5. Please indicate your perception of how your immediate superior would view your utilization of the acquired leadership skills used on the job. Circle the letter next to the most appropriate answer.

(a) Preventing: The boss forbids me from doing what I have been taught to do during IOLC.

(b) Discouraging: The boss doesn't say, "You can't do it," but he or she makes it clear that I should not change my behavior because it would make him or her unhappy. Or, the boss doesn't model the behavior taught during IOLC, and this negative example discourages me from changing.

(c) Neutral: My boss doesn't care what leadership style I use as long as the job gets done.

(d) Encouraging: The boss encourages me to learn and apply my learning on the job.

(e) Requiring: The boss knows what I learned during IOLC and makes sure that the leadership skills I learned transfer to the job.

6. The skills-related resources that were used in the class are available for use on the job (e.g., reference manuals and books on Leadership such as The Sit Lead II, the article and Leadership and the OneMinute Manager by K. H. Blanchard; The Transformational Leader by N. M. Tichy and M. A. Devanna; The 7 Habits of Highly Effective People by S. R. Covey, etc.) Circle your response.
(a) Yes
(b) No 


\section{Intermediate officer Leadership Course Survey}

\section{Part VI}

Demographics - The responses to the following demographic questions will be used to compare respondents from the types of duty and positions held that could assist curriculum developers with determining where to concentrate their improvement efforts.

7. The position you presently hold in your command?

Circle your response.
(a) Director
(b) Department Head
(c) Asst. Department Head
(d) Division Officer
(e) Other (please specify)

8. The position your immediate superior presently holds in your command? circle your response.
(a) Executive Officer
(b) Department Head
(c) Asst. Department Head
(d) Division officer
(e) Other (please specify)

9. Indicate the type of duty you have served since graduating from IOLC. If more than one response applies, choose the type of duty where you spent the majority of your time.
(a) Shore duty
(b) Sea duty
(c) Other (please specify)

10. Are you a line or staff officer? circle your response.
(a) Line
(b) Staff 
11. If you are a Line officer please indicate what community you are presently serving in. Circle your response.
(a) Unrestricted line
(b) Unrestricted line, limited duty officer
(c) Restricted line, Aerospace Maintenance Duty
(d) Restricted Iine, Aerospace Engineering Duty
(e) Restricted line, Oceanography
(E) Restricted line, Intelligence
(g) Restricted line, Public Affairs
(h) Other (please specify)

12. If you are a staff officer please indicate what community you are presently serving in. Circle your response.
(a) Supply
(b) Medical
(c) Dental
(d) Medical Service Corps
(e) Nurse Corps
(f) Judge Advocate General
(g) Civil Engineering Corps
(h) Limited duty officer
(i) Chaplain Corps
(j) Other (please specify)

13. Indicate your status since graduating from IOLC.

\section{circle your response.}
(a) Active duty
(b) Selected Reservist
(c) Training and Administration of Reserves (TAR)
(d) Other (please specify)

14. What is your gender? Circle your response.
(a) Male
(b) Female 
15. Indicate approximately how long you have been assigned to your present command.

days/weeks/months/years (fill in the number and circle either days/weeks/months/years)

The following question is to determine the race/ethnic classification of the respondent and is structured as per the standard Department of Defense (DOD) Race/Ethnic categories for demographic reporting (http://www.bupers.navy.mil/mentor/demo_class.htm).

16. What is your race/ethnic background? Circle your responses.
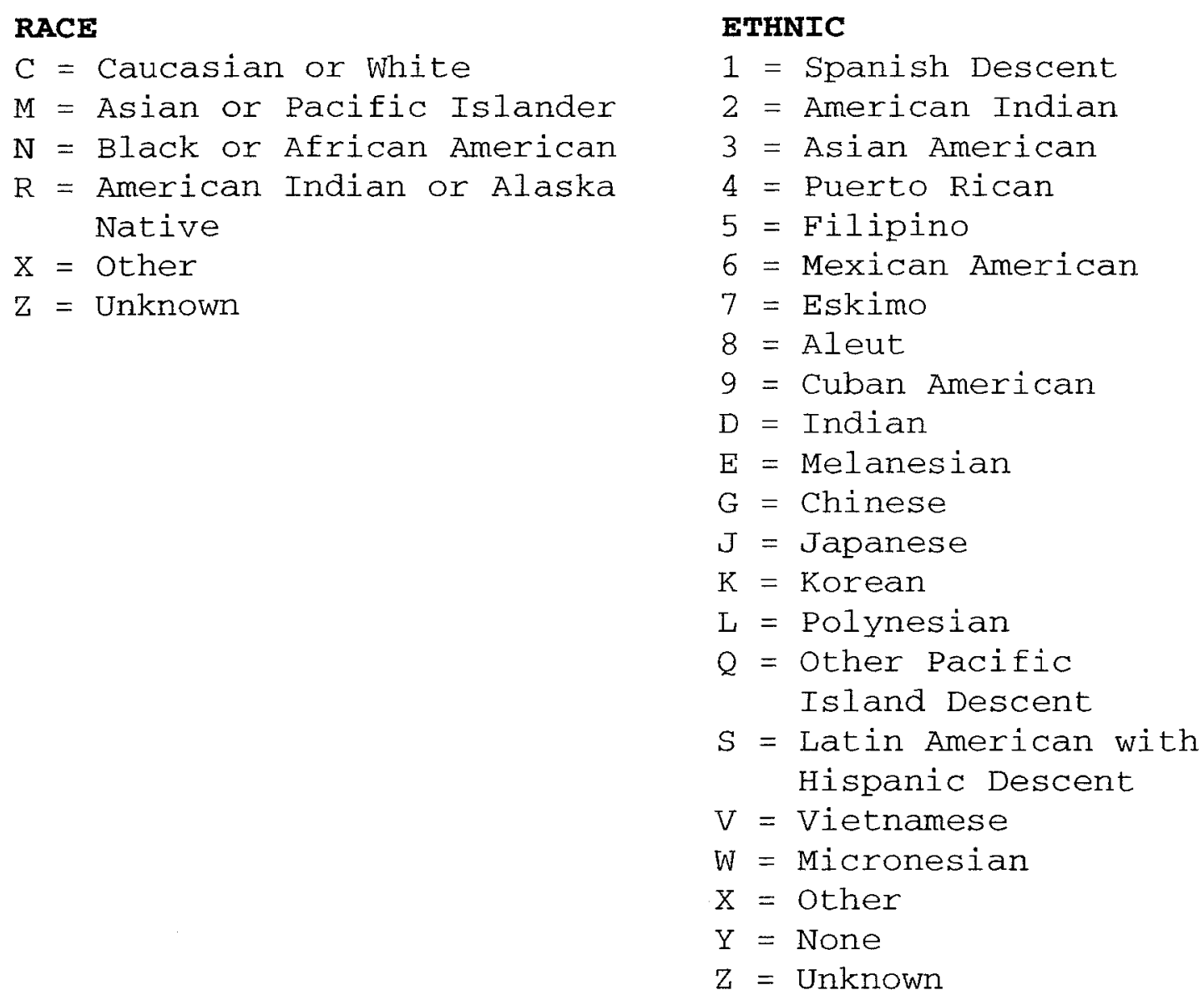
Optional Comments

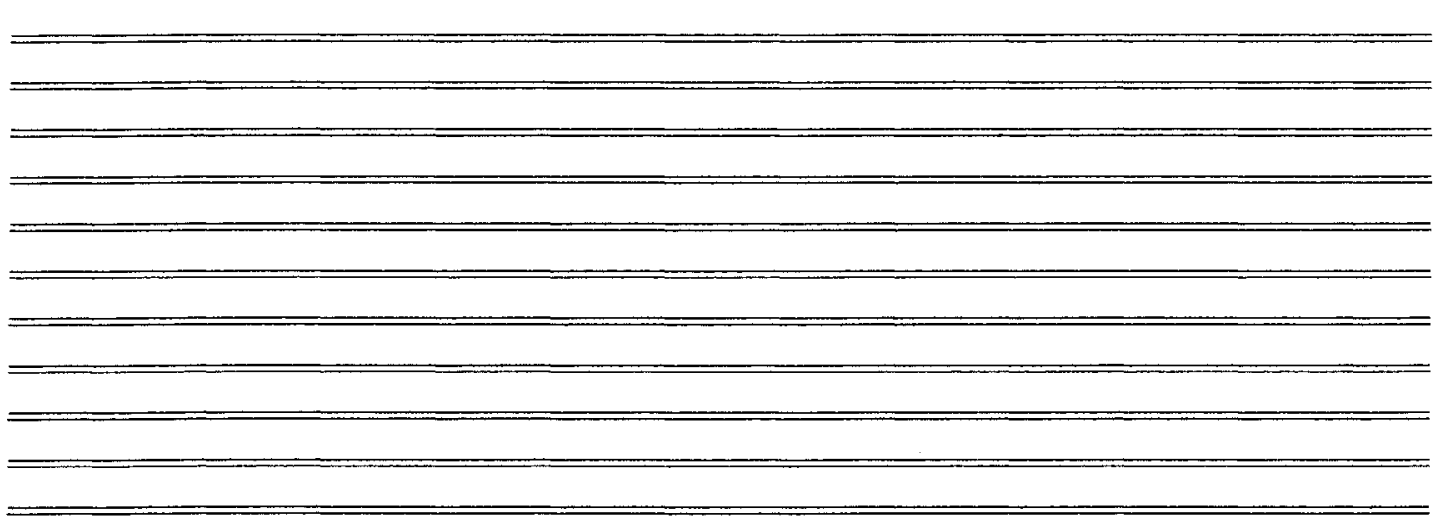

$=$

THANK YOU!

Reproduced with permission of the copyright owner. Further reproduction prohibited without permission. 


\section{APPENDIX D FOLLOW-UP E-MAIL}

06 February 2006

Dear Intermediate Officer Leadership Training Course Graduate:

Three weeks ago I sent to you an e-mail asking you to fill out an online survey for a study I am conducting. The study focuses on what graduates of the Navy's Leadership Continuum Intermediate Officer Leadership Training Course (IOLTC) say about the opportunity (or lack or opportunity) to use the leadership skills taught in the IOLTC course in their current work environments. Thus far, I have not received a survey from you; therefore, I am requesting that you go to $\mathrm{http}: / / \mathrm{www}$.surveymonkey.com/s.asp?u=214481642732 and take the survey.

Once again, I need to emphasize that your participation in this study is completely voluntary. Your answers are confidential and will be released only as summaries in which no individual's answers can be identified. When your survey is completed your name will be deleted from the e-mail list and never connected to your answers in any way. You can help me by taking a few minutes to share your opinions. If for some reason you prefer not to respond, please let me know by replying to this e-mail or anonymously on line.

If you have any questions about this study, please contact me at (832) 606-0620 or hammond terrence@hotmail.com. You can also contact my dissertation advisor Dr. Robert Donmoyer at (619) 260-7445 or donmoyer@sandiego.edu.

Thank you very much for helping with this important study.

Sincerely,

Terrence E. Hammond 


\section{APPENDIX E SURVEY SPONSOR LETTER}

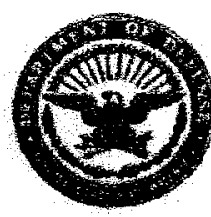

\section{DEPARTMENT OF THE NAVY}

CEMTEA FOA NAVAL LEADERSHIP

1575 GATOR BOULEVARO, SUTE SEIA

NOAFOIK VIRGINIA 2352:-2T44

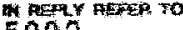

FIRST ENDORSEMENT On LCDR Hammond It Of 12 MaY 2005

From: Commanding of icer, Cencer for Naval Leadership

To: Commander, Navy Personnel Command (PERS 014)

SUbj: REQUEST FOR SPONSOR AND APPROVAL OF NAVY PERSONNEL SURVEY

Ref: (a) OPNAVINST $5300.8 B$

1. The Center for Navel Leadership (GNL) accepts sponsorship and approves the survey to collect information regarding bartiers and incentives rOETC graduates encounter that eithex encourage or discourage their use of acquired zoLTC leadership bkills within their work envixonments. The survey proposed by LCDR Hamond is an efective means for gathering this informetion in support of CNL's mission and to provide the Navy, and the general pubitic, a data point for Leadership training and the return on this investment.

2. I understand this survey wil requixe approximately 219 hotrs (439 personnel $X$.5 houx) of Navy service members time to complete. Should the survey be completed during working hours, the indirect cost to the Navy would be approximately $\$ 4000.00$. I consider tha to be potentialiy great return on investment in the Navy's future.

3. Ag the sporsoning activity, CNI will receive a copy of the dissertation and have disect access to the researcher for any questions or concerns.

4. My POC for this survey is CDR R. $I$. Conn, she can be reached at Comm (757) 462-1572 or DSN 253-1572.

D. D. MCDONALD

CAPT USA 
$\operatorname{Dec} 7,2005$

From: Paul Rosenfed, Navy Survey Approval Manager (PERS-14)

To: LCDR Terrence E. Hammond

Subj: REPORT CONTROL SYMBOL AND APPROVAL FOR OFFICER'S USE OF LEADERSHIP SKILLS SURVEY

Ref: (a) OPNAVINST $5300.8 \mathrm{~B}$

1. Your request for survey approval is granted. The Report Control Symbol (RCS) is 5351-1. This RCS expires on 31 Dec 2006. The RCS and expiration date must appear in the Privacy Act Statement of the survey instrument

2. Please send electronic copies of any briefings/reports generated from these data to my Deputy, Dr. Gerry Wilcove, gerry.wilcove@navy.mil for data warehousing purposes.

3. Best of luck with your project!

Paul Rosenfeld, Ph.D.

Navy Survey Approval Manager 
APPENDIX G RAW SUMMARY OF RESULTS

\section{IOLTC Survey (Summary Results)}

1. Please enter your survey number as provided the subject line of your invitation e-mail.
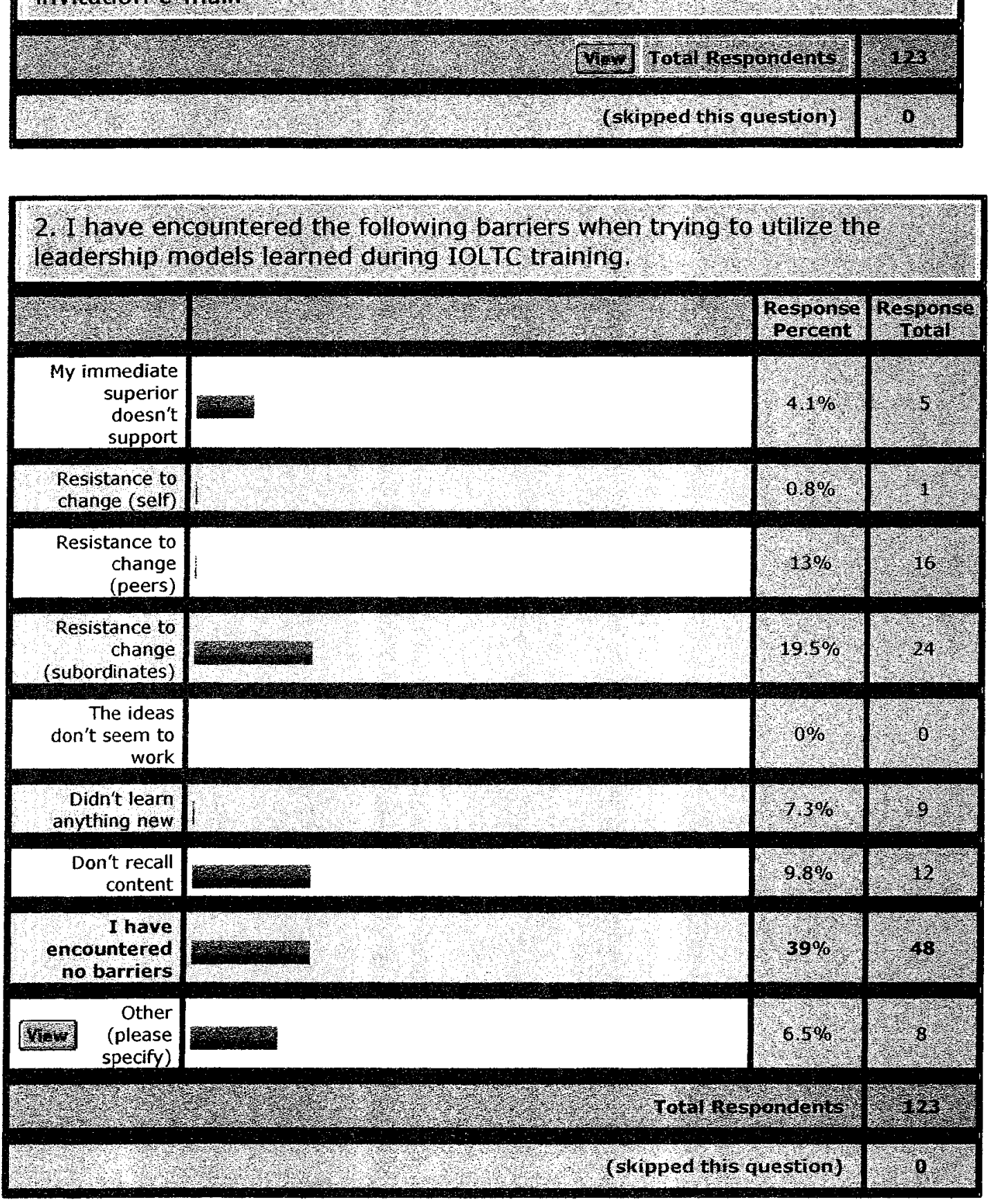


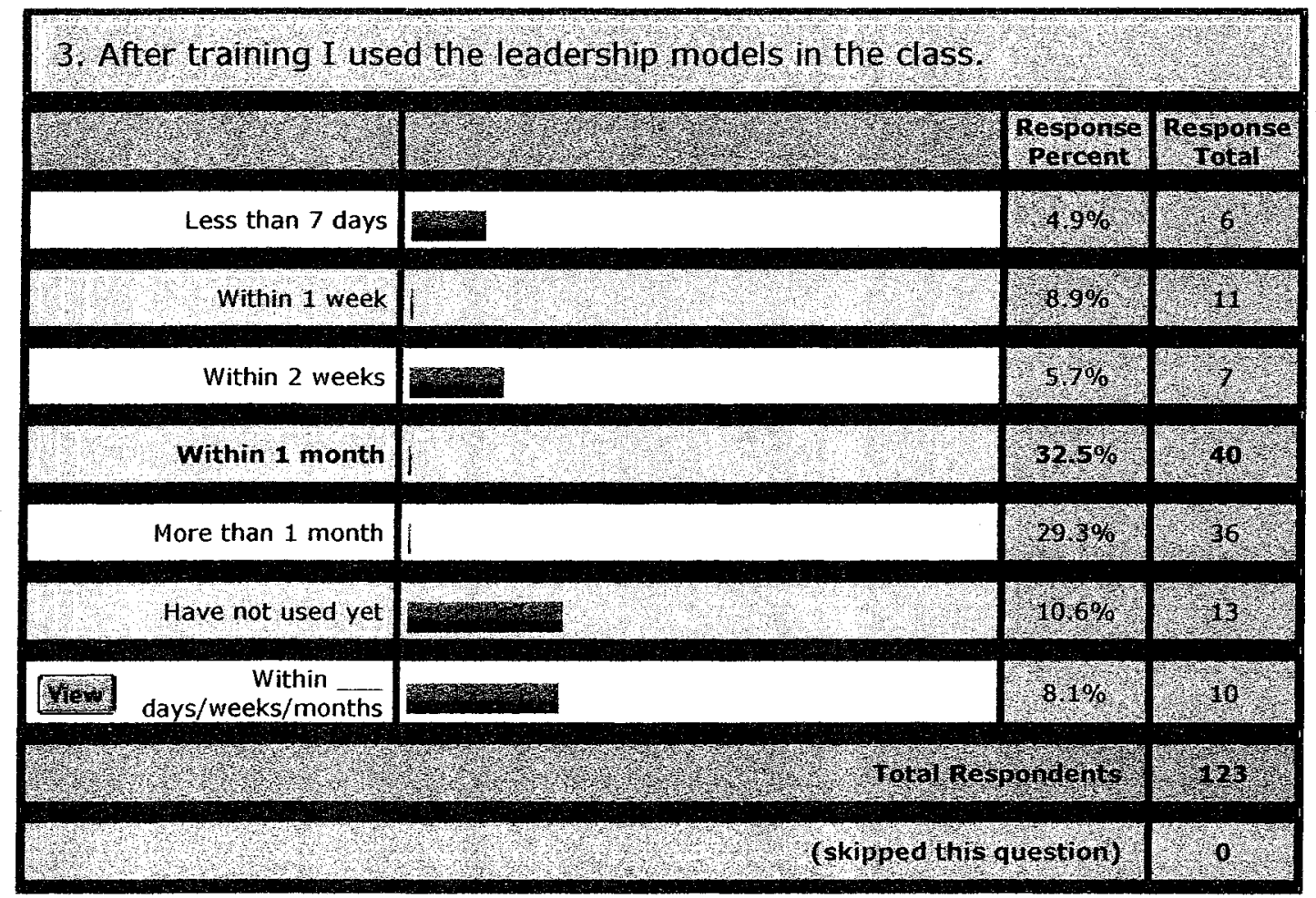




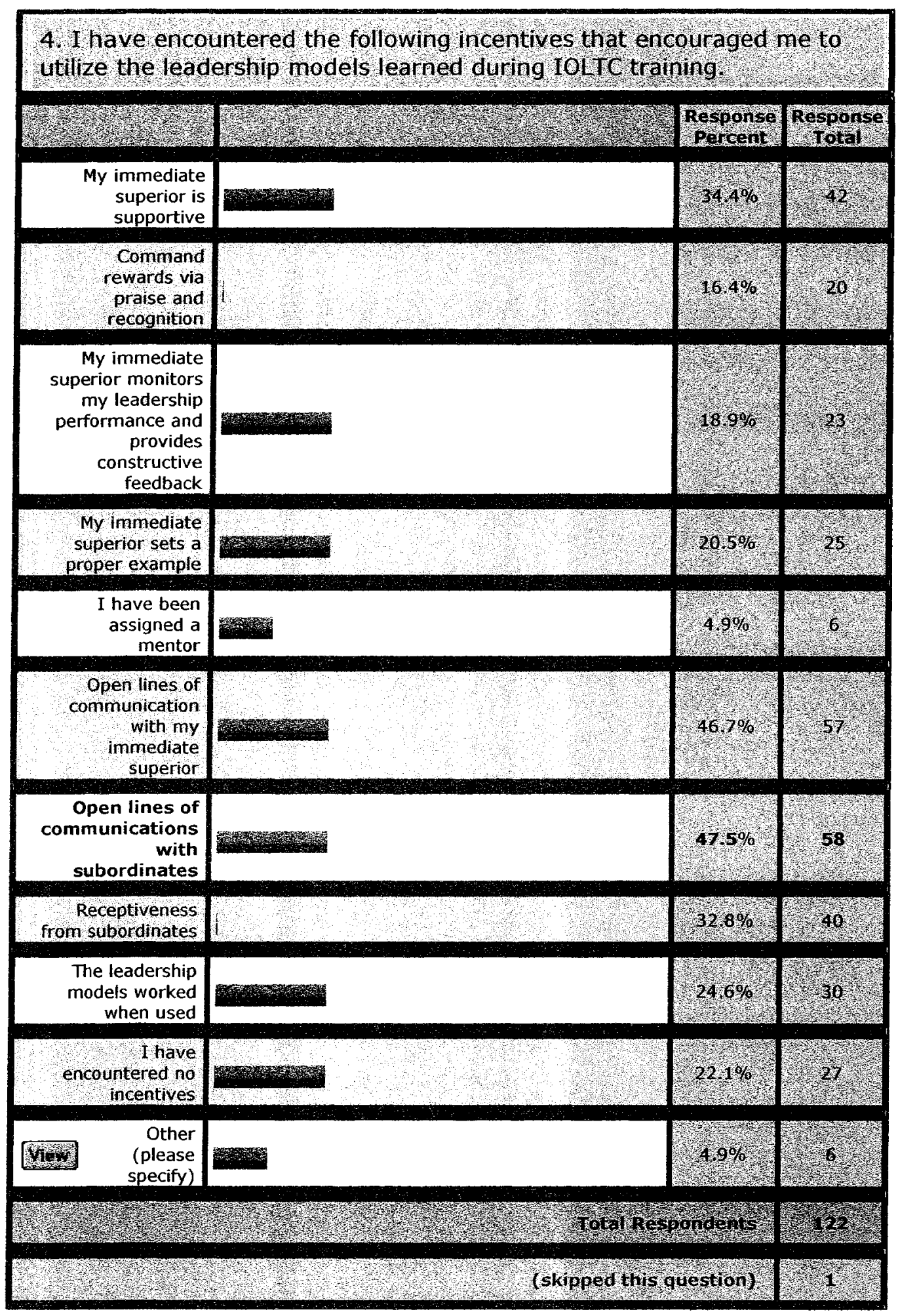




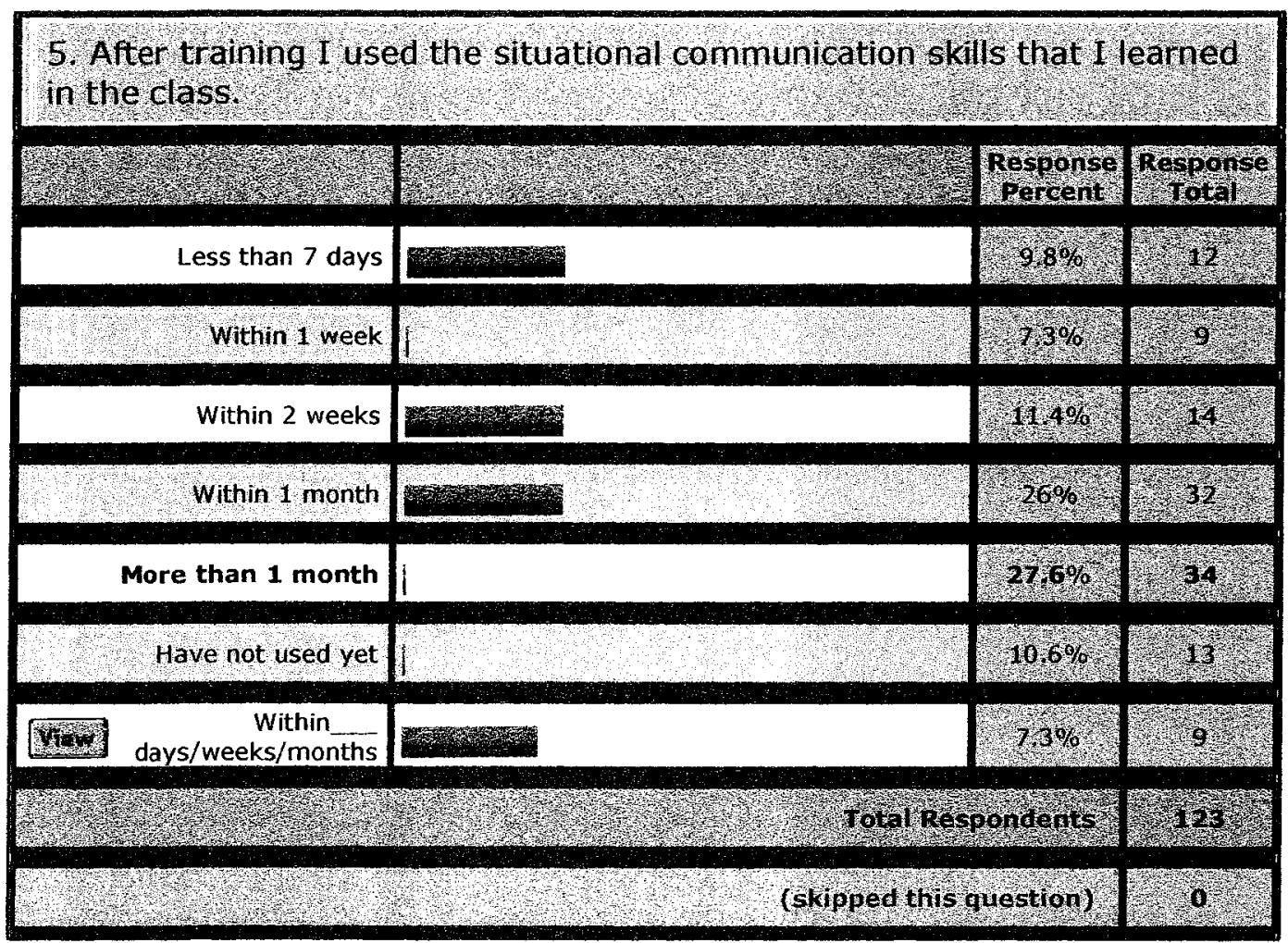




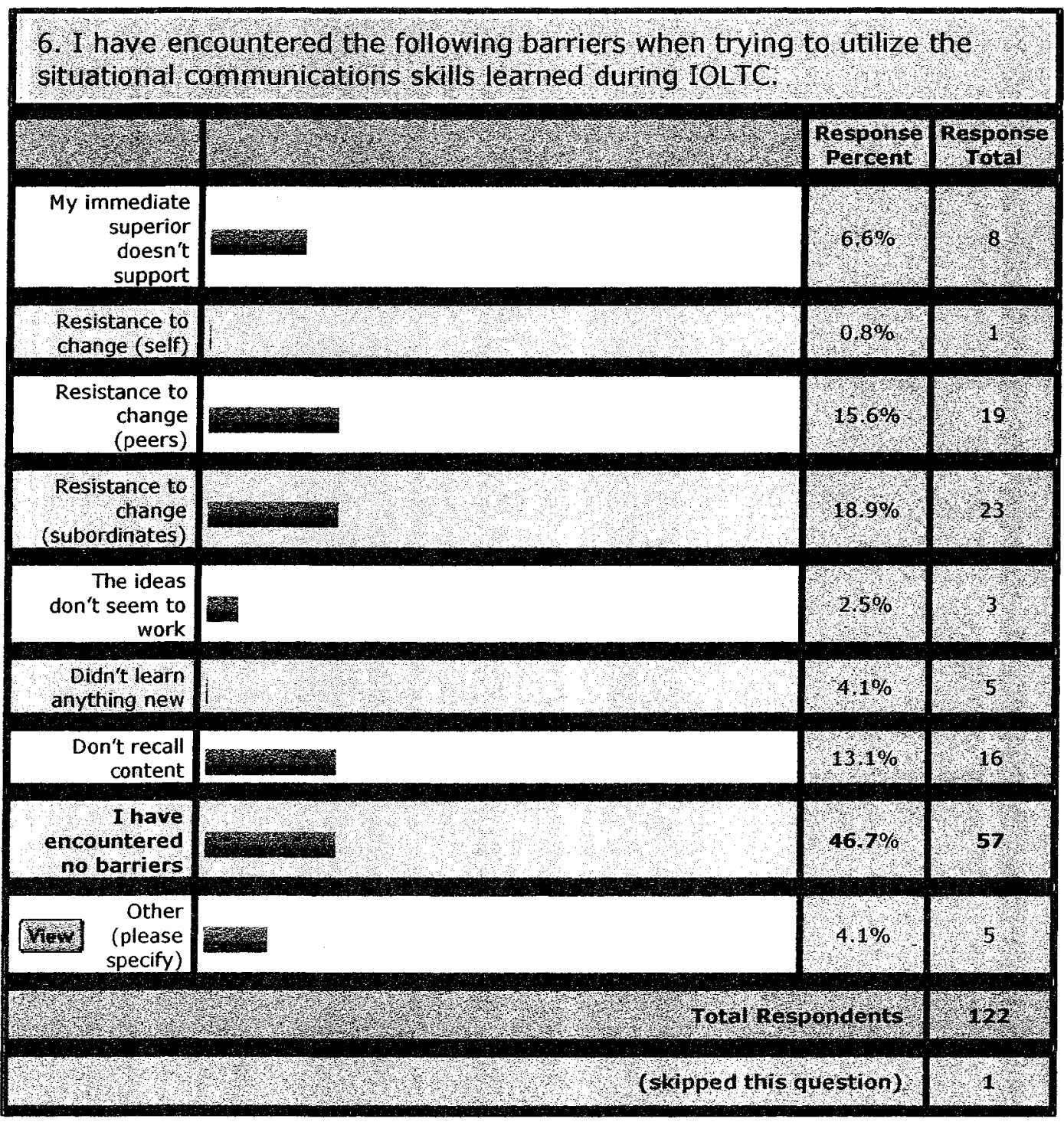




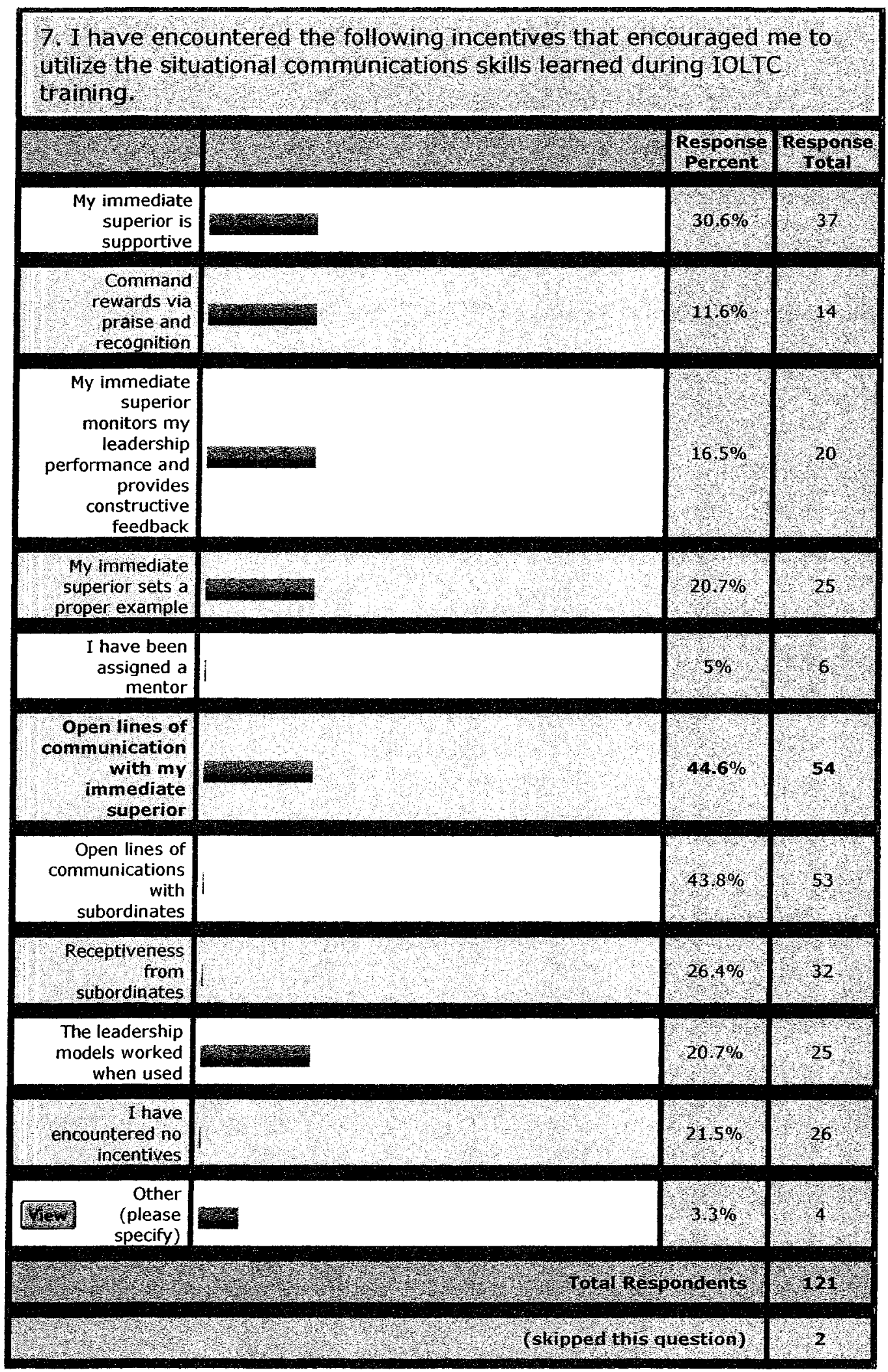




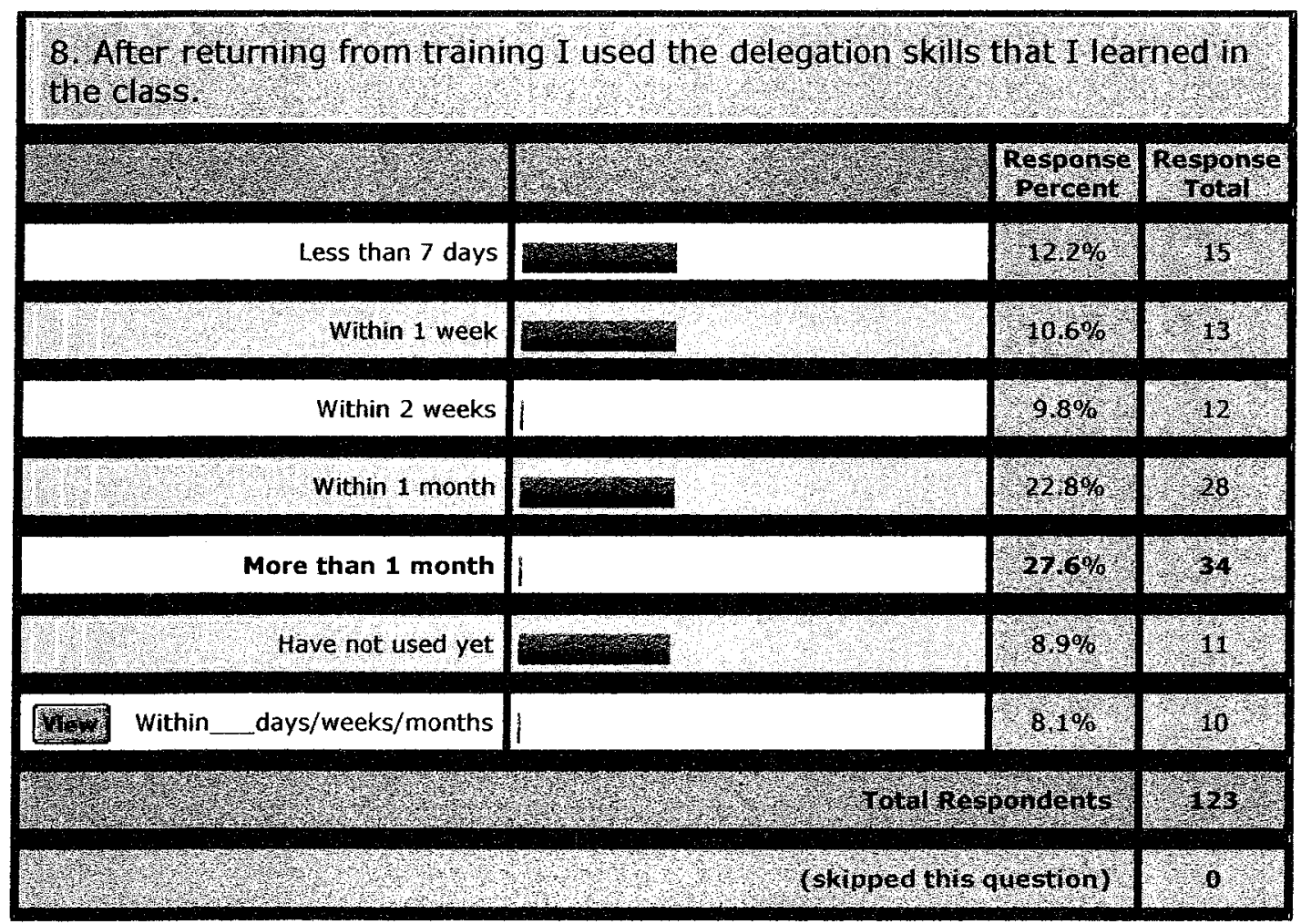




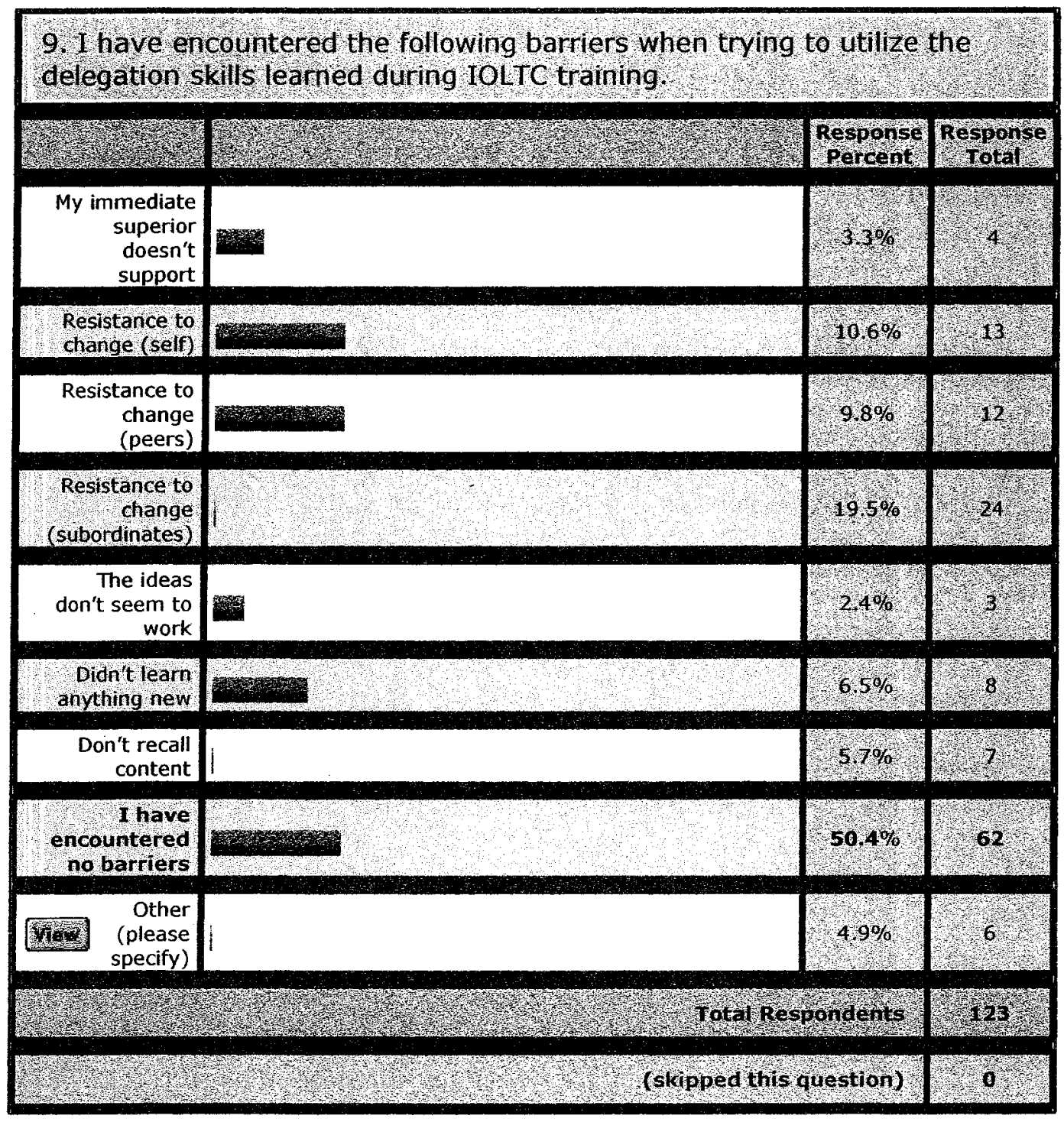




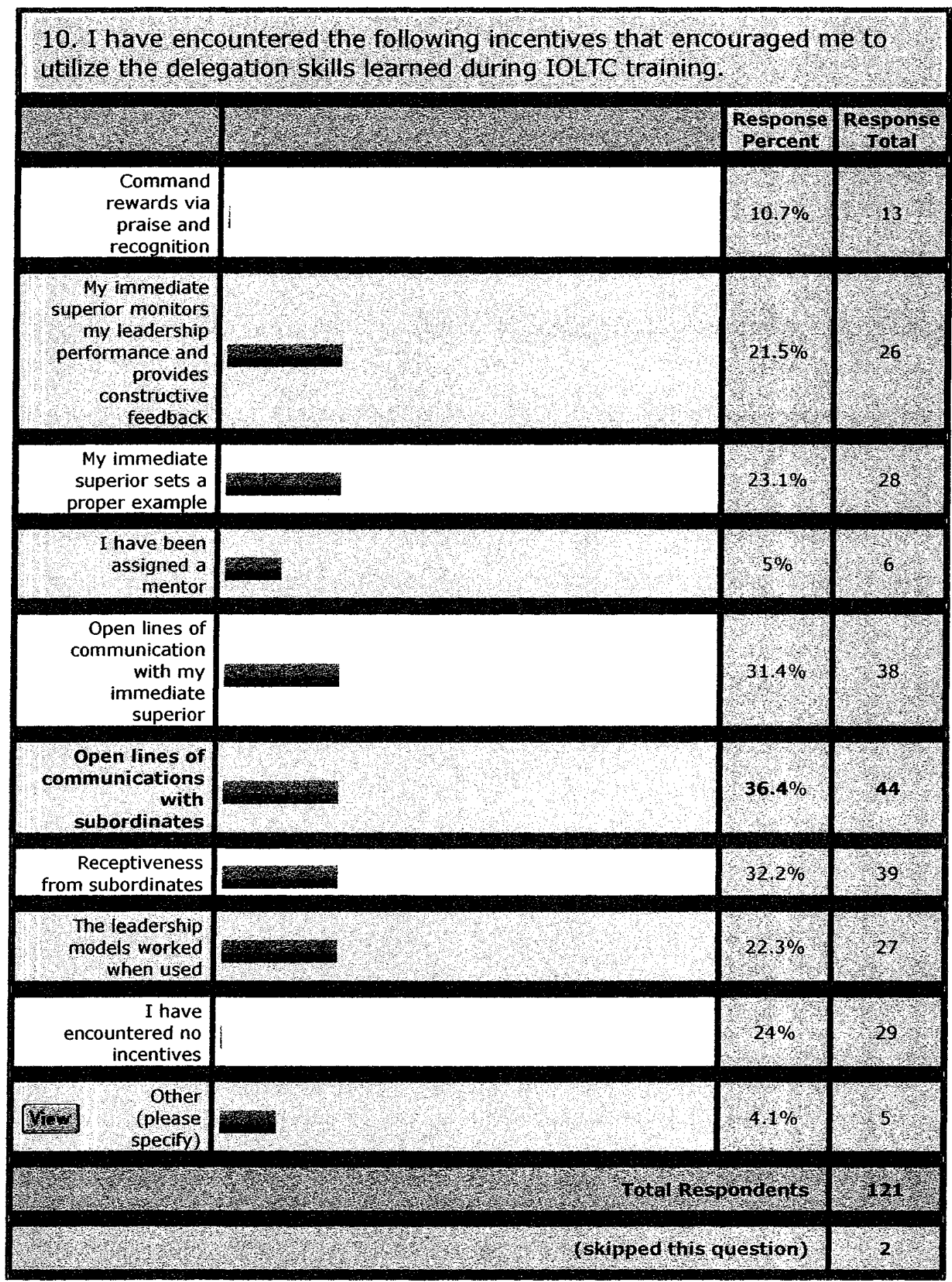




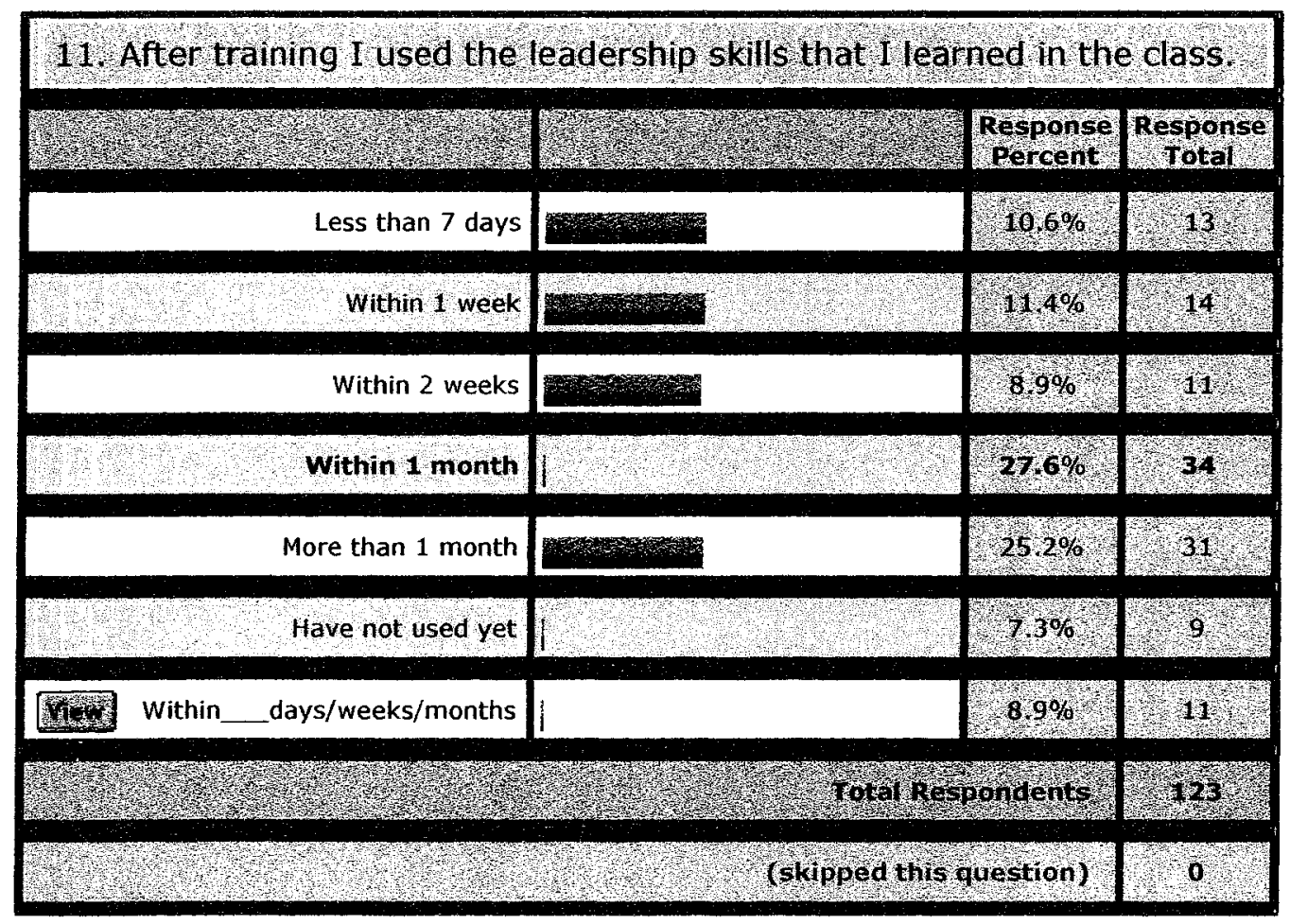




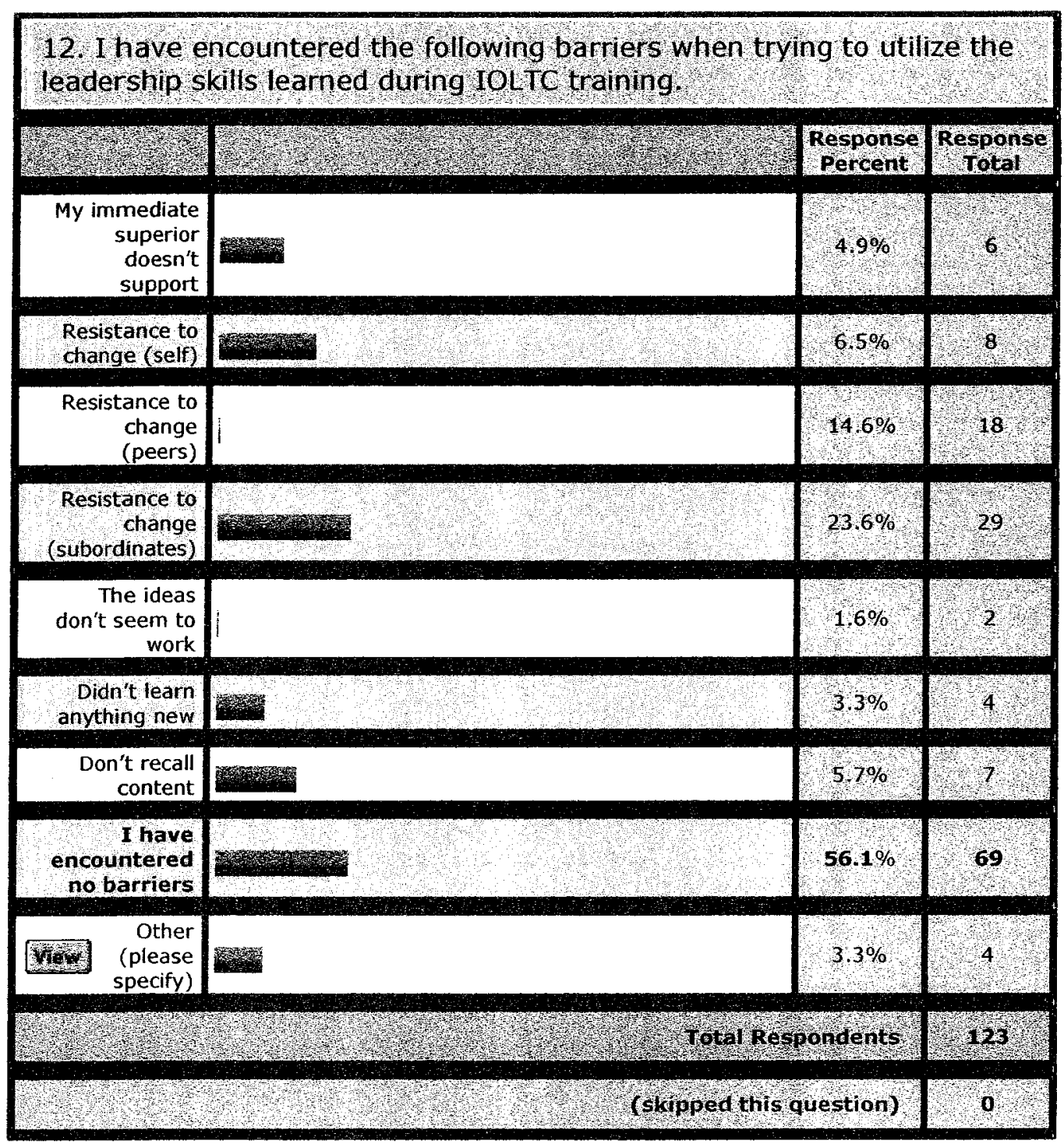




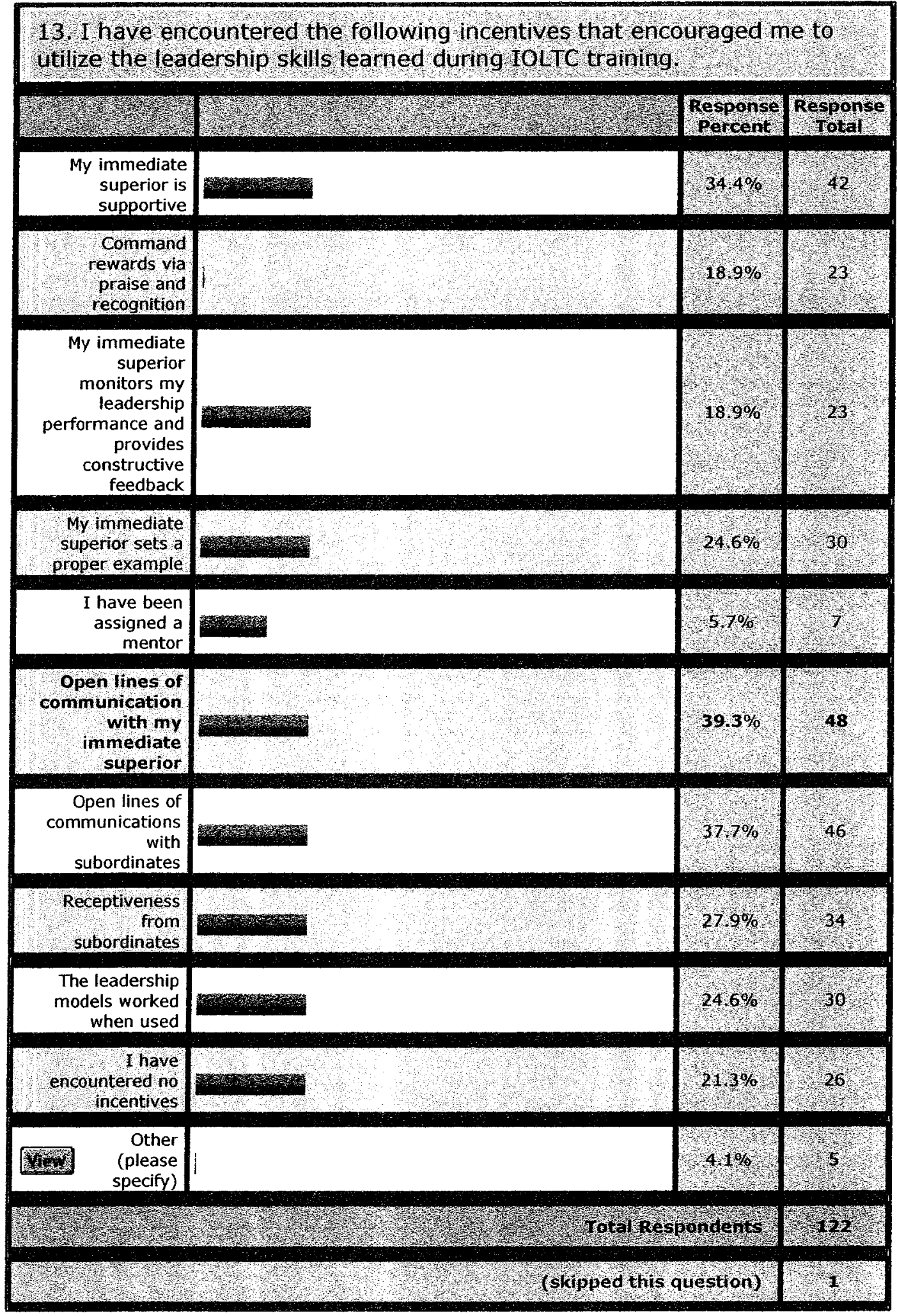




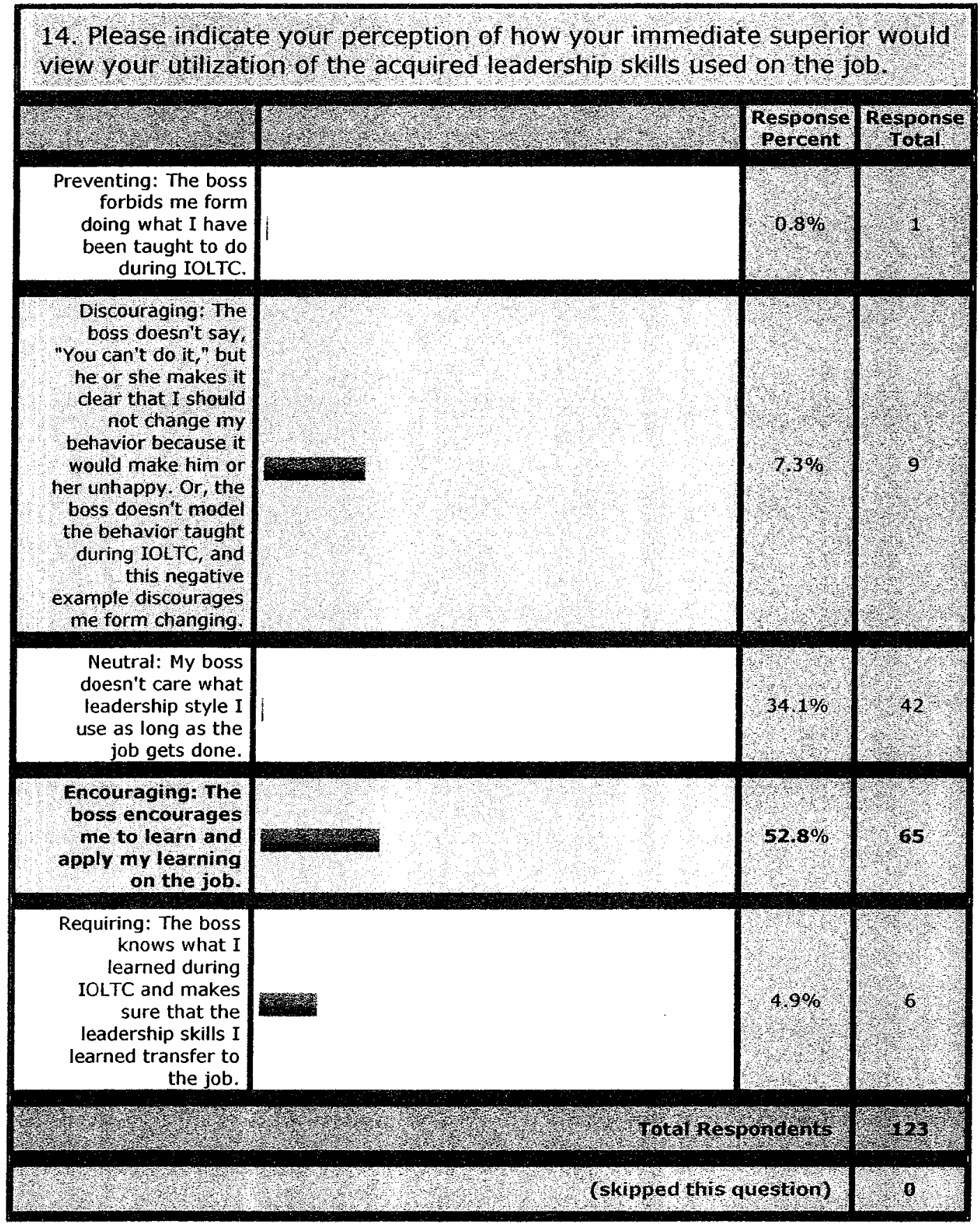



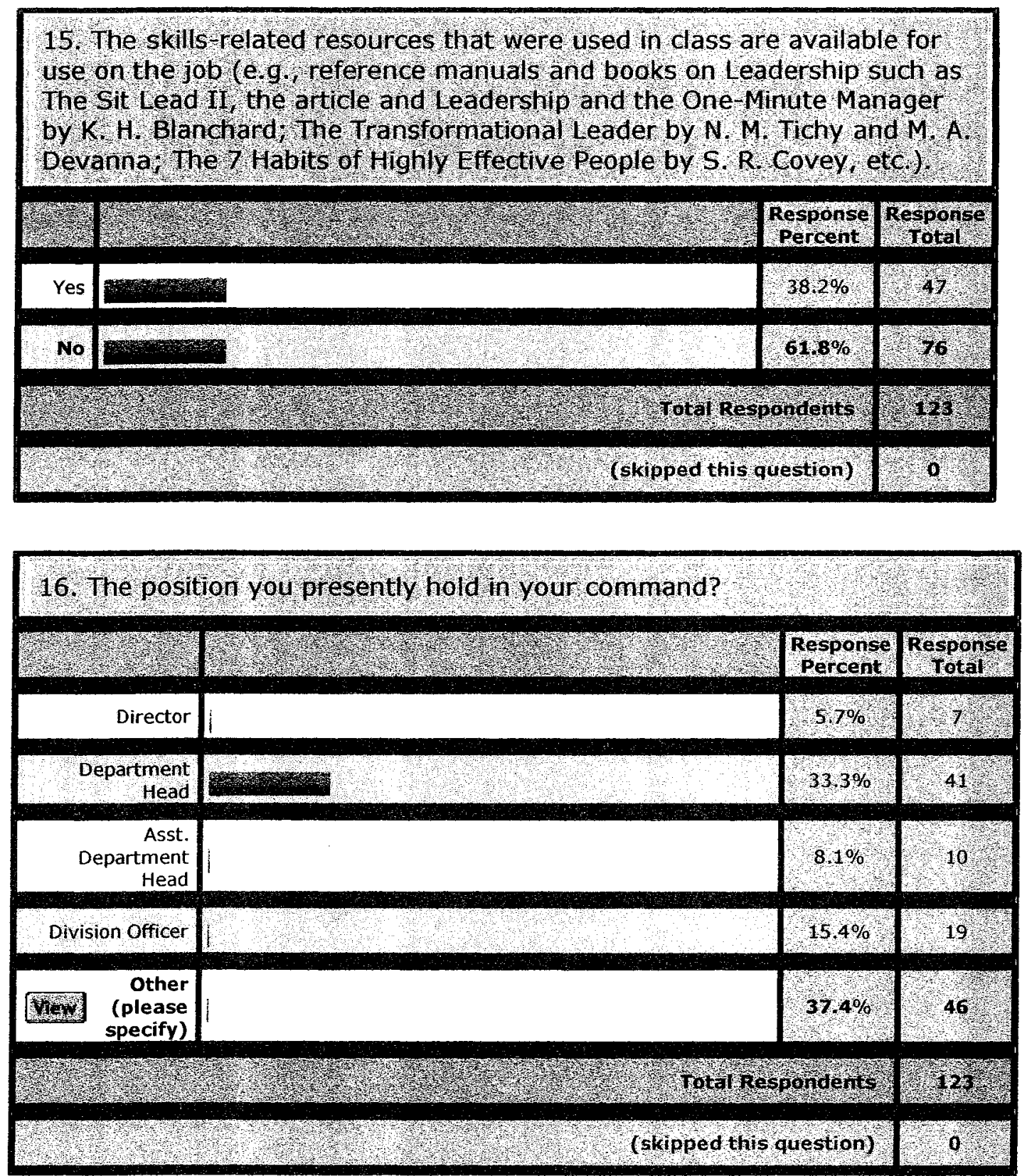

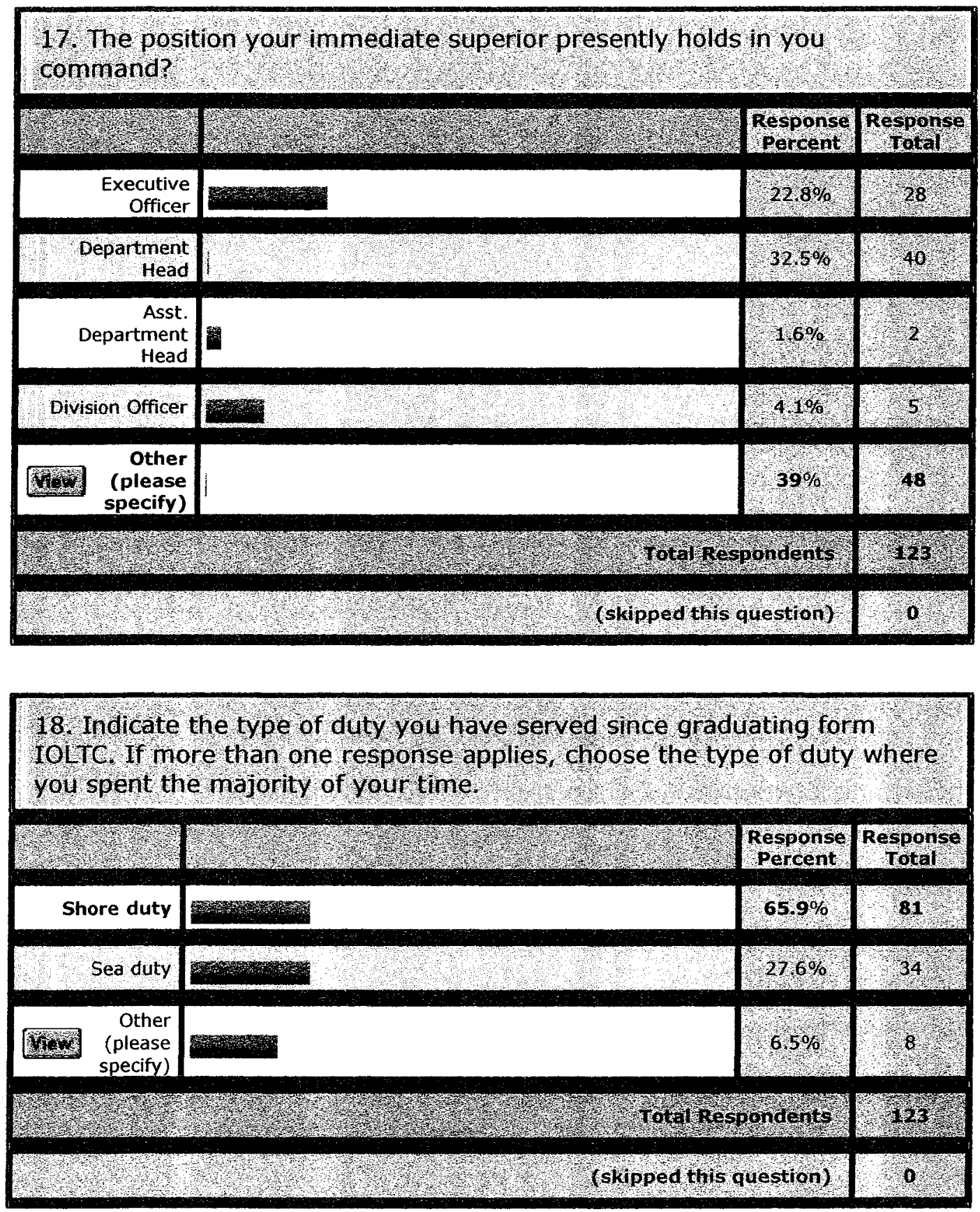

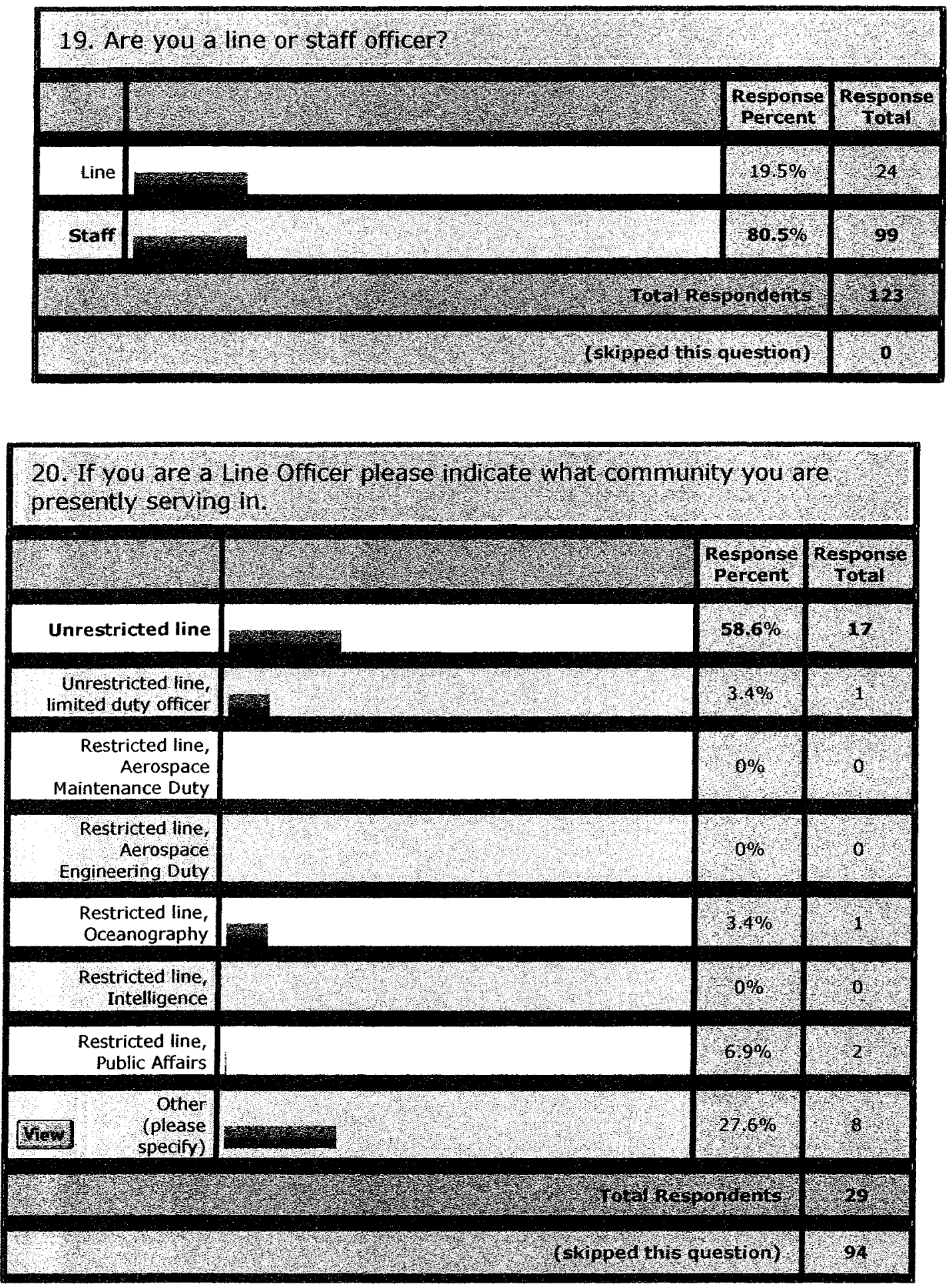


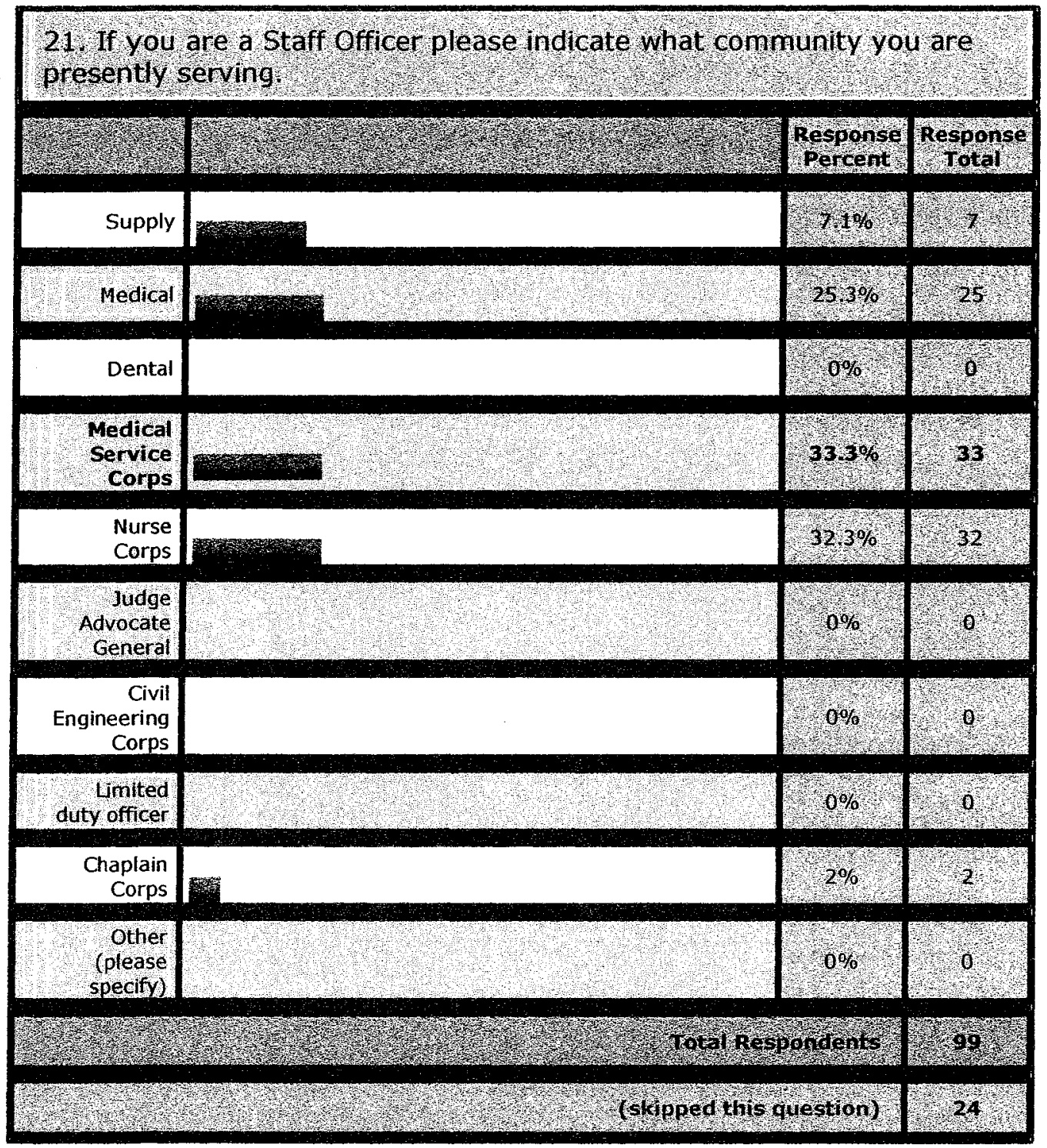



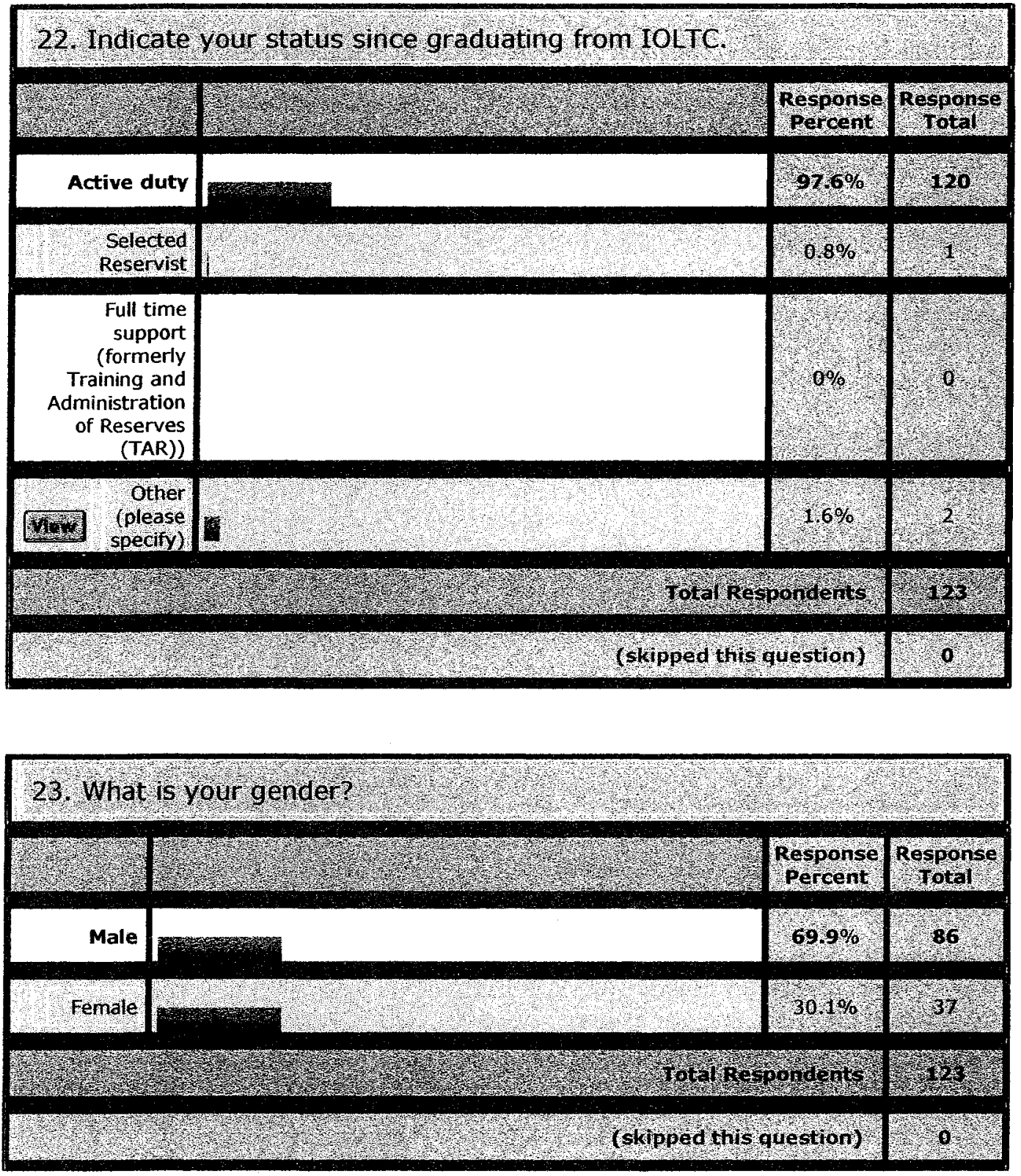


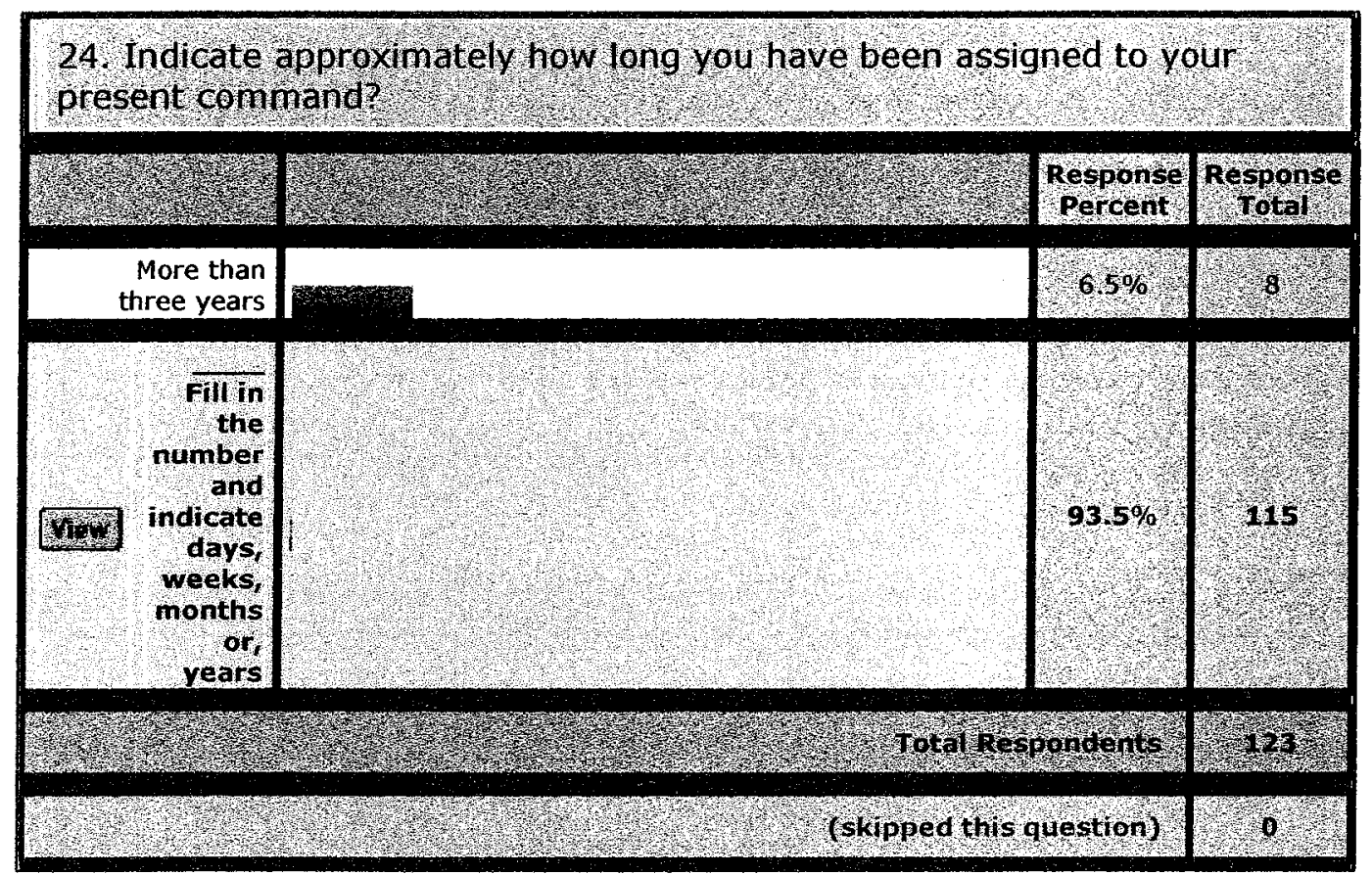

25. With reference to your race/ethnic background are you of Spanish, Hispanic or Latino origin?

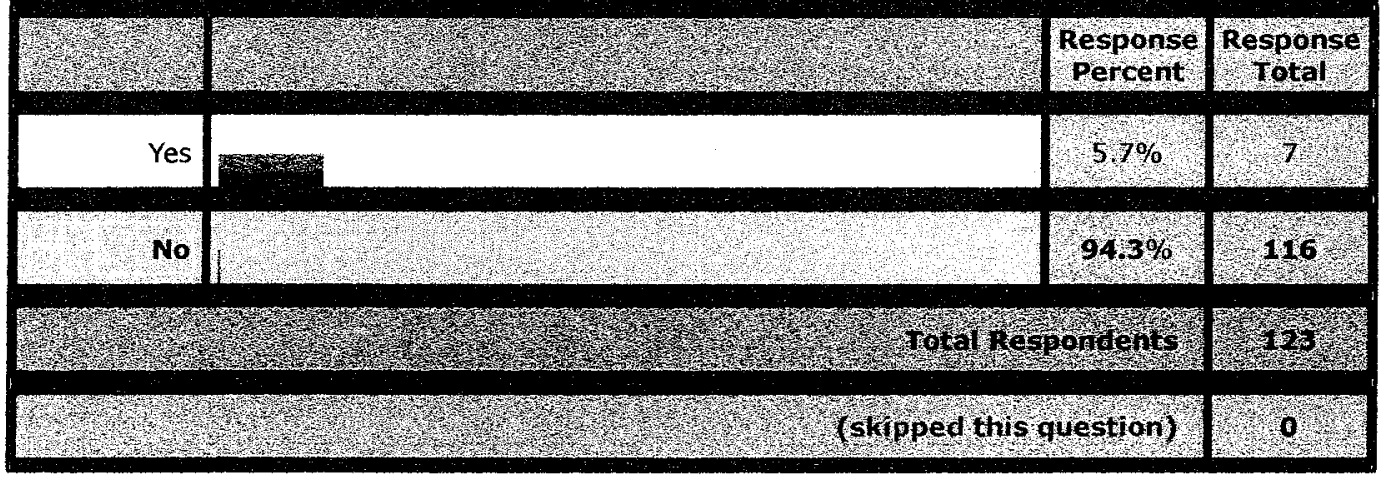



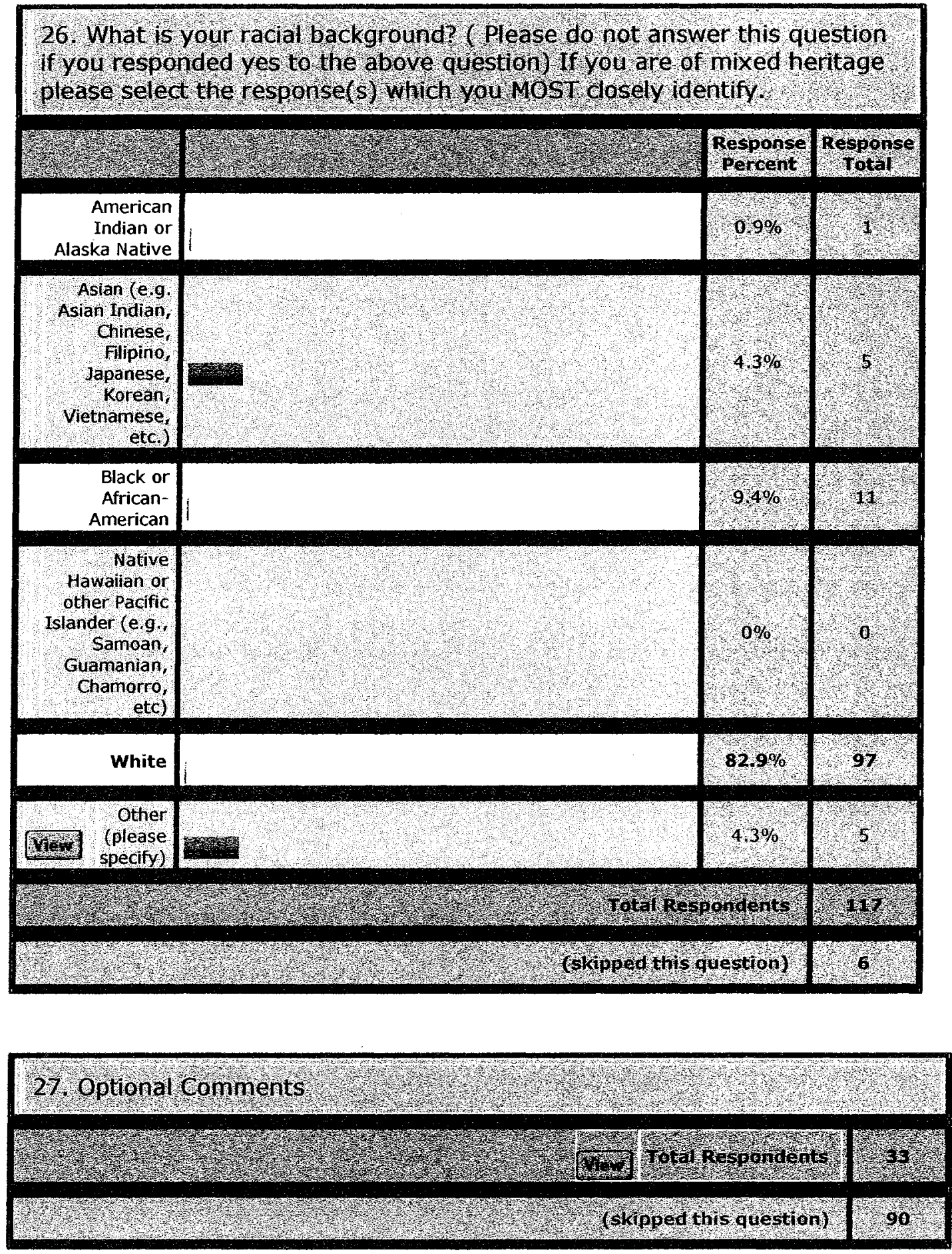


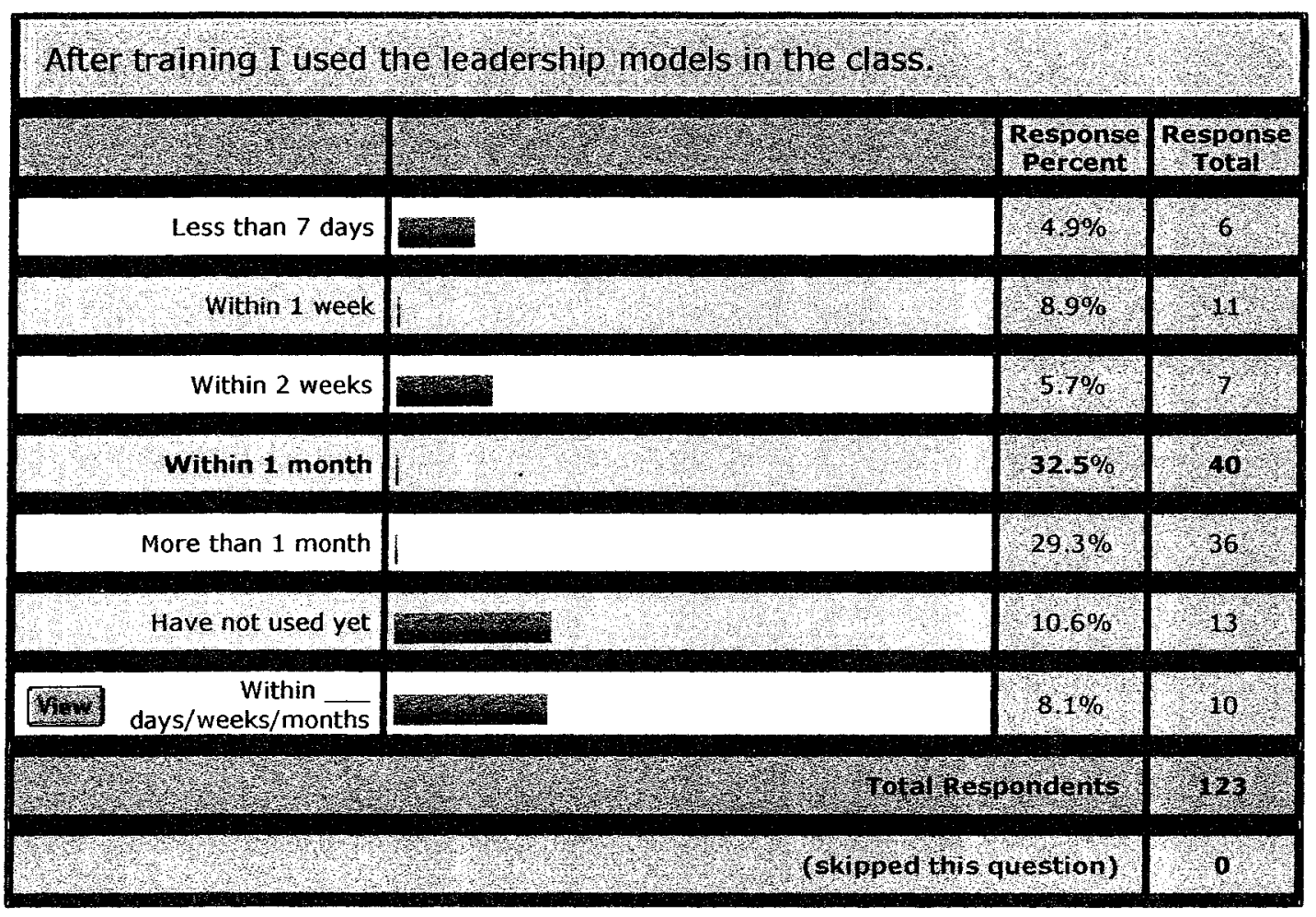




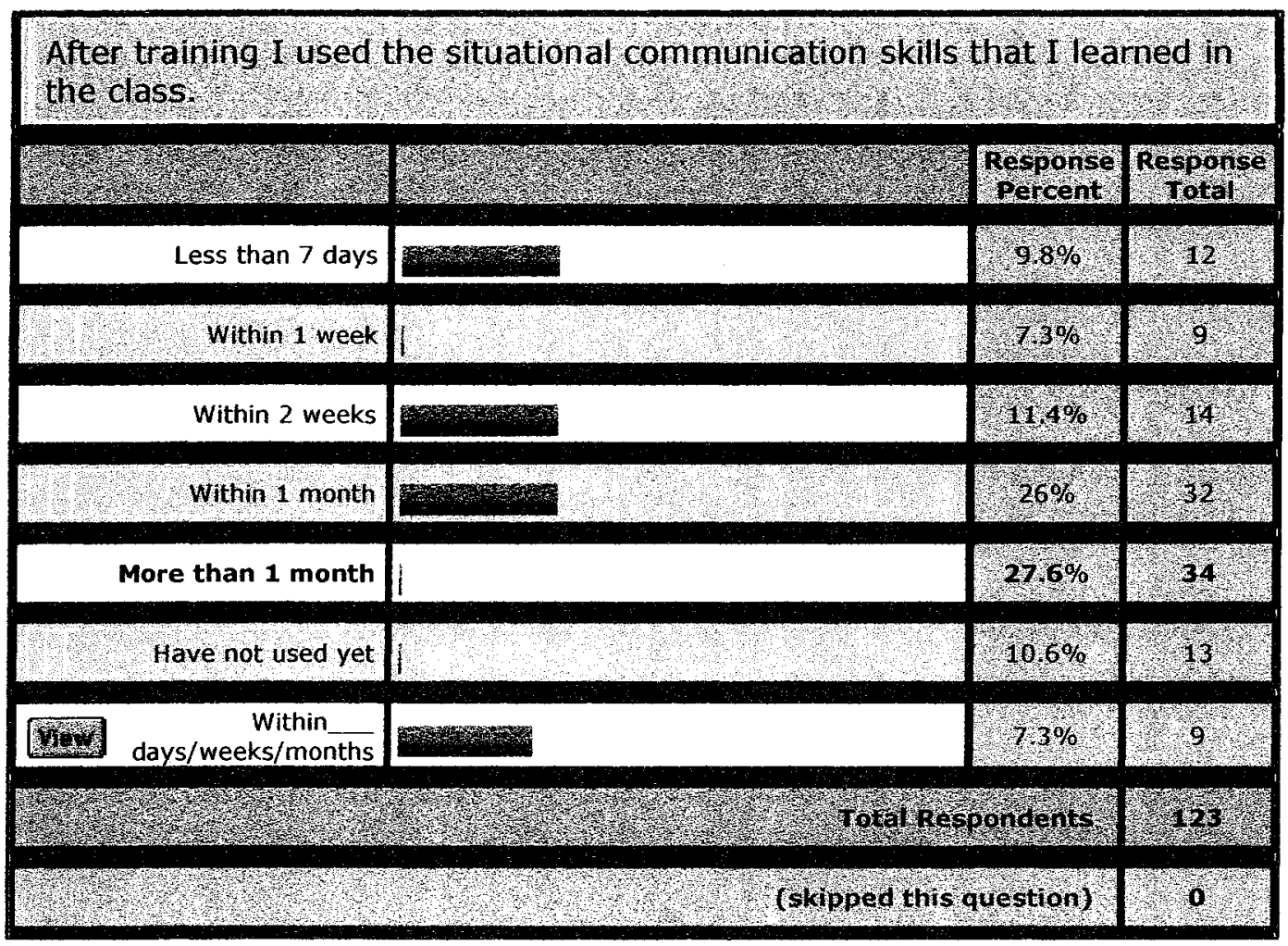




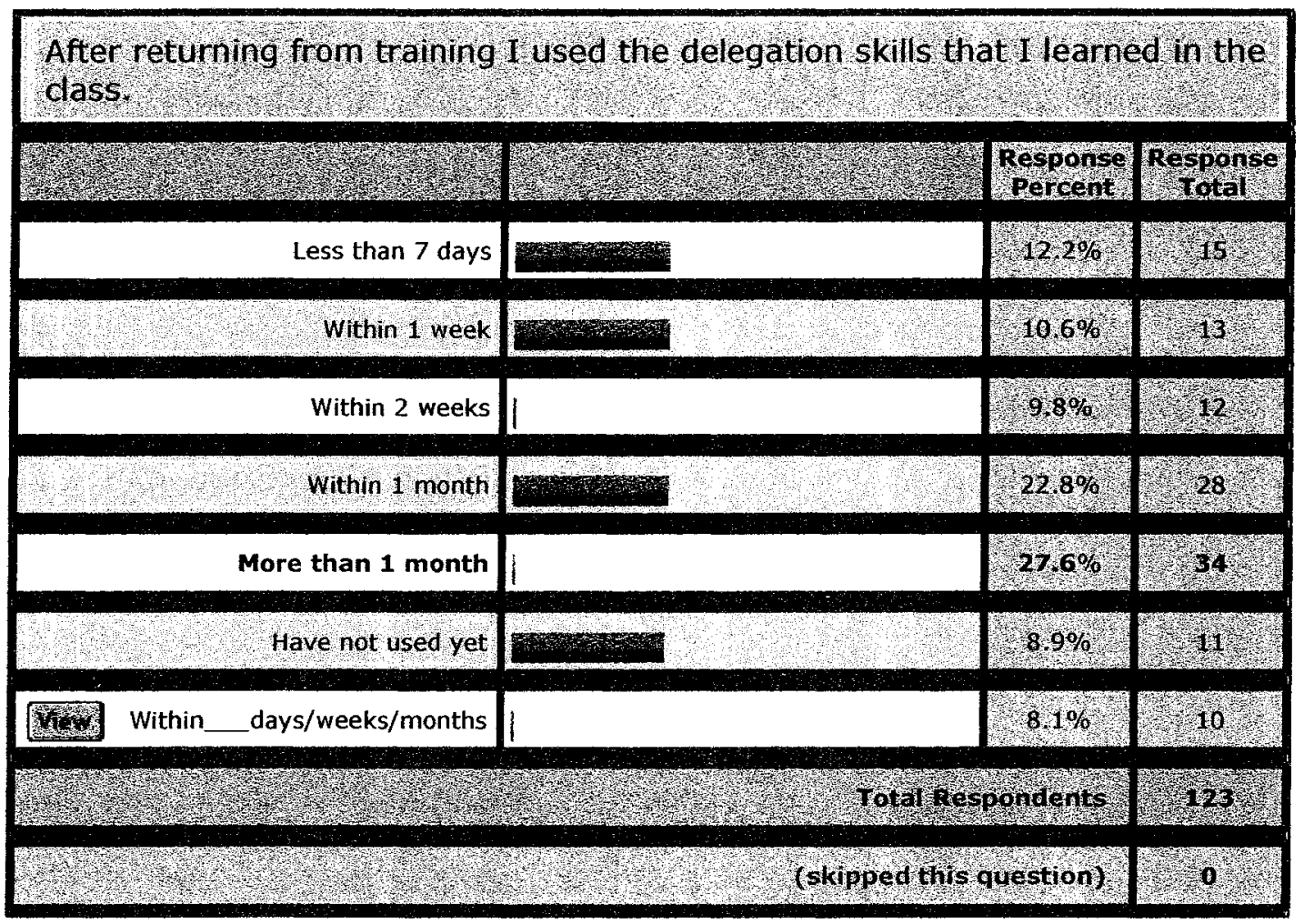




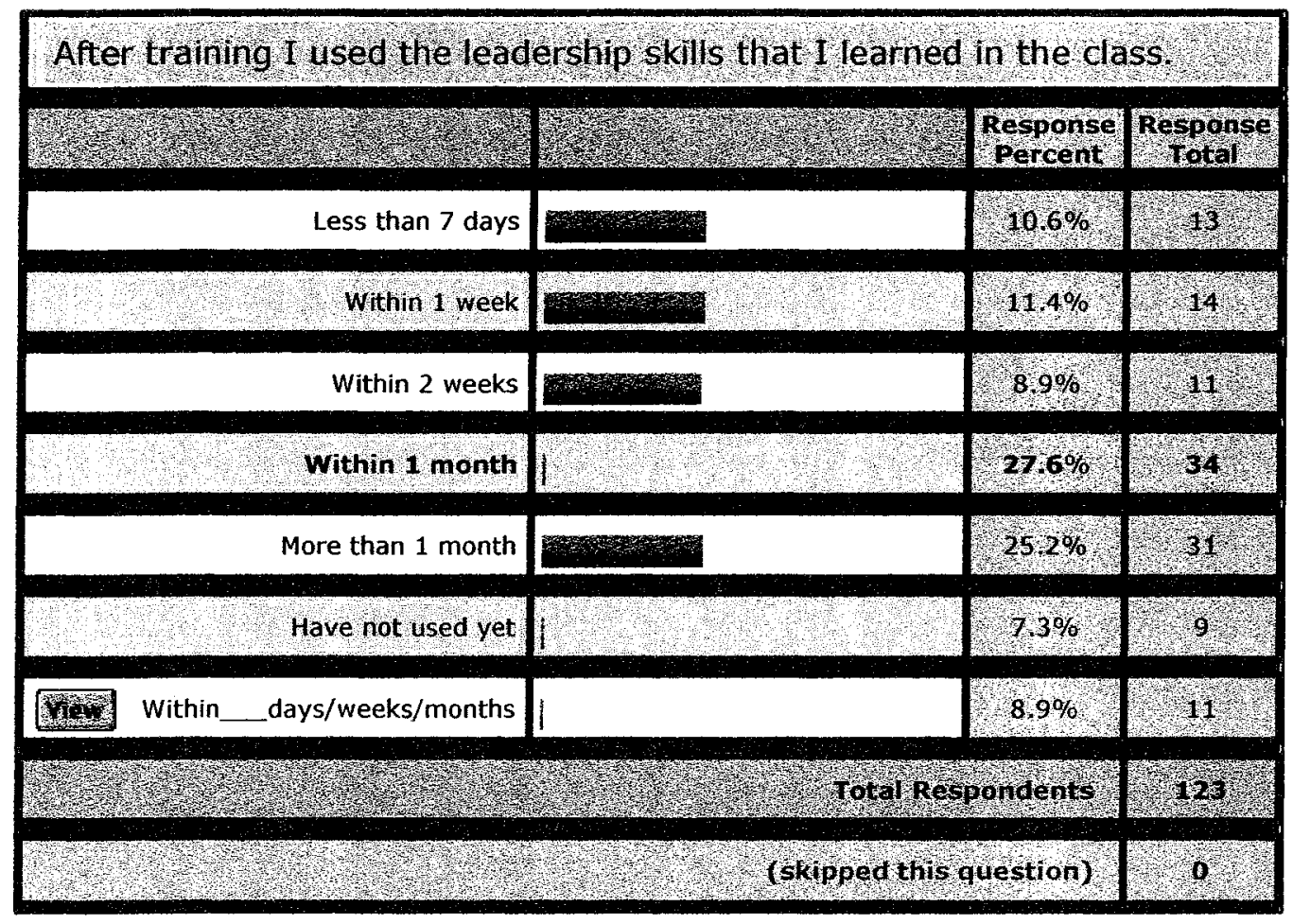


APPENDIX L LEADERSHIP MODELS BARRIERS

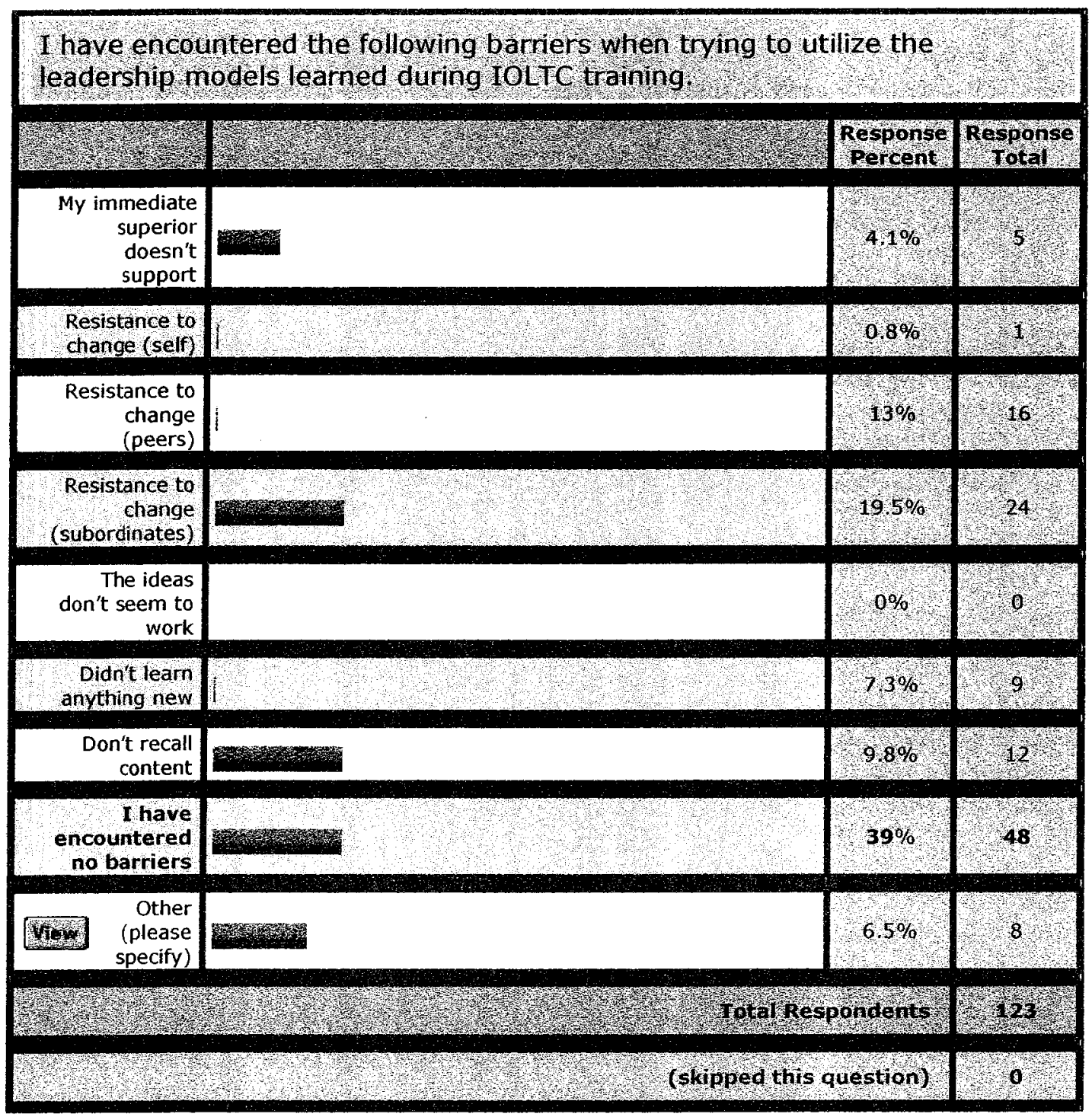




\section{APPENDIX M SITUATIONAL COMMUNICATION BARRIERS}

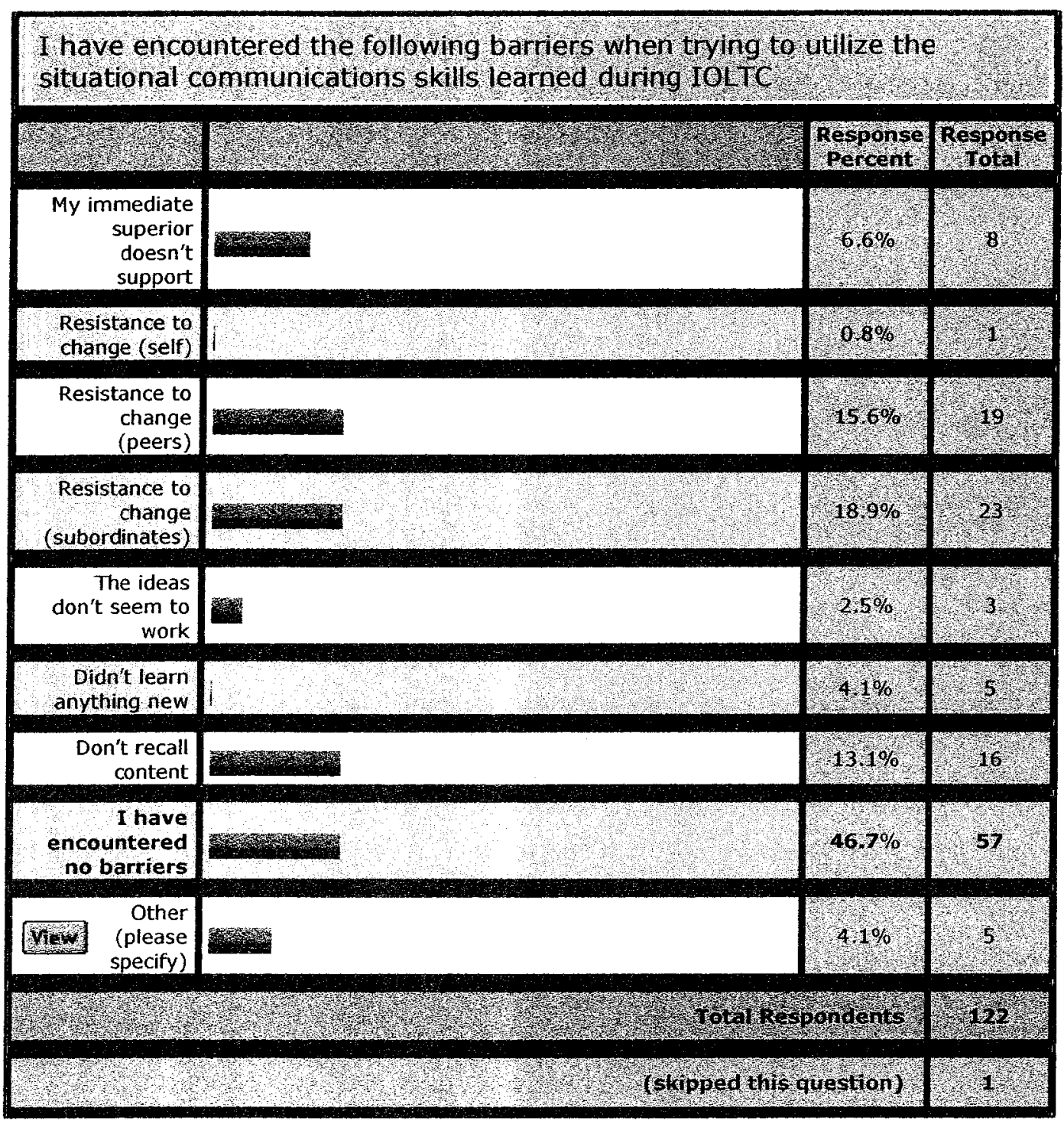




\section{APPENDIX N DELIGATION BARRIERS}

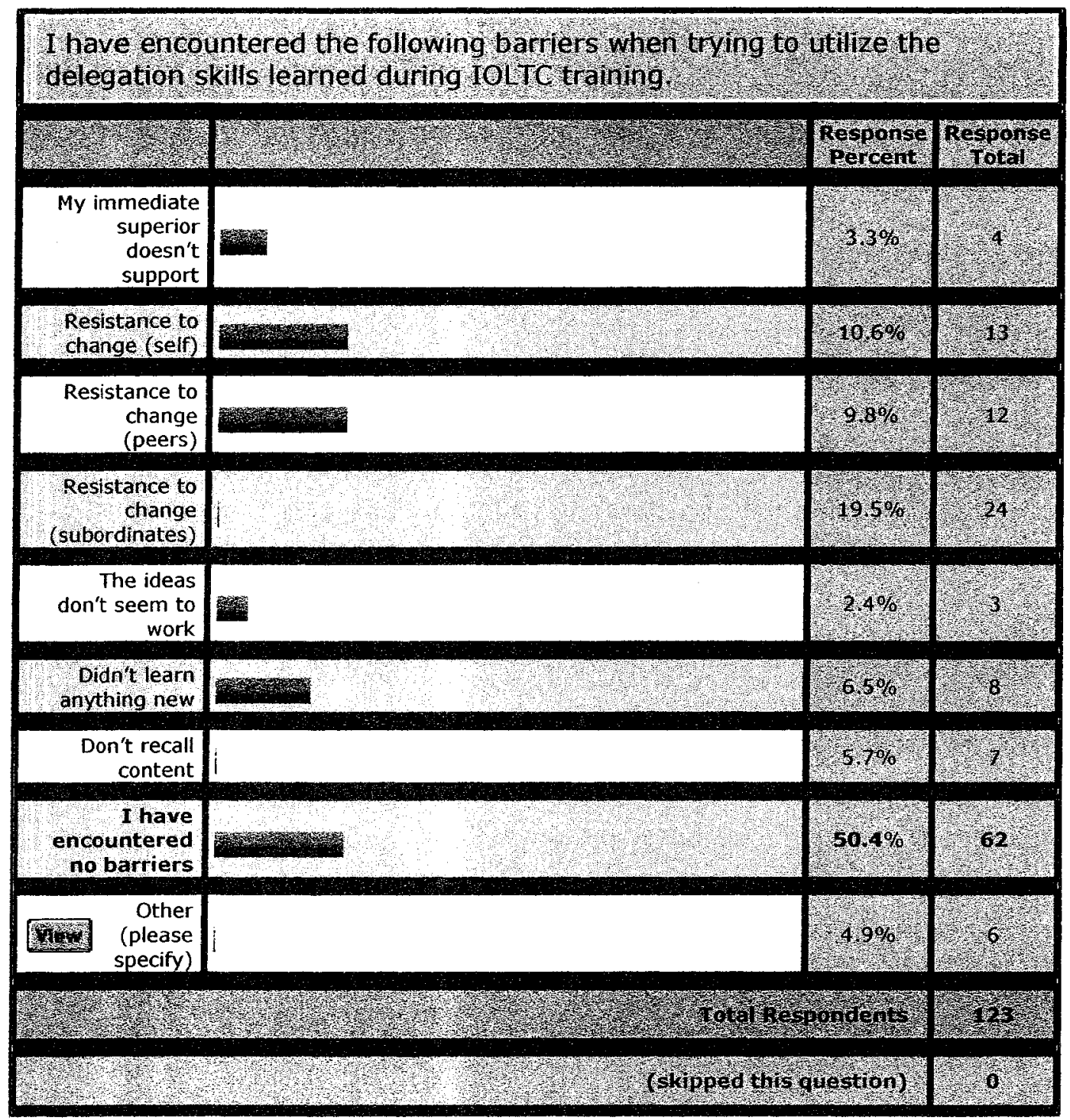


APPENDIX O COMMAND CLIMATE BARRIERS

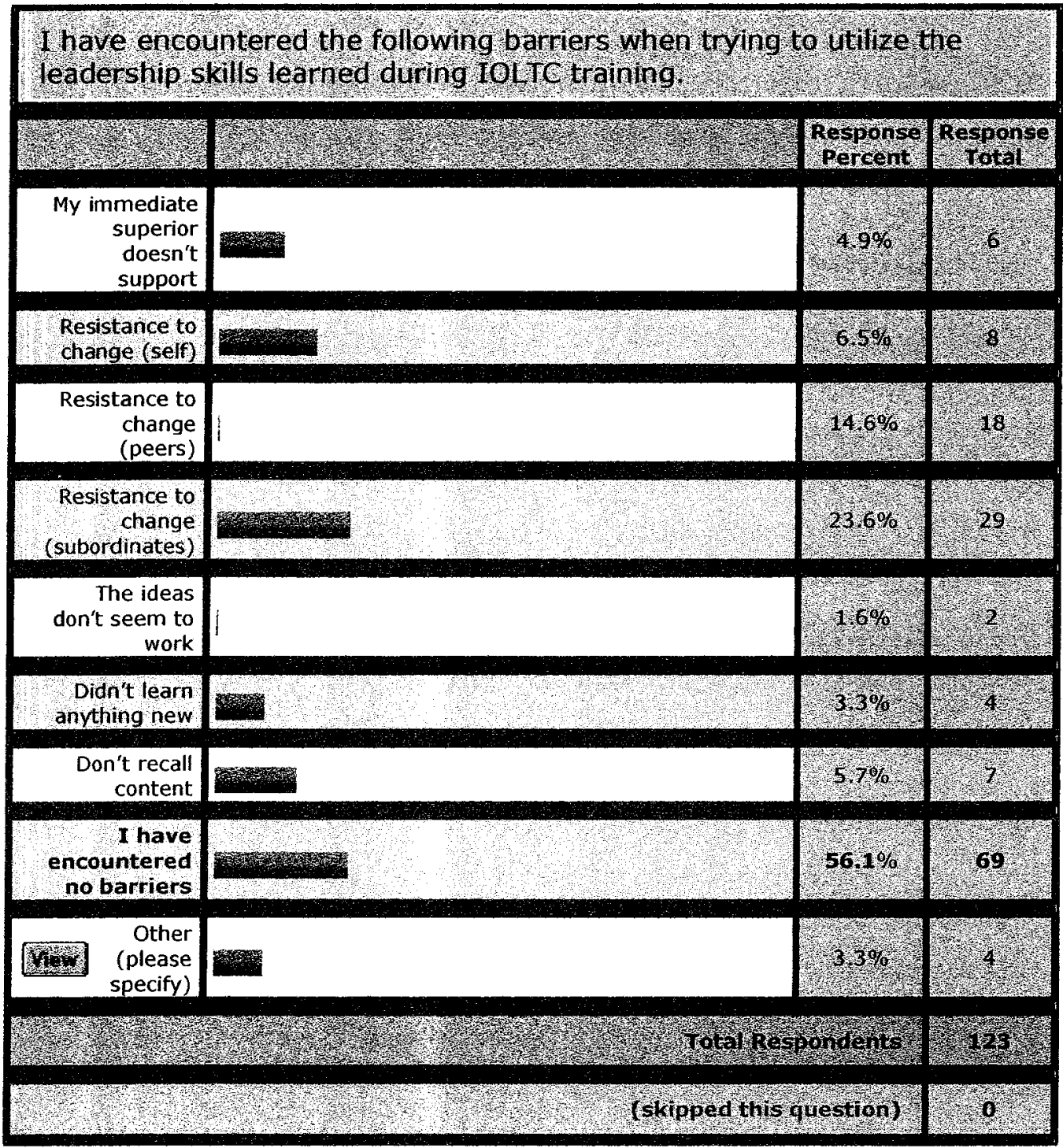




\section{APPENDIX P LEADERSHIP MODLES INCENTIVES}

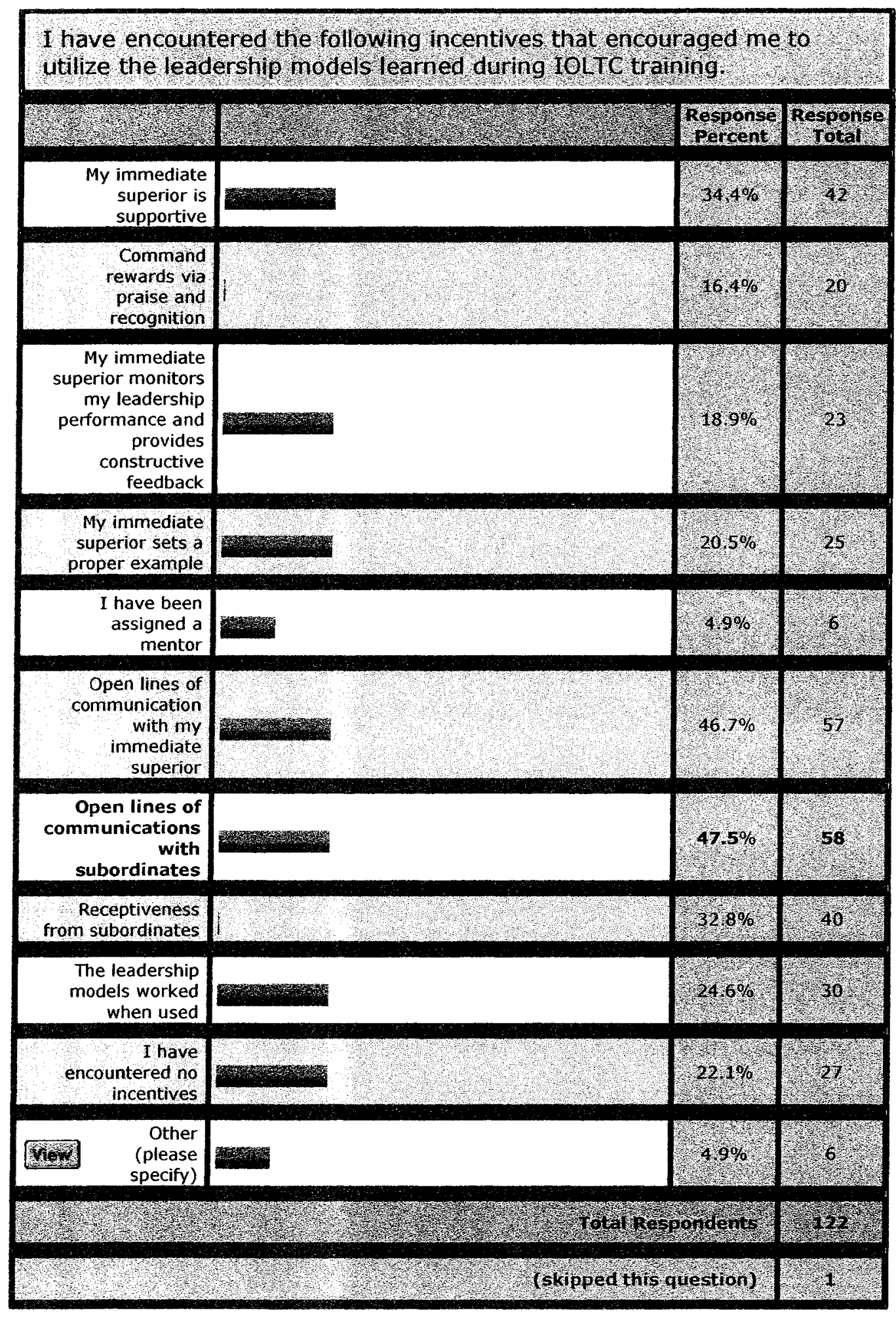




\section{APPENDIX Q SITUATIONAL COMMUNCIATON INCENTIVES}

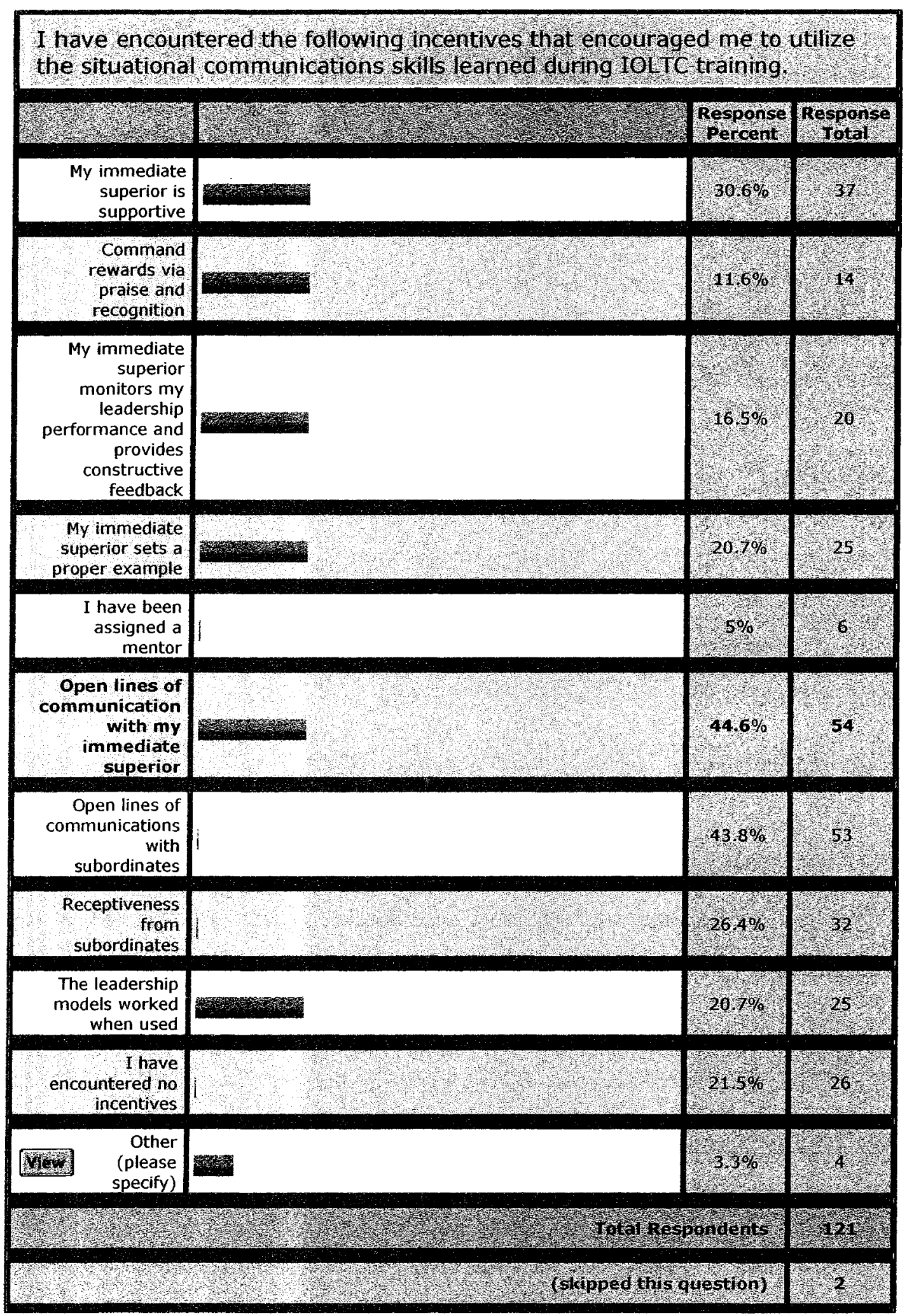




\section{APPENDIX R DELIGATION INCENTIVES}

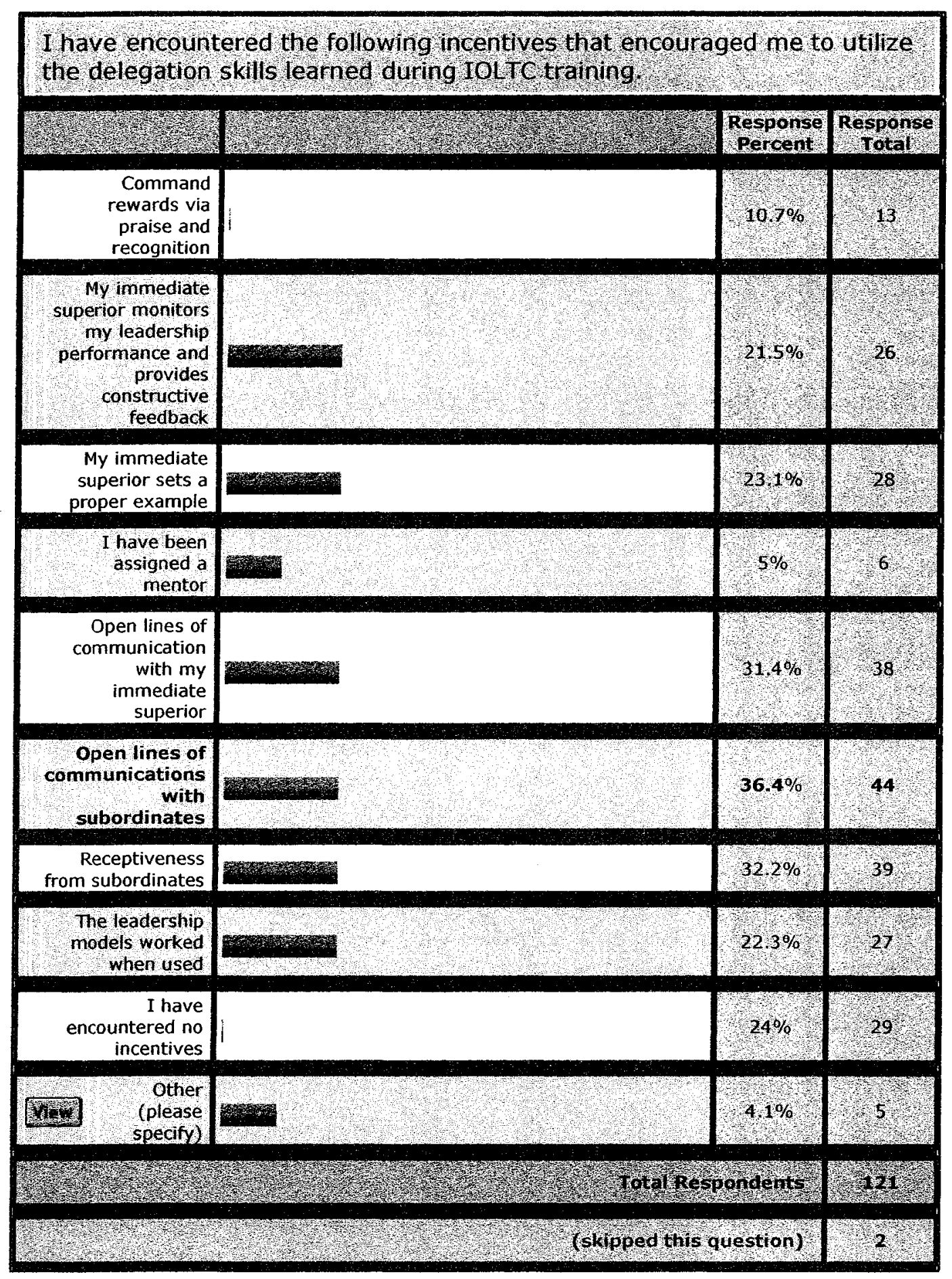




\section{APPENDIX S COMMAND CLIMATE INCENTIVES}

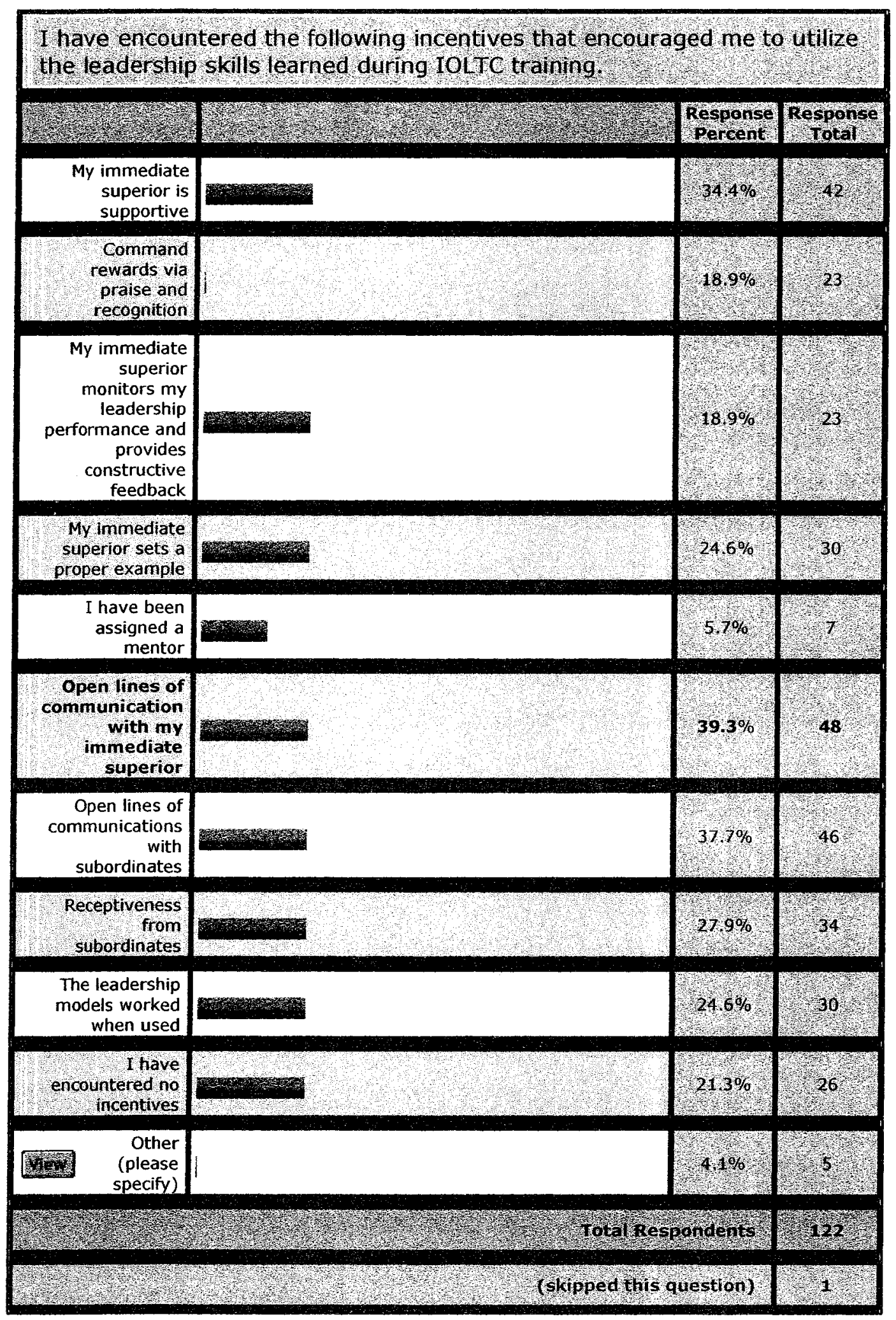




\section{APPENDIX T RACE/ETHNIC HISPANIC OR LATINO}

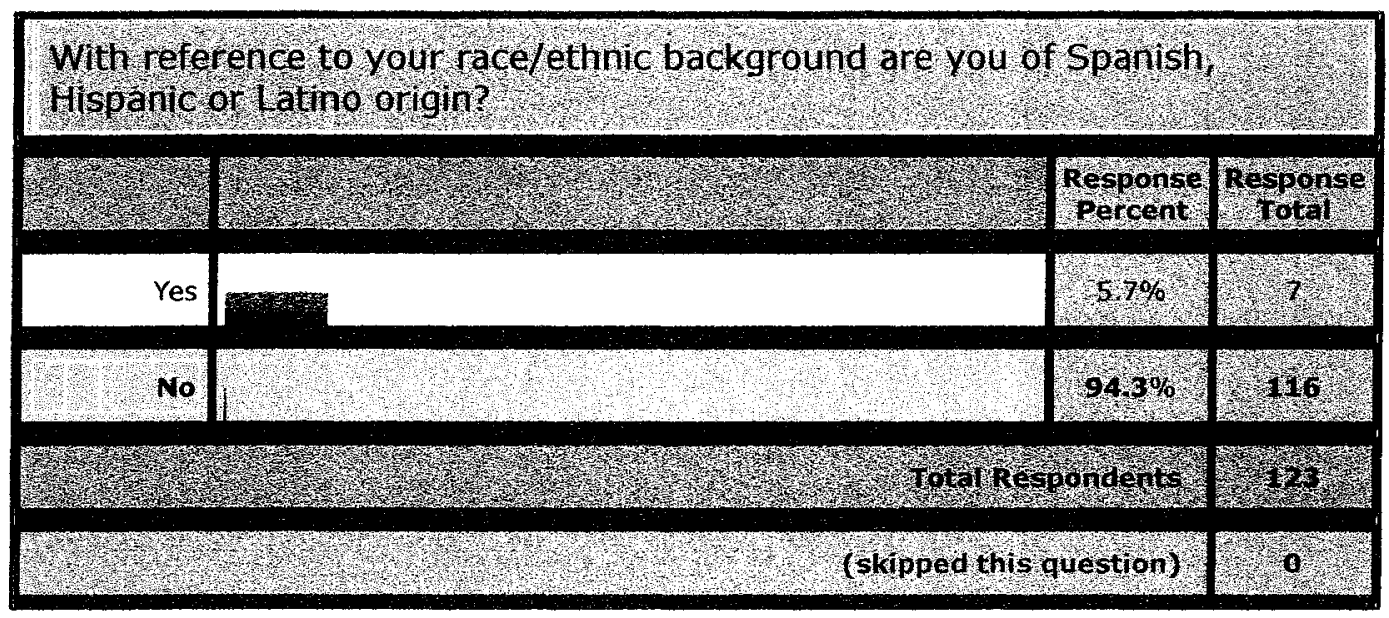




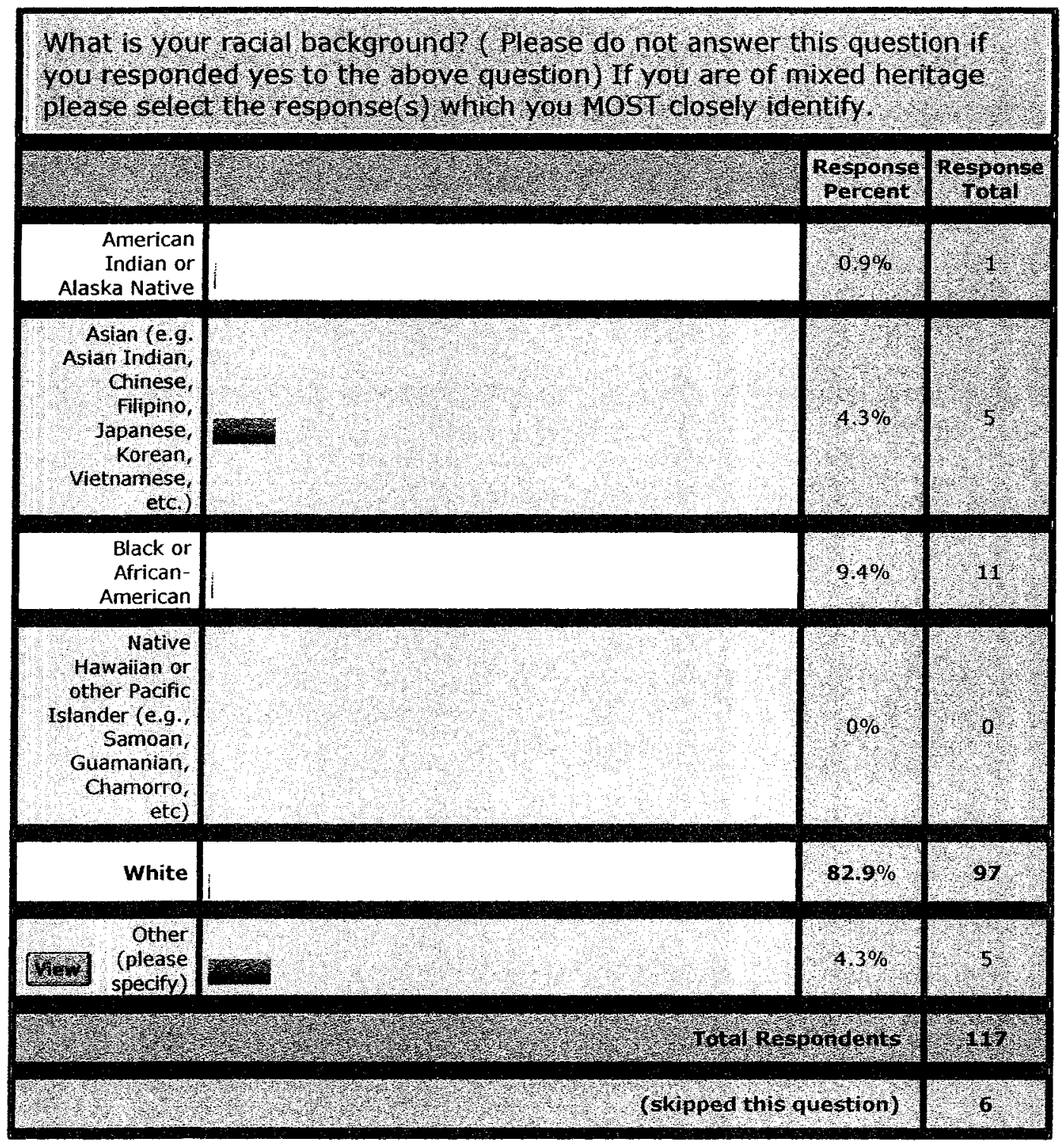




\section{APPENDIX V SURVEY OPTIONAL COMMENTS}

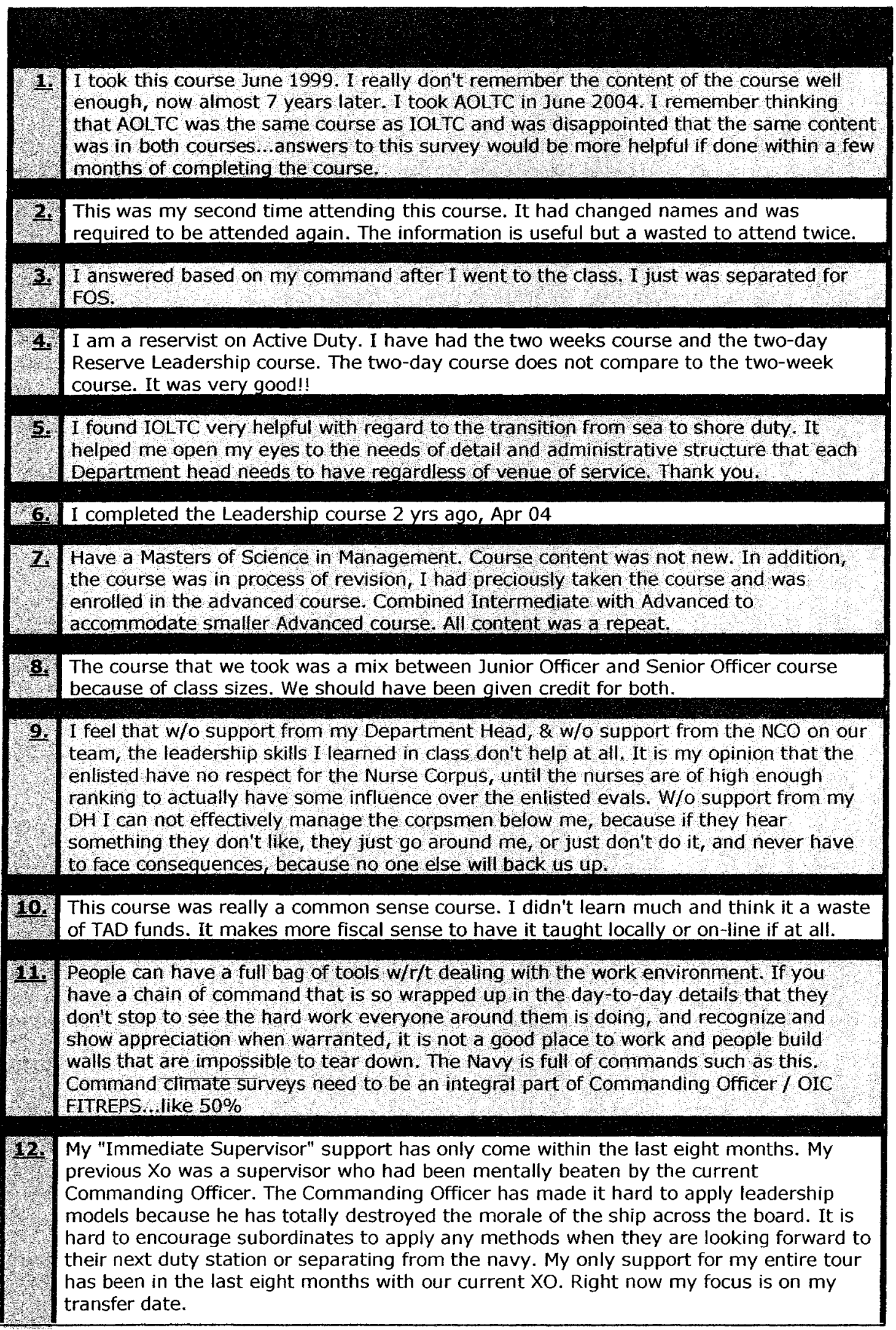




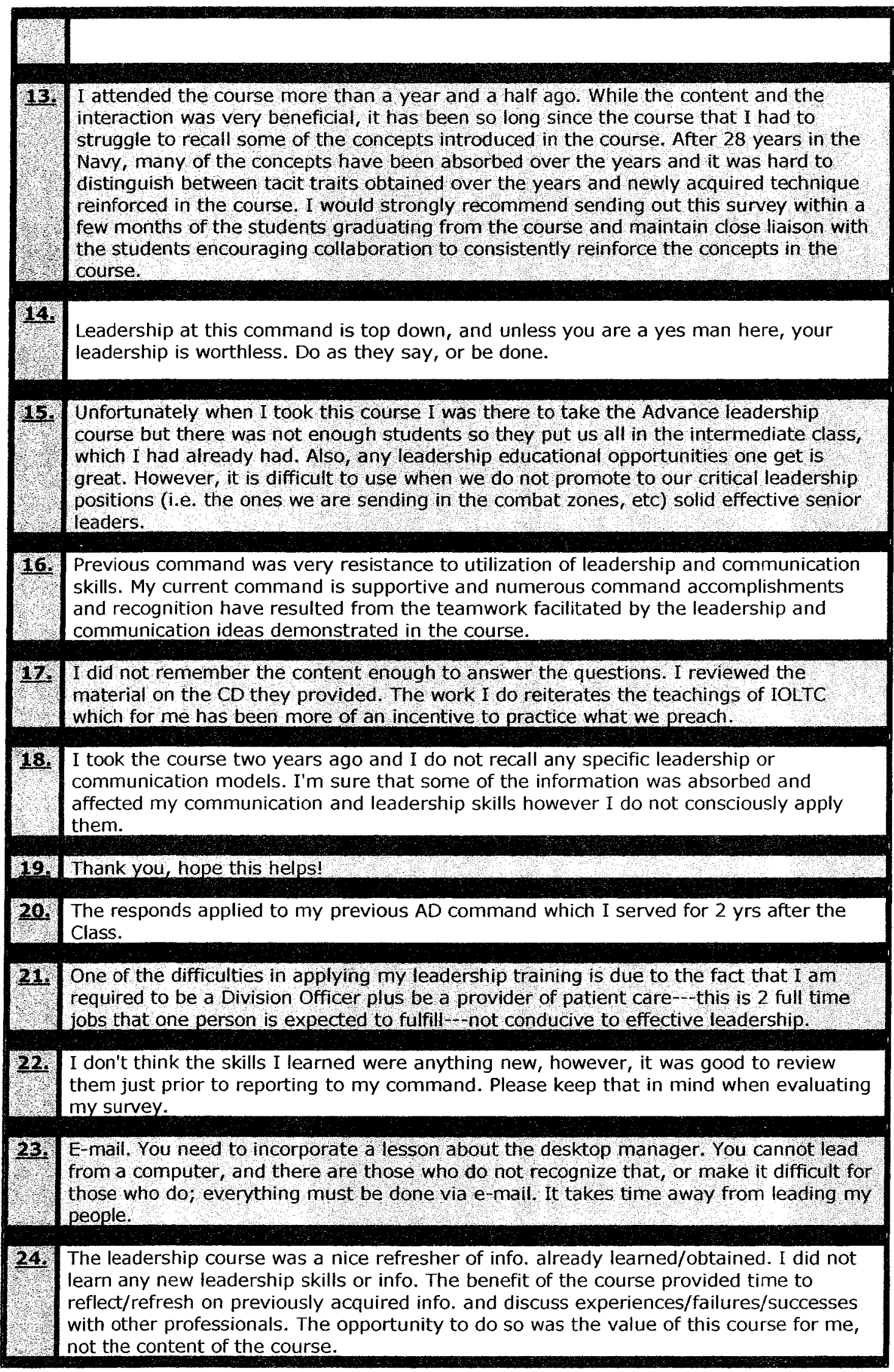


25. The course was well coordinated and the information was appropriate and well presented. It was for all intensive purposes the same basic ILMET course 1 attended 15 years ago. Well designed and topical for those in a mid career stride. I would suggest a bit more challenging course for 05 and above. Although I did enjoy interacting with a large group of LTs, the money may have been better spent elsewhere.

26. The course has supercharged my career and improved my reputation in the organization.

27. I did find the Team Memory Jogger useful remote from the IOLTC course which gave me some organizational tools for being a project manager for a Muliti-directorate, Cross-Functional, Inter-agency project of high visibility, Feedback that I received was that the "kick-off" meeting was "one of the best presentations ever. " $I$ think that the IOLTC mellow/atmosphere of mingling with good baseline leaders and the knowledge gained of where to find resources (such as the memory jogger) were the intangible things that 1 benefited from.

28. I was scheduled for Senior Leadership so they counted the Intermediate course as the senior course. The instructors were very poor leaders who were burned-out, passedover and on their twilight tours. They were rigid thinkers--not open to discussion or new ideas. Some were not too bright. One officer, Tammy Nathan, was extremely helpful and top notch. Why are the poorest leaders assigned to teach leadership? It must be the worst assignment in the Navy.

29. 1. The class 1 attended was AOLTC and not IOLTC. 2 . Your questions $3,5,8,11$ and others presume that these skills were learned during AOLTC. I did not think my time spent at AOLTC was of value, it was a ticket-punching requirement. 3 . In questions 8 and 9 , the correct spelling is delegation. 4 . In question 17 the correct spelling is Executive. 5 . Question 14 assumes my immediate superior knows or cares that 1 attended this course. Neither is true. This question needs to be more open-ended; none of these answers applies, yet I am required to choose one. This is not going to give you accurate data.

30. great course but can't implement at commands

31. I thoroughly enjoyed the leadership courses I have attended

32. I cannot recall the specifics covered during AOLTC. I found the course to be beneficial as a review of the concepts covered in your survey. After nearly 18 years in the Navy, I have developed a leadership style. The course, I'm sure, served to refine and build on this leadership foundation, but I can't comment on the specific situational communication, delegation and leadership skills covered in the course. I do recall leaving the class knowing that it was well worth my time. Thanks for the opportunity to offer my views.

33. Unfortunately due to some poor timing on my orders, it was about nine months after I completed the class until I was actually in my DH job.

34. The comments are in reference to my immediate supervisor after the course.

35. Question 12 is identical to question 9 -barriers to delegation I believe it meant to ask about "barriers to leadership" since question 13 asked about "incentives to leadership". Question 20 - It may be helpful to know what community the restricted line officer comes from: Aviation, Surface, Submarine, or Spec Ops. 